\title{
Survey of Foreign Maglev Systems
}

by J.L. He, D.M. Rote, and H.T. Coffey

Center for Transportation Research, Energy Systems Division,

Argonne National Laboratory, 9700 South Cass Avenue, Argonne, Illinois 60439

July 1992

Work sponsored by United States Army Corps of Engineers

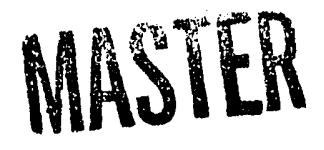




\section{Contents}

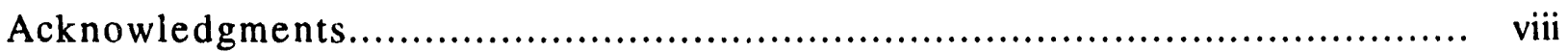

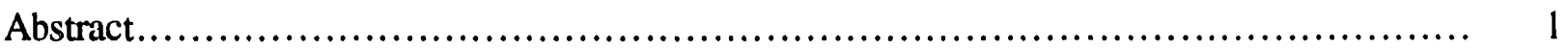

1 Introduction ..............................................................................

2 German High-Speed Transrapid Maglev System ................................... 3

2.1 System Description............................................................... 3

2.2 Historical Development of the Transrapid Vehicle Family ............................. 5

2.2.1 Preliminary Test Vehicles...................................................... 5

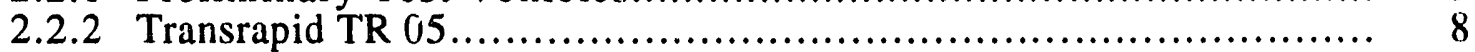

2.2.3 Transrapid TR 06........................................................ 9

2.2.4 Transrapid TR 07.................................................... 12

2.3 Linear Propulsion System .......................................................... 13

2.4 Power-Supply System ....................................................... 17

2.5 Test Facility at Emsland.................................................. 18

2.6 Present Status and Future Prospects......................................... 20

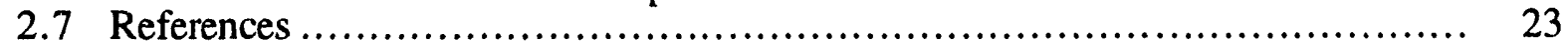

3 Japanese High-Speed Surface Transport Maglev System........................... 26

3.1 System Description.................................................................. 26

3.2 Overview of the HSST Family .............................................. 29

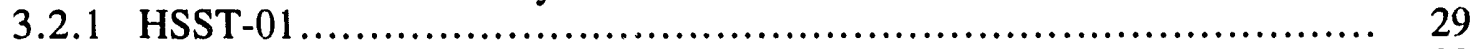

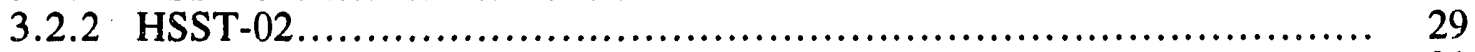

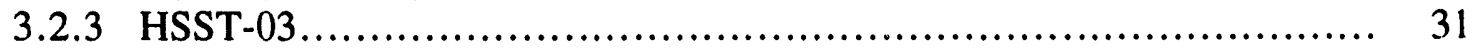

3.2.4 HSST-04 and HSST-05 .............................................. 35

3.3 Present Status and Future Prospects....................................... 35

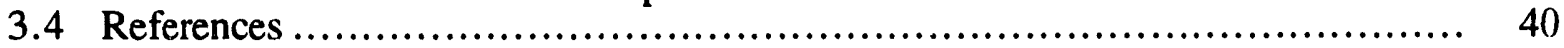

4 Japanese Maglev Systems with Electrodynamic Suspension ........................ 42

4.1 Introduction.................................................................. 42

4.2 Overview of Japanese Electrodynamic-Suspension Maglev Systems.................... 45

4.2.1 ML-500........................................................... 45

4.2.2 MLU001 .................................................................... 46

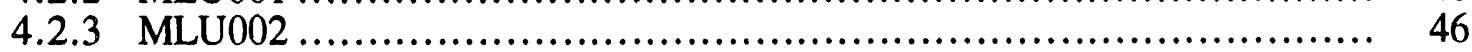

4.2.4 Commercial Vehicle................................................. 50

4.3 Superconducting Magnets............................................... 52

4.4 Electrodynamic-Suspension Maglev-System Guideway............................... 54

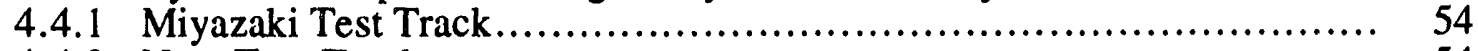

4.4 .2 New Test Track................................................ 54

4.5 Propulsion and Power-Supply Systems ...................................... 54

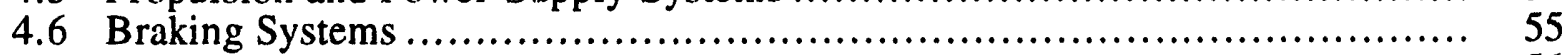

4.7 Present Status and Future Prospects.............................................. 56

4.8 References ........................................................................ 57 


\section{Contents (Cont.)}

5 German M-Bahn Maglev System ............................................. 59

5.1 System Description............................................................. 59

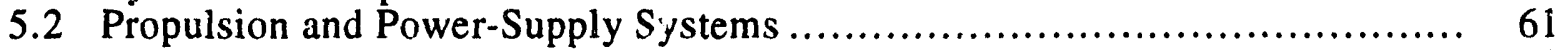

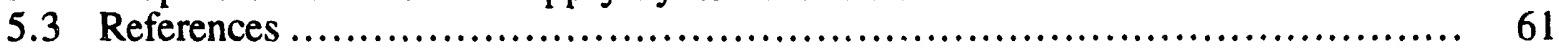

6 Maglev-System Research and Development in the United Kingdom..................... 63

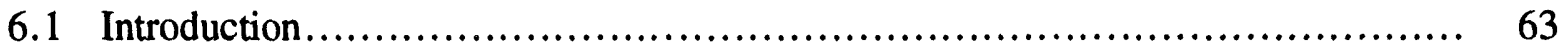

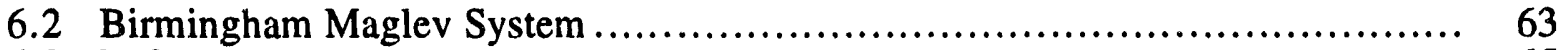

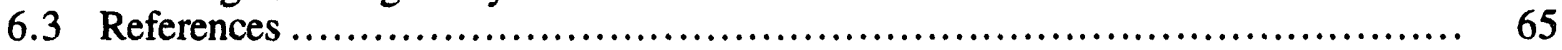

7 Maglev-System Research and Development in Canada.................................... 69

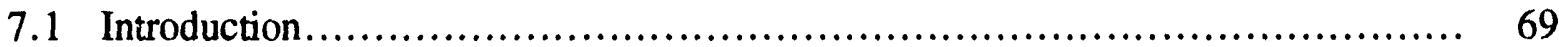

7.2 Conceptual Design of the Canadian Maglev System .......................... 69

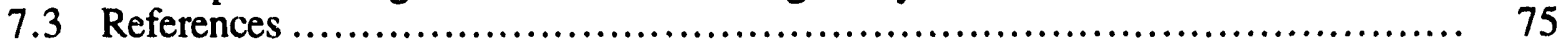

8 Maglev-System Research and Development in Other Countries..................... 77

8.1 Research and Development Efforts ........................................ 77

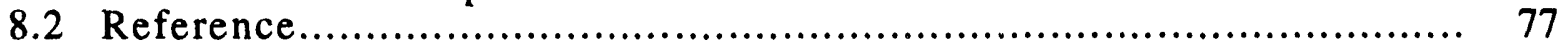

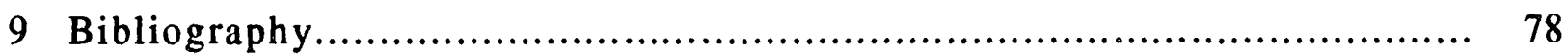

Tables

2.1 Summary of Data for the Transrapid Series Vehicles............................. 6

2.2 Operating Data for the Transrapid TR 06 Maglev System ....................... 11

2.3 Operating Data for the Transrapid TR 07 Maglev System ........................ 14

2.4 Summary of Data for the Propulsion and Power Systems of the Transrapid TR 06 Maglev System ....................................... 17

2.5 Summary of Data for the Transrapid Test Facility at Emsland ................... 22

3.1 Operating Data for the HSST-01 Maglev System ............................... 30

3.2 Operating Data for the HSST-02 Maglev System ............................... 32

3.3 Operating Data for the HSST-03 Maglev System ............................... 34

3.4 Operating Data for the HSST-04 Maglev System .............................. 37

3.5 Operating Data for the HSST-05 Maglev System ............................. 38 


\section{Tables (Cont.)}

3.6 Operating Data for the HSST-100 Maglev System................................ 39

4.1 Operating Data for the MLU001 ............................................. 47

4.2 Operating Data for the MLU002 ..................................... 49

4.3 Design Specifications of the New Commercial Maglev System .................. 51

4.4 Main Specifications of Superconducting Magnets for the Japanese Electrodynamic-Suspension Maglev Systems ................................ 53

5.1 Operating Data for the M-Bahn Maglev System............................. 62

6.1 Operating Data for the Birmingham Maglev System ........................ 66

7.1 Milestones of the Canadian Maglev Program..................................... 70

7.2 Parameters for the Original-Design Canadian Electrodynamic-Suspension Maglev System ............................................................ $\quad 72$

7.3 Parameters for the Revised-Design Canadian Electrodynamic-Suspension Maglev System.

\section{Figures}

2.1 Schematic Diagram of the Transrapid Maglev System............................. 4

2.2 First Transrapid Maglev Test Vehicle, TR 01, Built by Krauss Maffei in 1969

2.3 Test Vehicle, Built by Messerschmitt-Bölkow-Blohm in 1971.................... 7

2.4 Transrapid TR 02 Test Vehicle, Built by Krauss Maffei in $1971 \ldots \ldots \ldots \ldots \ldots . . .7$

2.5 Electrodynamic-Suspension Test Vehicle, Built by AEG-Telefunken AG, Brown Boveri \& $\mathrm{Cie}$ AG, and Siemens AG in 1974.

2.6 Circular, 900-m-Long, Electrodynamic-Suspension Test Track at Erlangen in 1974, with Aluminum Sheet Arranged on the Guideway............... 8

2.7 Transrapid TR 04 Test Vehicle, Built by Krauss Maffei in 1973 ............... 9

2.8 KOMET Maglev Test Vehicle, Built by Messerschmitt-Bölkow-Blohm in 1976. 


\section{Figures (Cont.)}

2.9 HMB Test Facility and Vehicle for Developing Long-Stator Propulsion Technology, Built by Thyssen Henschel Industrie AG in Kassel in 1976.

2.10 Transrapid TR 05, the World's First Maglev Train Authorized to Carry Passengers, Built by Krauss Maffei, Messerschmitt-Bölkow-Blohm, and Thyssen Henschel Industrie AG in 1979.

2.11 Transrapid TR 06 Test and Demonstration Vehicle, Built in 1983

2.12 Mechanical Structure of the Levitation and Guidance System of the Transrapid TR 06 Maglev System.

2.13 Transrapid TR 07 Application-Prototype Vehicle, Built in $1988 \ldots \ldots \ldots \ldots \ldots \ldots \ldots .15$

2.14 Interior Design of the Transrapid TR 07 Application-Prototype Vehicle

2.15 Cross-Sectional View of the Long-Stator Linear Synchronous Propulsion Motor

2.16 Basic Circuit Diagram of the Drive System ................................ 18

2.17 Transrapid Test Track at Emsland, Showing Steel Guideway Beams with Concrete Pillars.

2.18 Transrapid TR 06 Approaching the Bending Switch of the Test Track at Emsland

2.19 Test Center of the Transrapid Test Facility at Emsland ....................... 20

2.20 Site Plan of the Transrapid Test Facility at Emsland ............................ 21

3.1 Cutaway View of an HSST Revenue-Type Maglev Vehicle .................... 26

3.2 Schematic Diagram of the HSST Maglev System ............................ 27

3.3 Schematic Diagram of the Suspension and Propulsion Principles of the HSST Maglev System

3.4 HSST-01 Test Vehicle, Built in 1975, for Which a Speed of $307.8 \mathrm{~km} / \mathrm{h}$ on a 1,300-m-Long Guideway Was Recorded on February 14, 1978 ........... 29

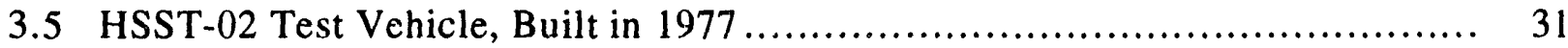

3.6 HSST-03 Operating at the EXPO'85 in Tsukuba, Japan......................... 33

3.7 HSST-03 Operating at the EXPO'86 in Vancouver, British Columbia, Canada

3.8 HSST-04 Operating at the Saitama Expo 


\section{Figures (Cont.)}

3.9 HSST-05 Operating at the YES'89 Exposition....................................... 36

4.1 Operating Principle and Coil Arrangement for the Japanese ElectrodynamicSuspension Systems: (a) Facing Suspension System and (b) Sidewall, Null-Flux Suspension System

4.2 ML-500 Test Vehicle, for Which a Maximum Speed of $517 \mathrm{~km} / \mathrm{h}$ Was

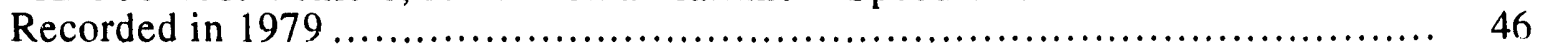

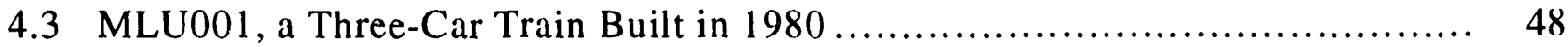

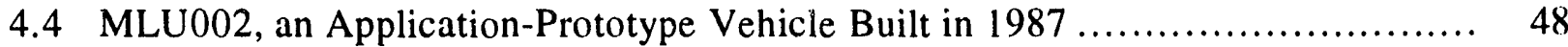

4.5 Arrangement of Superconducting Magnets on Various Maglev Vehicles.............. 50

5.1 M-Bahn Maglev System Operating in West Berlin.................................... 59

5.2 Basic Features of the M-Bahn Guideway and Vehicle.......................... 60

6.1 Birmingham Maglev Vehicle Approaching Airport Station ......................... 64

6.2 Schematic Diagram of the Birmingham Maglev System.............................. 64

7.1 Cross-Sectional View of the Revised Canadian Maglev-System Design ............ 71 


\section{Acknowledgments}

The authors wish to express their gratitude to the following reviewers for their valuable comments: John D. Matthews, A. Dohrman, R. Armstrong, Richard Baker, Ken Shaver (all, the U.S. Corps of Engineers), Zenichiro Shiozawa (HSST Corporation, Japan), Junji Fujie (Railway Technical Research Institute, Japan), William W. Dickhart III (U.S. Consultant to Transrapid International), and R.G. Rhodes (Warwick University, United Kingdom).

The report includes many historical maglev figures that were obtained from various sources. The authors appreciate the copyright permissions given by the Institute of Electrical Engineering in Japan, Hestra-Verlag in Germany, and the Institute of Electrical and Electronic Engineering in the United States. In particular, the authors wish to thank E. Masada (The University of Tokyo, Japan), Z. Shiozawa (HSST Corporation, Japan), Y. Kyotani (Technova Inc., Japan), and H. Tanaka (Railway Technical Research Institute, Japan) for permission to reproduce figures in this report and for their assistance in obtaining copyright $\mathrm{p}_{\mathrm{i}}$.missions.

The authors would also like to thank Ellen Hathaway (Argonne National Laboratory) for technical editing. 


\title{
Survey of Foreign Maglev Systems
}

by

\author{
J.L. He, D.M. Rote, and H.T. Coffey
}

\begin{abstract}
Magnetic levitation (maglev) transportation systems represent an innovative technology that promises to provide pollution-free, contact-free, high-speed ground transportation for the twenty-first century. Great interest in maglev systems has been developing in the United States over the past two years under the auspices of the U.S. National Maglev Initiative. The objective of the survey presented in this report is to provide the U.S. maglev community with information on various maglev concepts that were developed in foreign countries over the past two decades. The main maglev systems included in the survey are the German Transrapid series and the M-Bahn, the Japanese HSST and MLU series, and the British Birmingham. Each maglev system is introduced and discussed according to its type, historical development, unique features, current status, and future prospects. Advantages and disadvantages of each system are briefly noted.
\end{abstract}

\section{Introduction}

For many years, highway vehicles and commercial jet aircraft have been the only available modes for intercity transportation for the majority of travelers in the United States. These modes have been able to satisfy our travel demands up to now, but with the well-known penalties of increasing dependence on petroleum imports, continued noncompliance with air quality standards, and longer trip times due to greater congestion. Unfortunately, because systemi capacity is not increasing with travel demand, these problems are likely to worsen.

Of the several technology options that have been proposed to help solve these problems and provide greater mobility in the United States, a magnetic levitation (maglev) transportation system appears to have the greatest promise. However, since the mid-1970s, when research and development on maglev stopped in the United States, little has been done to address the issues that must be resolved before such a new technology as maglev can be implemented. In 1991, the National Maglev Initiative was enacted to address a number of these issues, including technical and economic feasibility and viability, the role of the federal government, and whether the United States should buy foreign technology, form cooperative agreements with foreign developers to jointly adapt these technologies to U.S. markets, or develop a new maglev system tailored to U.S. needs. 
Maglev systems can be classified into two major types according to their suspension concepts. One, called the electromagnetic-suspension (EMS) system, utilizes the attractive force between controlled direct-current (dc) electromagnets aboard the vehicle and ferromagnetic rails on the guideway. The other, called the electrodynamic-suspension (EDS) system, utilizes the repulsive force between eddy currents induced in nonferromagnetic conductors on the guideway and superconducting magnets aboard the vehicle. The EMS category includes the German Transrapid and M-Bahn, the Japanese High-Speed Surface Transport (HSST), and the British Birmingham system. The Japanese MLU is of the EDS type.

Regardless of which system gains widespread commercial application, the experience acquired over the last two decades by experts in Germany, Japan, Great Britain, Canada, and elsewhere represents an impressive body of technical and economic knowledge. In this document, only the highlights of developments in each country can be reported.

We hope that this document will provide the reader with a sense of the variety of possible maglev concepts and some measure of the work pursued in various countries. We also hoye that the material reported here will stimulate readers to devise new and innovative maglev concepts to better satisfy the needs and constraints of specific markets in the United States and elsewhere. 


\section{German High-Speed Transrapid Maglev System}

\subsection{System Description}

The German Transrapid maglev system, an EMS system, has been under development for about 20 years, during which time more than 10 prototype vehicles have been built and tested. ${ }^{1-8}$ In particular, the development of two full-scale application-type vehicles, the Transrapid 06 (TR 06) in 1983 and the Transrapid 07 (TR 07) in 1988, has given the Transrapid system its worldwide reputation. 9-20 This system is almost ready for revenue-application service. The TR 06 attained a maximum speed of $412.6 \mathrm{~km} / \mathrm{h}$ on the $31.5-\mathrm{km}-\mathrm{long}$ Emsland test track on January 22, 1988, establishing the world speed record for a passenger-carrying maglev vehicle. (A Japanese vehicle, the ML-500, attained a speed of $517 \mathrm{~km} / \mathrm{h}$ in December 1979, but it was not carrying any passengers.)

The characteristic features of the Transrapid maglev system include (1) contact-free attractive electromagnetic suspension and guidance; (2) long-stator, iron-core, linear synchronous motor (LSM) propulsion; (3) the same controlled dc electromagnets used for suspension and propulsion; (4) active elevated gvideway with sequential motor-section energization; (5) pulsewidth-modulated inverter powcr supply for the propulsion motor [both variable voltage and variable frequency (VVVF)]; (6) small clearance between the vehicle and the guideway (typically $7-10 \mathrm{~mm}$ ); and (7) high-speed operation (up to $500 \mathrm{~km} / \mathrm{h}$ ).

A schematic diagram of the Transrapid maglev system is shown in Figure 2.1, from which one can see that the support and guidance systems follow the principle of electromagnetic levitation. Individually controlled $\mathrm{dc}$ support and guidance magnets are arranged in the undercarriage of the vehicle. The three-phase armature windings or stator windings of the linear motor, fed power by the VVVF pulse-width-modulated inverter system, are embedded in the slots of a laminated iron core that is mo'anted on the underside of the guideway. The controlled dc suspension magnets, energized by on-board power-conditioning equipment, including batteries, pulse-width-modulated power supply, and inductive power pickup, also provide excitation fields for the linear propulsion motor. The air gap, typically a centimeter, is kept as small as possible to increase the efficiency and power factor of the system. The main advantages of the Transrapid maglev system include the following:

- High overall operating efficiency because the use of ferromagnetic materials results in low leakage reactance and low magnetic drag;

- Low stray magnetic flux density around the vehicle because of the use of ferromagnetic material;

- Pure contact-free operation, permitting high speed; 


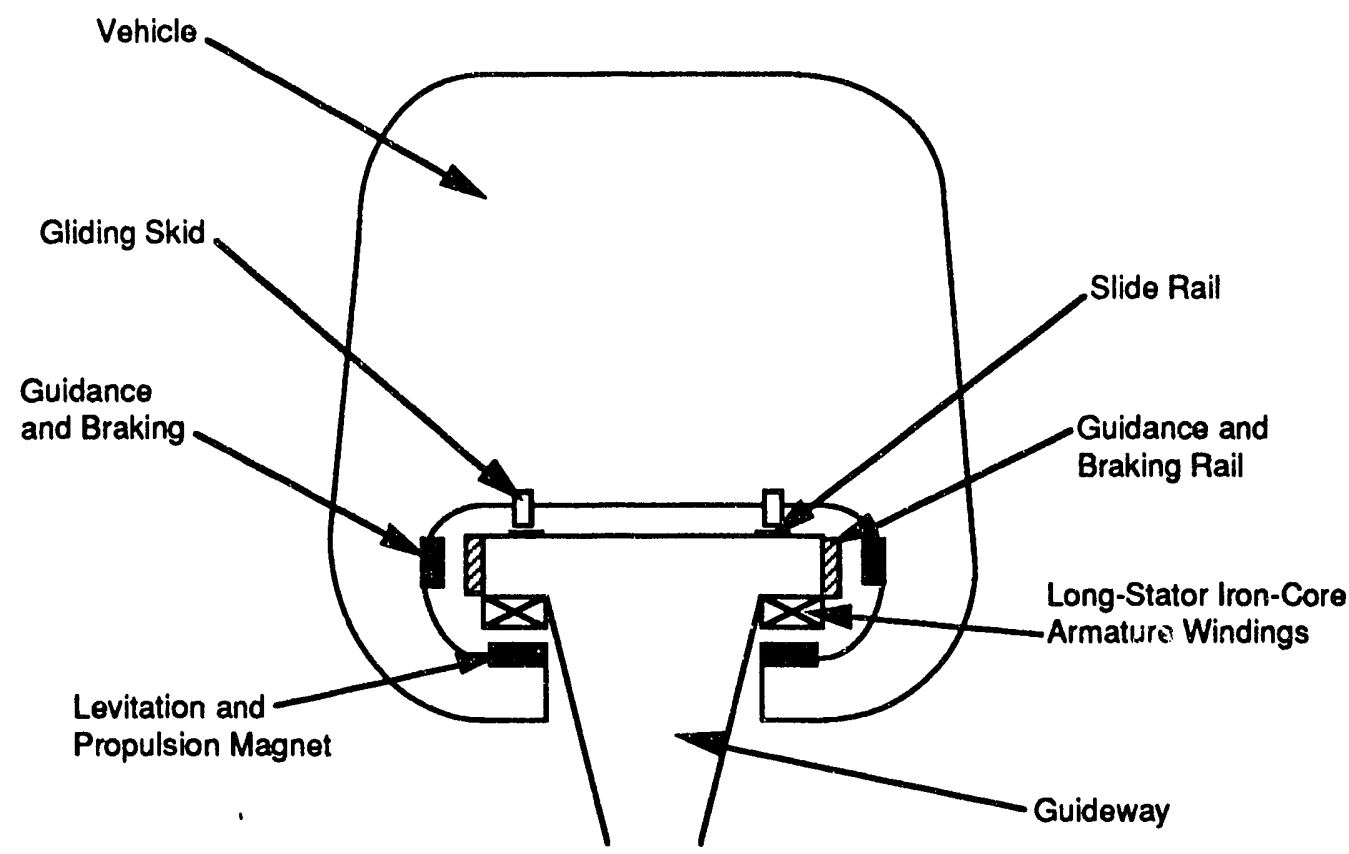

FIGURE 2.1 Schematic Diagram of the Transrapid Maglev System

- Observed reliability and comfortable ride;

- Proven technology;

- Levitation achieved over the entire range of speed, including at rest; and

- Use of concrete or steel guideway beams.

There are some possible drawbacks of the system:

- Complex control systems for suspension and lateral guidance;

- High cost of installing and maintaining the guideway because of the small clearance between vehicle and guideway and because of the heavy weight of the vehicles;

- Possible limit on maximum speed dite to the inability to rapidly control suspension and lateral guidance magnets and due to the associated weight of onboard power-conditioning equipment; 
- Possible clearance problems caused by ice and snow (clearance between magnets and guideway is about $1 \mathrm{~cm}$, whereas clearance between slide rail and skids is somewhat larger); and

- Possible limit on performance over existing rights-of-way that require frequent speed changes or have sharp curves because of the nontilting vehicle design, the maximum guideway superelevation of $12^{\circ}$, and the relatively modest acceleration (maximum $=0.85 \mathrm{~m} / \mathrm{s}$ ) of the vehicle. (Freedom to choose route alignment could improve performance.)

\subsection{Historical Development of the Transrapid Vehicle Family}

\subsubsection{Preliminary Test Vehicles}

Data for all the major prototype Transrapid vesis. it.- that have been built and tested during the past 20 years are summarized in Table 2.1.1-8 The development of the Transrapid maglev system dates back to about 1969, when two groups, Krauss Maffei (KM) and MesserschmittBölkow-Blohm (MBB), began competing to develop maglev systems. The two groups developed different versions: MBB employed separate magnets for support and for guidance, while KM pursued a combined system. The first Transrapid maglev test vehicle, TR 01 , was built by KM in 1969 (Figure 2.2). The vehicle was powered by a short-stator, linear induction motor (LIM). Two years later MBB built the first passenger-carrying vehicle (shown in Figure 2.3 and designated MBB in Table 2.1). That vehicle had a total weight of 5.8 metric tons, a passenger compartment with four seats, and a shoit-stator LIM for propulsion with a 10-mm air gap. It attained a maximum speed of about $100 \mathrm{~km} / \mathrm{h}$ in 1971 on a 700 -m-long test track.

In $1971 \mathrm{KM}$ built a second test vehicle, the Transrapid TR 02, as shown in Figure 2.4. The TR 02 used an electromagnetic support and guidance system with an air gap of $15 \mathrm{~mm}$. The vehicle weighed 10.7 metric tons and had eight seats. In 1971 the TR 02 attained a maximum speed of $164 \mathrm{~km} / \mathrm{h}$ on a 930 -m-long guideway. Using an alternative concept, KM built the Transrapid TR 03, an air-cushion-suspension vehicle, in 1972. The TR 03 had four seats aboard, a weight of 8 metric tons, and a 3-mm air gap, and this vehicle attained a maximum speed of $140 \mathrm{~km} / \mathrm{h}$ on the same guideway as had been used for testing the TR 02 . The basic features of the TR 03 are an air-cushion suspension and a short-stator LIM for propulsion. The performance of the TR 03 was judged to be inferior to that of the TR 02 because the TR 03 consumed more power and was noisier.

New competition on maglev systems appeared in 1972 when AEG-Telefunken AG, Brown Boveri \& Cie AG, and Siemens AG formed the "Project Group for Magnetic Levitation Technique," with the objective of developing an EDS system. To test the EDS maglev concept, a test vehicle designated the EET (17 metric tons, $12 \mathrm{~m}$ long; see Figure 2.5) was built in 1974 and 
TABLE 2.1 Summary of Data for the Transrapid Series Vehiclés

\begin{tabular}{|c|c|c|c|c|c|c|}
\hline $\begin{array}{c}\text { Vehicle } \\
\text { Designation }\end{array}$ & $\begin{array}{l}\text { Year } \\
\text { Built }\end{array}$ & $\begin{array}{l}\text { Weight } \\
\text { (metric } \\
\text { tons) }\end{array}$ & $\begin{array}{c}\text { Maximum } \\
\text { Speed } \\
(\mathrm{km} / \mathrm{h})\end{array}$ & $\begin{array}{l}\text { Guideway } \\
\text { Length } \\
\text { (m) }\end{array}$ & $\begin{array}{l}\text { Suspension } \\
\text { System }\end{array}$ & $\begin{array}{c}\text { Propulsion } \\
\text { System }^{b}\end{array}$ \\
\hline TR 01 & 1969 & - & $\cdots$ & $\cdots$ & EMS & SSICLIM \\
\hline MBB & 1971 & 5.8 & 100 & 700 & EMS & SDICLIM \\
\hline TR 02 & 1971 & 10.7 & 164 & 930 & EMS & SDICLIM \\
\hline TR 03 & 1972 & 8 & 140 & 930 & $A C$ & SDICLIM \\
\hline TR 04 & 1973 & 18.5 & 253.2 & 2400 & EMS & SDICLIM \\
\hline EET & 1974 & 17 & 200 & 900 & EDS & SDACLIM \\
\hline KOMET & 1970 & 8.8 & 401.3 & 1300 & EMS & Booster \\
\hline HMB 2 & 1976 & 2.5 & 36 & 100 & EMS & LSICLSM \\
\hline TR 05 & 1979 & 30.8 & 75 & 908 & EMS & LSICLSM \\
\hline TR 06 & 1983 & 122 & 412.6 & 31,500 & EMS & LSICLSM \\
\hline 7 & 1989 & 110 & $500^{c}$ & 31,500 & EMS & LSICLSM \\
\hline
\end{tabular}

a Abbreviations for suspension systems: EMS, electromagnetic suspension; $A C$, aircushioned suspension; EDS, electrodynamic suspension.

b Abbreviations for propulsion systems: SSICLIM, short-stator, single-side, iron-core, linear induction motor; SDICLIM, short-stator, double-side, iron-core, linear induction motor; SDACLIM, short-stator, double-side, air-core, linear induction motor; LSICLSM, long-stator, single-side, iron-core, linear synchronous motor.

c Design speed.

tested on a 900-m-long circular guideway at Erlangen (Figure 2.6). The vehicle was supported by four superconducting magnets, each with a 40-kA exritation current. An aluminum sheet was arranged on the guideway as a reaction rail. The vehicl attained a maximum speed of $200 \mathrm{~km} / \mathrm{h}$.

In the meantime, $\mathrm{KM}$ and $\mathrm{MBB}$ continued developing maglev vehicles using the EMS system. Krauss Maffei began testing the Transrapid TR 04 (Figure 2.7) on a 2,400-m-long guideway in December 1973. The vehicle weighed 18.5 metric tons and was able to carry 20 passengers at $253.2 \mathrm{~km} / \mathrm{h}$. MBB designed and built the KOMET (Figure 2.8), a driverless component carrier that weighed 8.8 metric tons, was $8.5 \mathrm{~m}$ long, and operated with a $14-\mathrm{mm}$ air gap. In February 1976, the KOMET was accelerated by six steam rockets to $401.3 \mathrm{~km} / \mathrm{h}$ on a 1,300-m-long track.

To effectively utilize test facilities and share research results for maglev technology, KM and MBB merged in 1974 to form an association called TRANSRAPID E.M.S. The major objective of the TRANSRAPID E.M.S. was to pursue the development of an EMS maglev system and its full-scale application. 


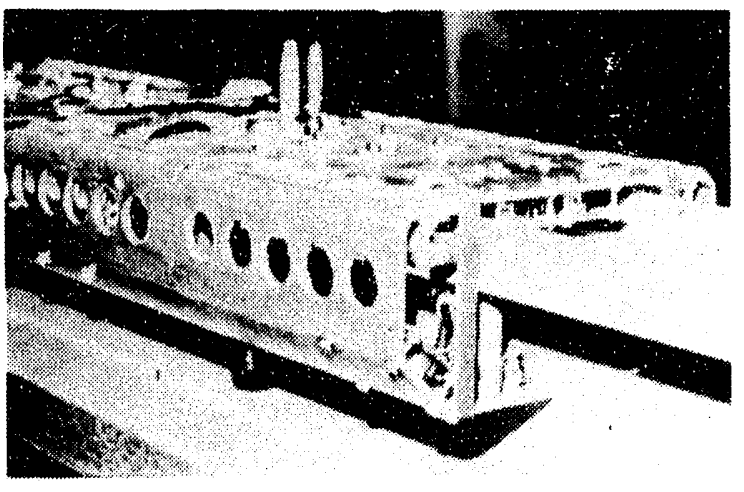

FIGURE 2.2 First Transrapid Maglev Test Vehicle, TR 01, Built by Krauss Maffei in 1969 (reproduced from Reference 3 with the permission of the copyright holder)

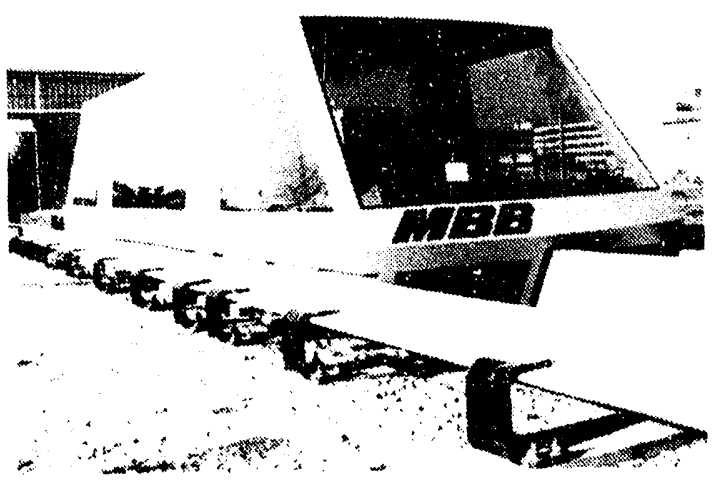

FIGURE 2.3 Test Vehicle, Built by Messerschmitt-Bölkow-Blohm in 1971 (reproduced from Reference 9 with the permission of the copyright holder)

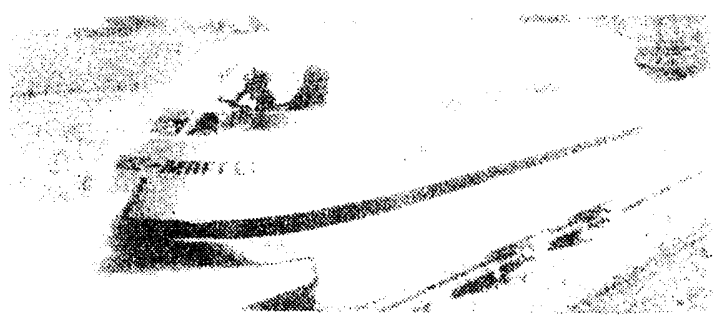

FIGURE 2.4 Transrapid TR 02 Test Vehicle, Built by Krauss Maffei in 1971 (reproduced from Reference 2 with the permission of the copyright holder)

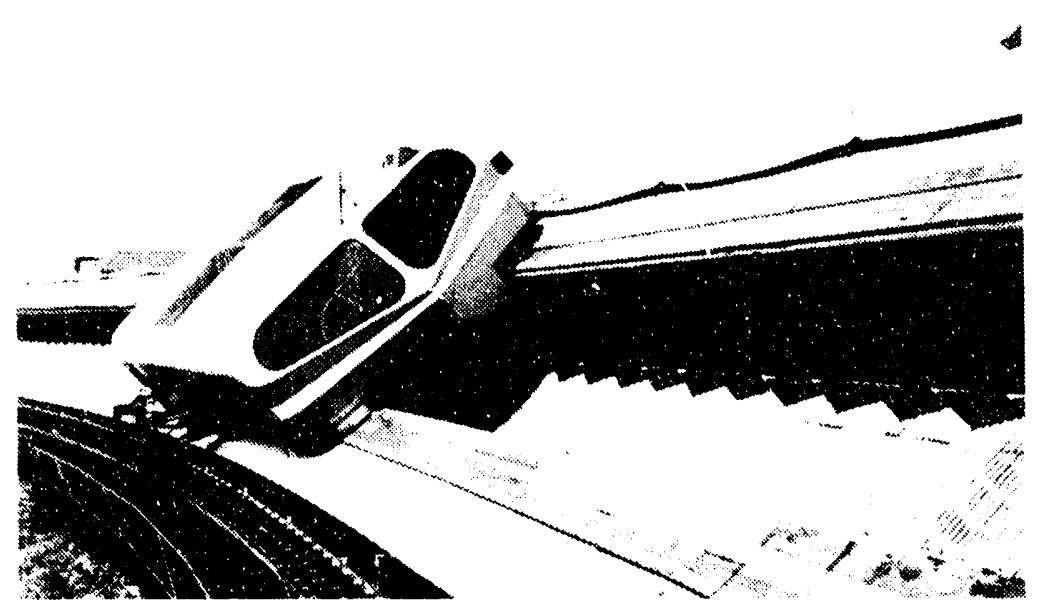

FIGURE 2.5 Electrodynamic-Suspension Test Vehicle (EET), Built by AEG-Telefunken AG, Brown Boveri \& Cie $A G$, and Siemens $A G$ in 1974 (reproduced from Reference 9 with the permission of the copyright holder) 


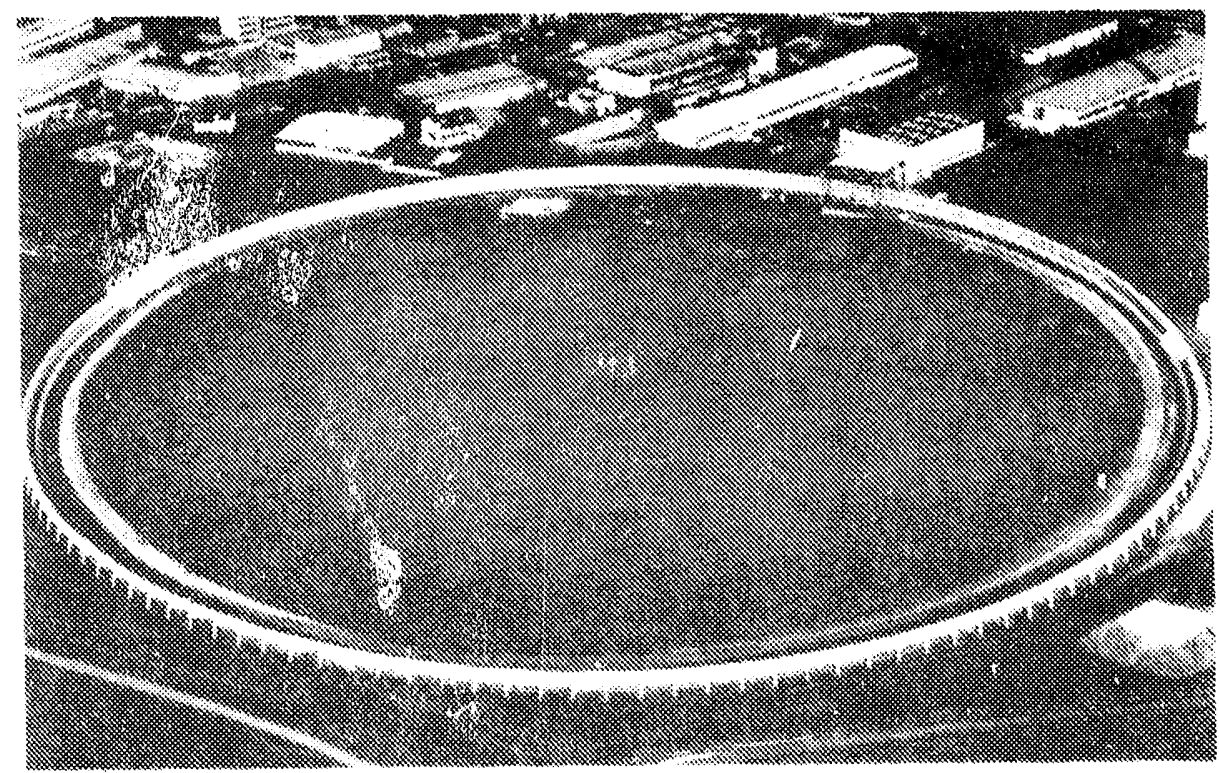

FIGURE 2.6 Circular, 900-m-Long, Electrodynamic-Suspension Test Track at Erlangen in 1974, with Aluminum Sheet Arranged on the Guideway (reproduced from Reference 1 with the permission of the copyright holder)

The development of long-stator magnetic linear propulsion technology began in 1975. A test platform designated HMB 1 and a vehicle designated HMB 2 (Figure 2.9) were built by Thyssen Henschel Industrie AG in Kassel during 1975 and 1976. The test system had the following parameters: vehicle weight of 2.5 metric tons. $5 \mathrm{~m}$ long, 4 seats. 1()-mm air gap. maximum speed of $36 \mathrm{~km} / \mathrm{h}$, and track length of $100 \mathrm{~m}$.

In 1977 the Federal Ministry of Research and Technology decided to support the EMS system. There were several reasons for this decision: (1) It was not financially possible to carry out development of both EMS and EDS systems: (2) time. expense, and risks of development were expected to be higher for the EDS system than for the EMS system; and (3) economic studies showed that, for the speed range from $3(0) \mathrm{t}(1) 4(0) \mathrm{km} / \mathrm{h}$, the EMS system could be cheaper than the EDS system. The Magnetbahn Transrapid consortium was established by AEG-Telefunken AG, Brown Boveri \& Cie AG, Dyckerhoff \& Widmann, KM. MBB, and Siemens AG in 1978 to develop an EMS maglev system. The decision to construct the Emsland Transrapid Test Facility (TVE) was made at that time.

\subsubsection{Transrapid TR 05}

On May 17, 1979, Transrapid TR 05, the world's first maglev vehicle authorized to carry passengers, went into operation (Figure 2.1(1). The vehicle was a full-scale prototype model designed and built by KM. MBB, and Thyssen Henschel Industrie AG. It weighed 3() .8 metric 
tons, had a total length of $26 \mathrm{~m}$, and was able to carry 68 passengers at $75 \mathrm{~km} / \mathrm{h}$ on a 908-m-long guideway. The characteristic features of the system included electromagnetic attractive suspension and guidance, and long-stator, iron-core LSM propulsion. The TR 05 carried 50,000 passengers during a six-month test period.

\subsubsection{Transrapid TR 06}

The Transrapid TR 06 was the next test and demonstration vehicle built in this series. ${ }^{9-20}$ It consisted of a two-car train

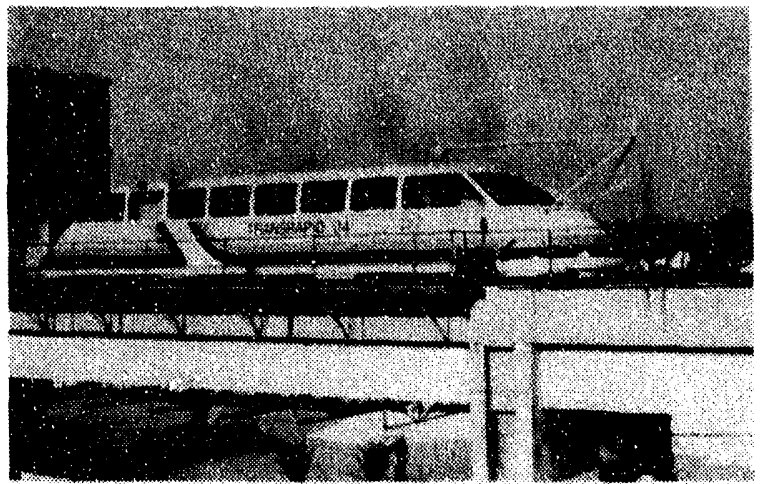

FIGURE 2.7 Transrapid TR 04 Test Vehicle, Built by Krauss Maffei in 1973 (reproduced from Reference 3 with the permission of the copyright holder) having a total length of $54 \mathrm{~m}$ and weighing about 122 metric tons, including a 20 -ton payload, with a total capacity of 196 passengers. The design speed of the TR 06 was $400 \mathrm{~km} / \mathrm{h}$. About 700 trial and demonstration runs were carried out on the TVE in 1985, during which the TR 06 covered a distance of more than $14,000 \mathrm{~km}$. The vehicle achieved a speed of $355 \mathrm{~km} / \mathrm{h}$ on December 12,1985 , on the $21.6-\mathrm{km}$-long northern loop of the TVE, and a speed of $412.6 \mathrm{~km} / \mathrm{h}$ on January 22,1988 , on the TVE test track after it was extended to $31.5 \mathrm{~km}$. Detailed parameters of the TR 06 are summarized in Table 2.2, and the

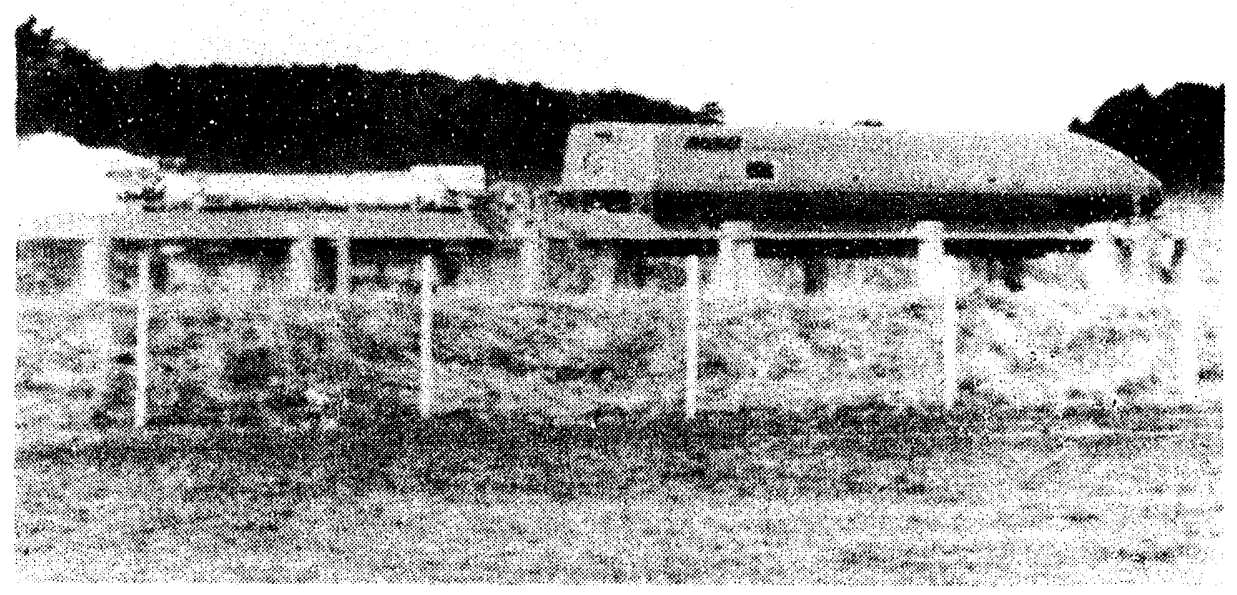

FIGURE 2.8 KOMET Magleiv Test Vehicle, Built by MesserschmittBölkow-Blohm in 1976 (reproduced from Reference 1 with the permission of the copyright holder) 

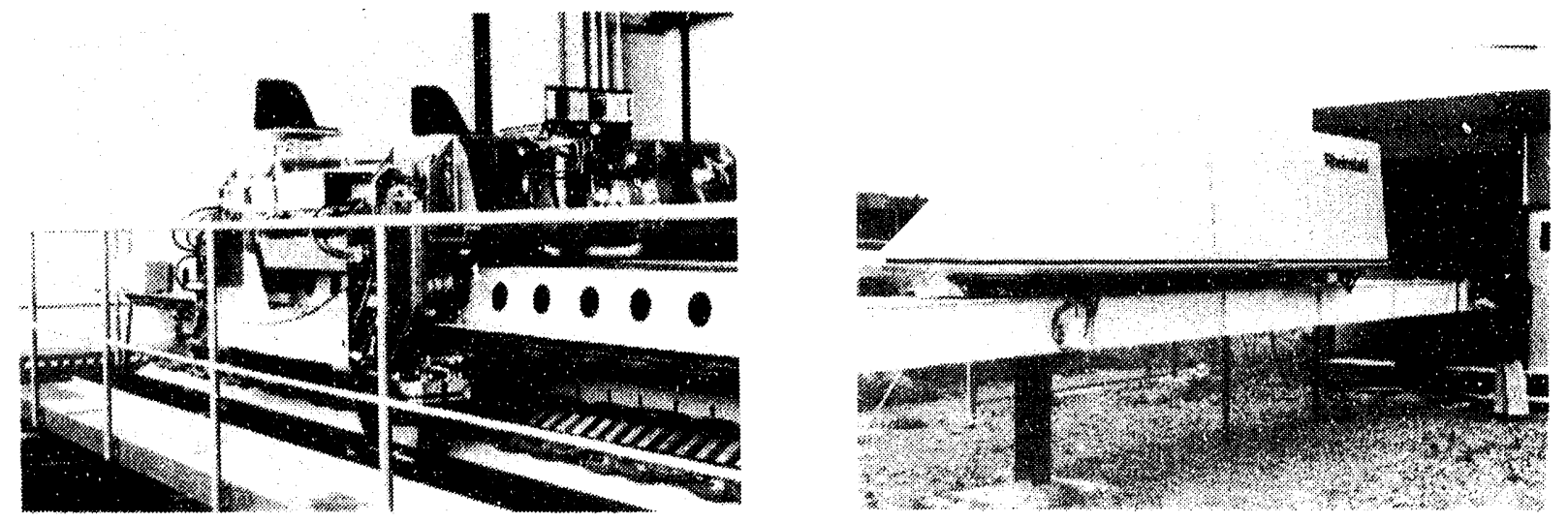

FIGURE 2.9 HMB Test Facility and Vehicle for Developing Long-Stator Propulsion Technology, Built by Thyssen Henschel Industrie AG in Kassel in 1976 (reproduced from Reference 3 with the permission of the copyright holder)

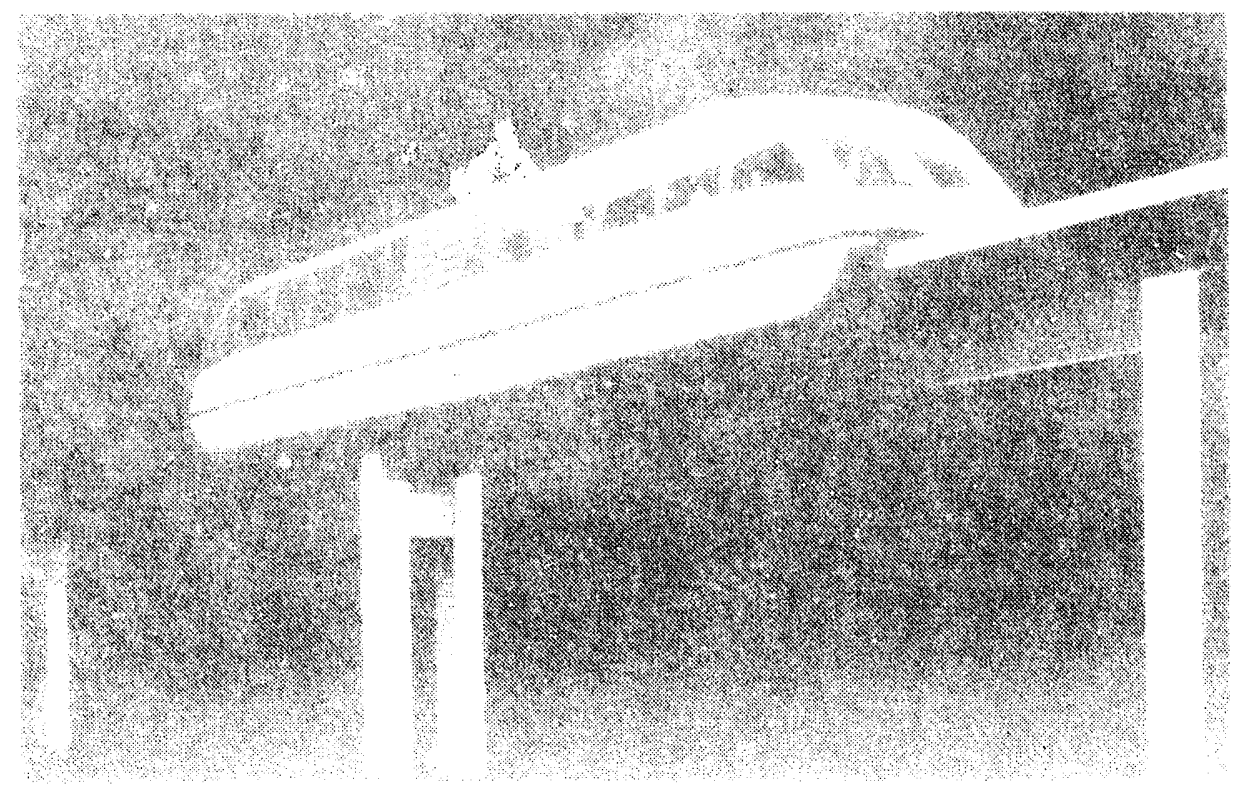

FIGURE 2.10 Transrapid TR 05, the World's First Maglev Train Authorized to Carry Passengers, Built by Krauss Maffei, Messerschmitt-Bölkow-Blohm, and Thyssen Henschel Industrie AG in 1979 (reproduced from Reference 1 with the permission of the copyright holder) 


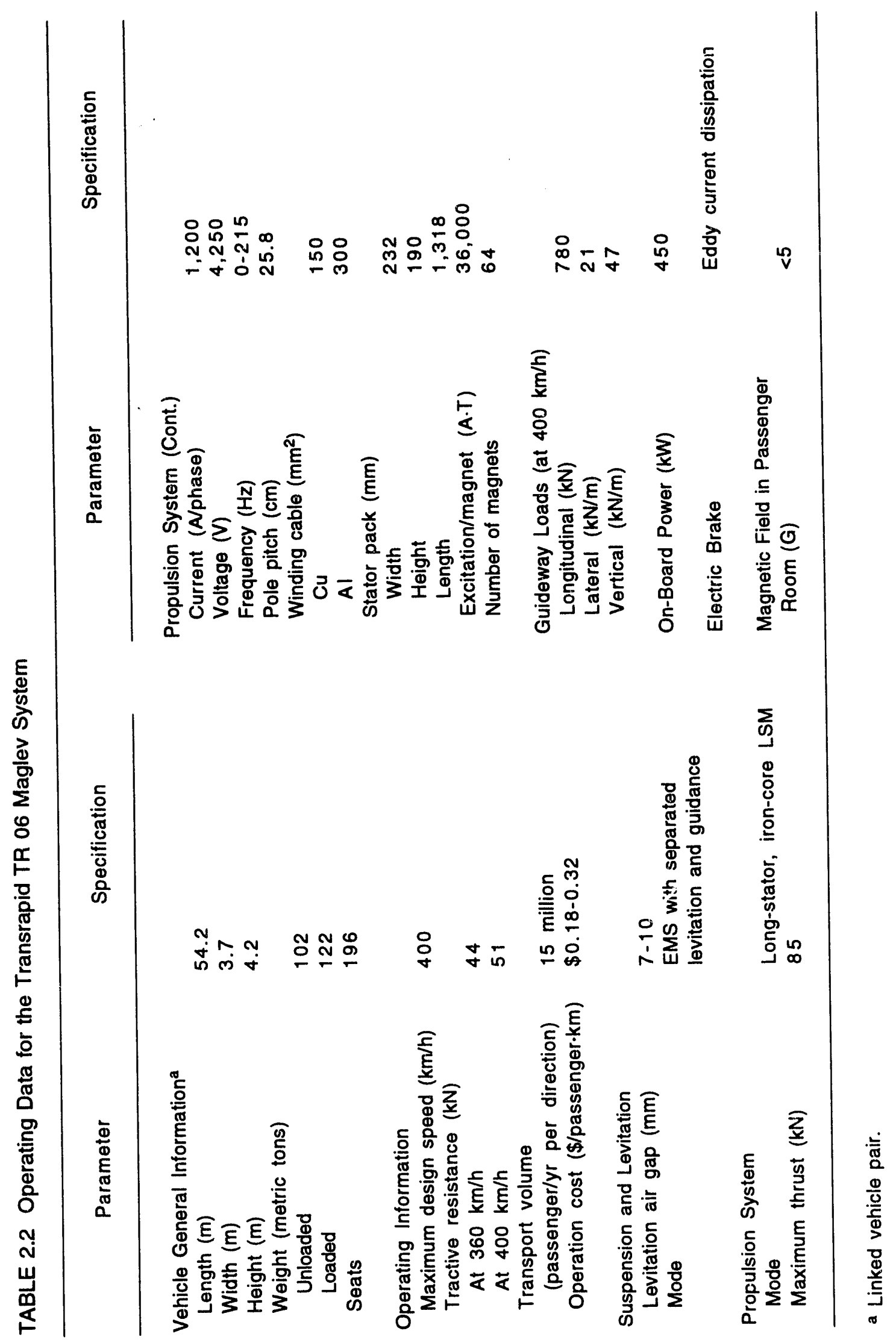


vehicle is shown in Figure 2.11. A schematic diagram of the levitation and guidance system is shown in Figure 2.12. The propulsion and power-supply systems of the TR 06 are discussed in Sections 2.3 and 2.4 .

\subsubsection{Transrapid TR 07}

Testing began on the Transrapid TR 07, a prototype revenue service vehicle, in January 1989. Named "Europa," TR 07 was presented for the first time to the public at the International Traffic Exhibition in Hamburg in June 1989. It had a design speed of $500 \mathrm{~km} / \mathrm{h}$. The vehicle consisted of two identical units with an overall length of $50 \mathrm{~m}$, a width of $3.7 \mathrm{~m}$, a height of $3.9 \mathrm{~m}$, a capacity of 200 passengers, and a total weight of 110 metric tons, including a payload of about 20 metric tons (Table 2.3). The TR 07 design was improved on the basis of the research on previous vehicle models, and in particular, on the experience and findings gained from the TR 06. A detailed study of aerodynamic drag resulted in a reshaping of the nose section and cowling around the magnets. These shape changes, together with a reduction in cross-sectional

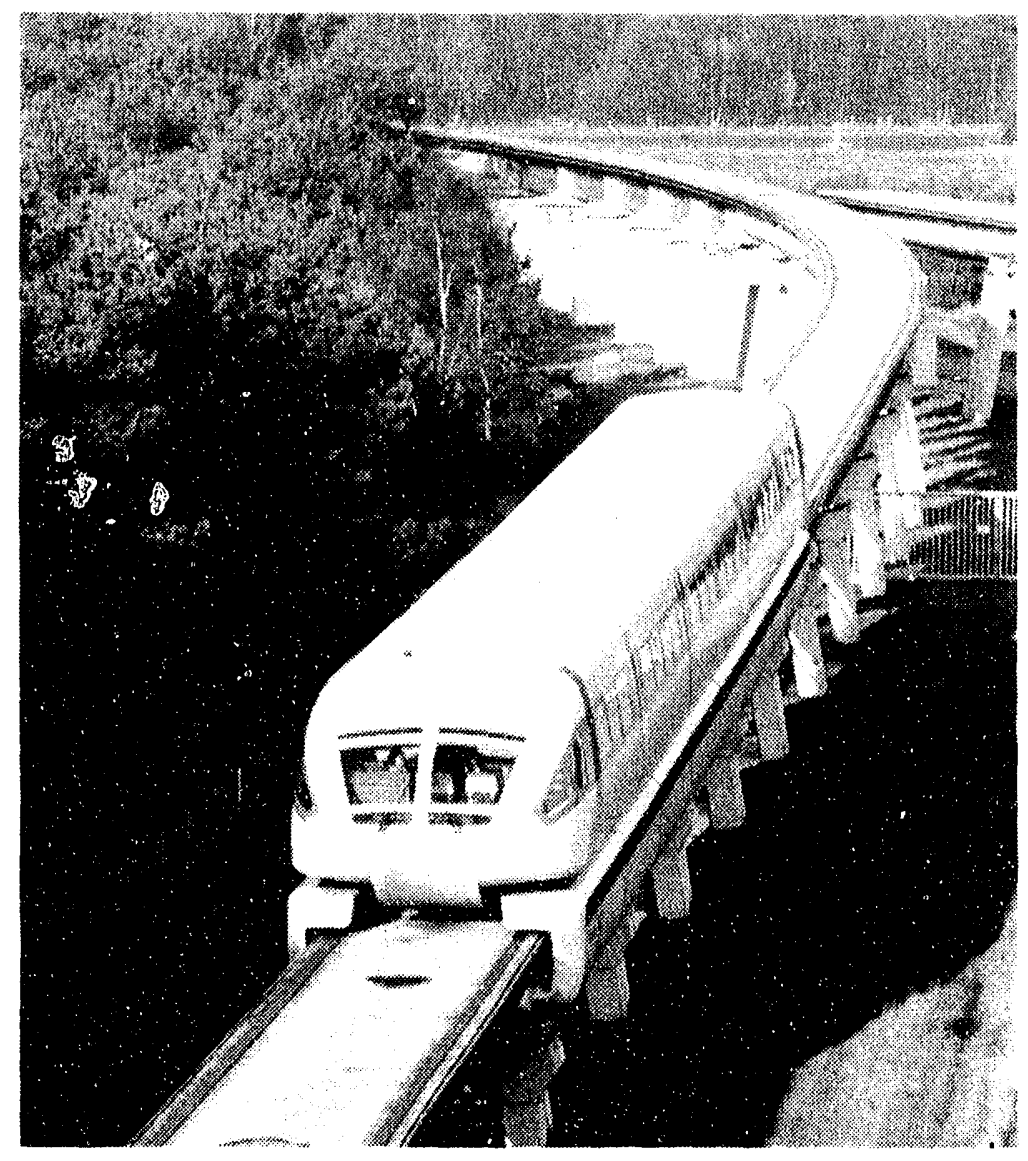

FIGURE 2.11 Transrapid TR 06 Test and Demonstration Vehicle, Built in 1983 (reproduced from Reference 9 with the permission of the copyright holder) 


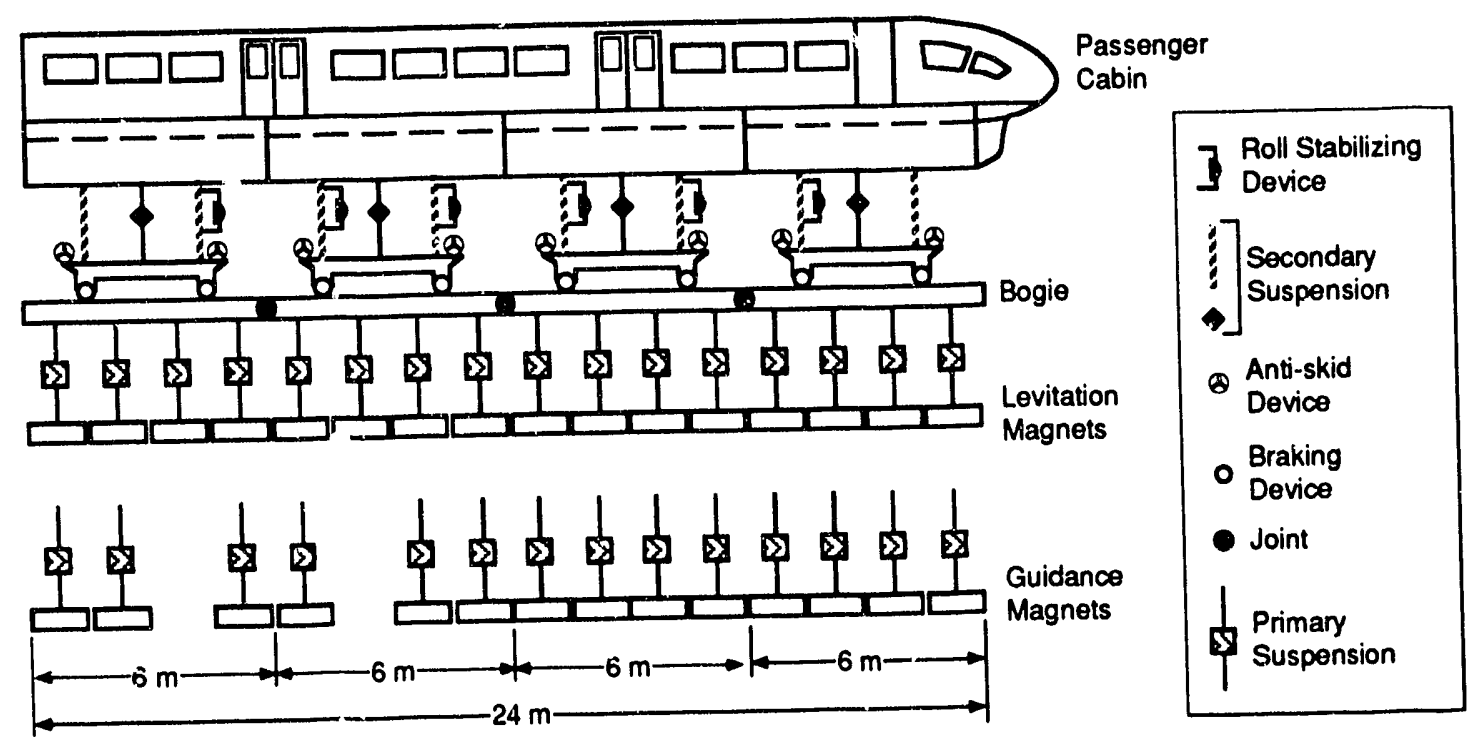

FIGURE 2.12 Mechanical Structure of the Levitation and Guidance System of the Transrapid TR 06 Maglev System

area of $10 \%$ and some other design changes, resulted in a substantial reduction of total drag force, from 51 to $35 \mathrm{kN}$ at $400 \mathrm{~km} / \mathrm{h}$. In addition, the TR 07 vehicle was designed with autonomous functions in all essential subsystems. It used newly developed electromagnetic, electronic, and mechanical components. The support and guidance system of the TR 07 was characterized by a chain-like arrangement of magnets controlled in two degrees of freedom, which was similar to the TR 06 system (Figure 2.12). A secondary suspension system between the levitation bogies and the carriage body ensured dynamic decoupling and a comfortable ride. In addition, the TR 07 was fitted with first-class seats, air conditioning, bright illumination, and audio/video equipment (Figures 2.13 and 2.14). More detailed information on the TR 07 can be found in References 9 , 14 , and 15.

Both TR 06 and TR 07 are revenue-service type vehicles. It has been estimated that the capital expenditure of a maglev system is about $\$ 15$ million to $\$ 25$ million $/ \mathrm{km}$ of double track. Total operating cost is about $\$ 0.18$ to $\$ 0.32 /$ passenger $\cdot \mathrm{km}$. The system should be able to transfer up to 15 million passenger/yr in each direction, with an energy consumption of about $60 \mathrm{~W} \cdot \mathrm{h} / \mathrm{seat}$ per kilometer.

\subsection{Linear Propulsion System}

Transrapid maglev vehicles are powered by an iron-core, long-stator LSM in combination with the magnetic attractive levitation system. The principle of operation of a long-stator synchronous motor is shown in Figure 2.15. Three-phase armature windings are arranged on the guideway in such a way that a traveling wave can be generated along the guideway when the armature windings are energized with a polyphase power source. The excitation-field magnets of 


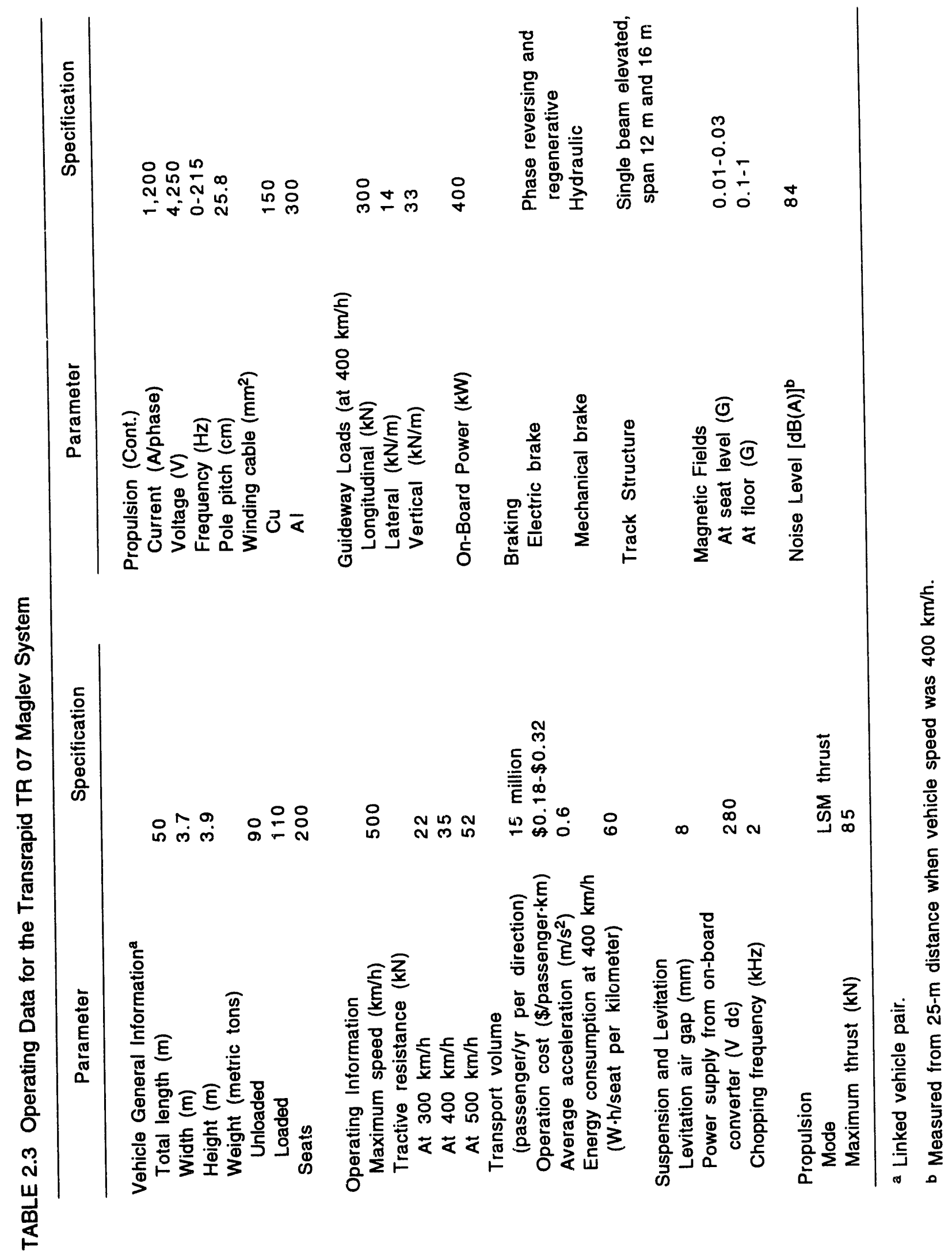




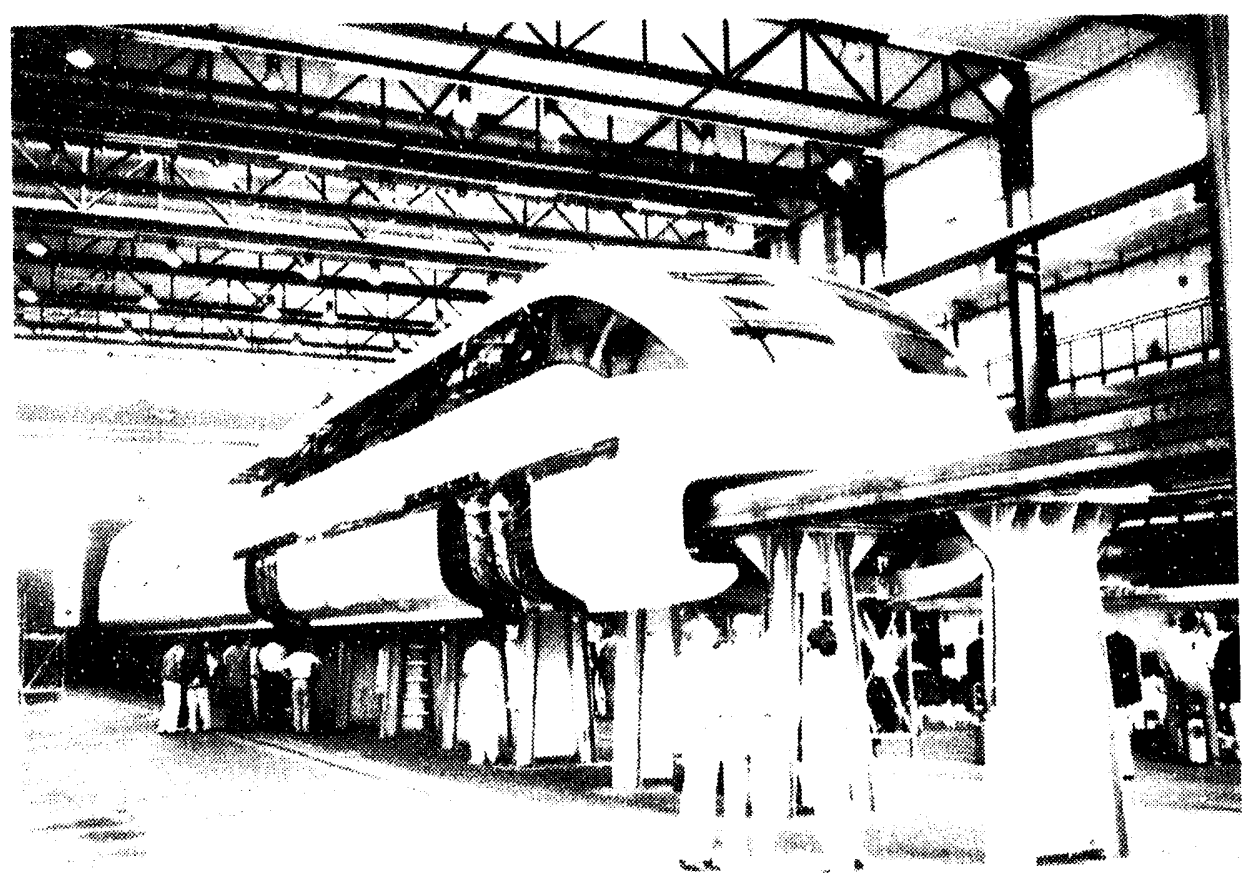

FIGURE 2.13 Transrapid TR 07 Application-Prototype Vehicle, Built in 1988

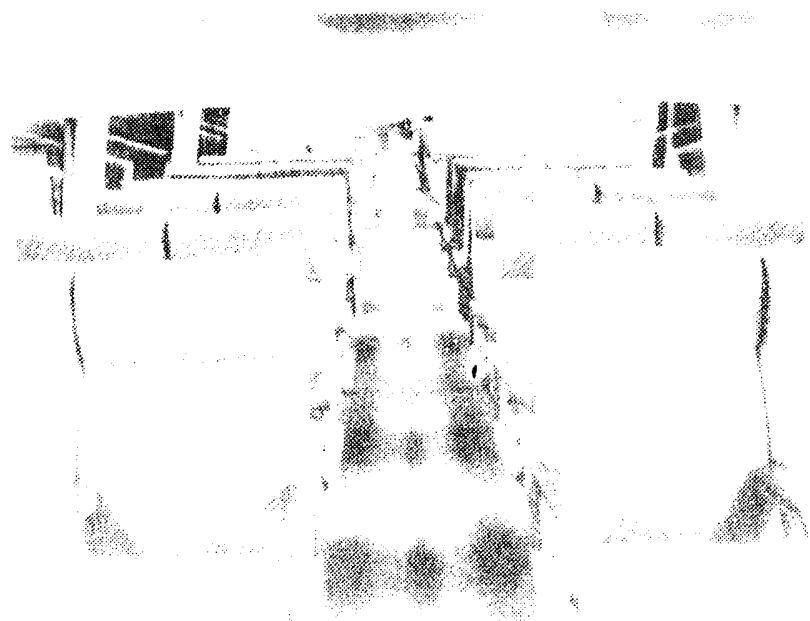

FIGURE 2.14 Interior Design of the Transrapid TR 07 Application-Prototype Vehicle (reproduced from Reference 15 with the permission of the copyright holder) 

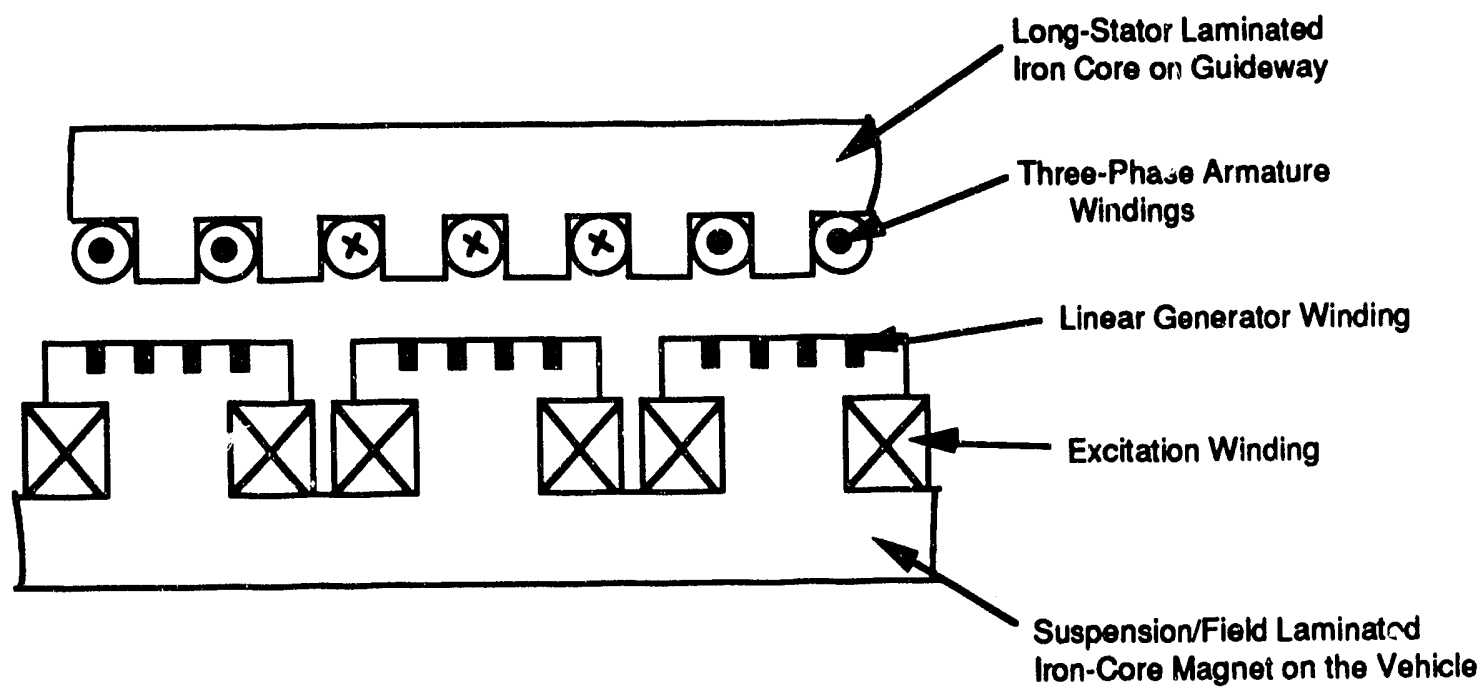

FIGURE 2.15 Cross-Sectional View of the Long-Stator Linear Synchronous Propulsion Motor

the propulsion system on the vehicle also act as the suspension magnets. A linear generator provides the power needed on board for propulsion, suspension, guidance magnet excitation, and other on-board facilities. Flux variations caused by the stator slots induce voltages in the linear generator windings. To increase the power utilization and efficiency of the system, the long-stator armature windings on the guideway are divided into separate motor sections. The TVE guideway, which has a total length of $31.5 \mathrm{~km}$, is divided into 58 motor sections. The length of the sections varies from $300 \mathrm{~m}$ in the high-speed zone to $2,000 \mathrm{~m}$ in the reversing loops. Some technical parameters for the linear propulsion system of the Transrapid TR 06 system are given in Table 2.4.9-20

The iron-core, long-stator LSM propulsion system is characterized by several features. The iron cores have small air gaps to achieve magnetic efficiency and to reduce the stray magneticflux density around the vehicle. The iveight of the vehicle is an important factor in determining the strength of the excitation field of the motor because the same magnets are used for the combination of suspension and propulsion systems. Because an energized motor section is much longer than the length of the vehicle, there is relatively poor power utilization by the system. However, the control system maintains synchronization between the traveling wave in each energized motor section and the vehicle. To maintain the constant air-gap flux density determined by the weight of the vehicle, the power supply employs VVVF. Finally, the thrust of the motor is controlled by the complex current (phase and amplitude) in the armature windings. 
TABLE 2.4 Summary of Data for the Propulsion and Power Systems of the Transrapid TR 06 Maglev System

\begin{tabular}{ll}
\multicolumn{1}{c}{ Parameter } & \\
\hline & \\
\hline & \\
Linear Synchronous Motor & 58 \\
Number of motor sections & 3 \\
Number of phases & 25.8 \\
Pole pitch (cm) & 215 \\
Maximum frequency (Hz) & 4,500 \\
Maximum voltage (V) & 1,200 \\
Maximum current (A) & \\
Conductor cross section (mm ${ }^{2}$ ) & 150 \\
Northern loop, Cu & 300 \\
Southern loop, Al & \\
Southern loop with $3.5 \%$ & 285 \\
gradient & 2 \\
Number of inverter systems & 30 \\
Number of switch stations & 85 \\
Thrust (kN) & 10 \\
Air gap (mm) & $6 / 10$ \\
Cable insulation level (kV) & $300-2,000$ \\
Motor section length (m) & \\
Power Supply & $31.5 \mathrm{MVA}, 110 / 20 \mathrm{kV}$ \\
High-voltage transformer & $2 \times 5.6 \mathrm{kVA}, 20 / 1.2 \mathrm{kV}$ \\
Rectifier transformers & $2 \times 3,300 \mathrm{~V}, 2 \times 1,300 \mathrm{~A}$ \\
Rectifiers & $8 \times 2.2 \mathrm{MVA}, 0-2,027 \mathrm{~V}, 680 \mathrm{~A}, 0-215 \mathrm{~Hz}$ \\
Inverters/system & $4 \times 2 \mathrm{MW}, 4 \times 800 \mathrm{~A}$ \\
Braking circuit & $4 \times 1.8 \mathrm{MVA}, \mathrm{Max} .4,500 / \mathrm{phase}, 55-215 \mathrm{~Hz}$ \\
Output transformer/system & \\
\hline
\end{tabular}

\subsection{Power-Supply System}

The TVE Test Facility is supplied with power from the $110-\mathrm{kV}$ public-utility grid (Figure 2.16). A dc-link circuit is supplied with $2.6 \mathrm{kV}, 2 \times 33 \mathrm{kA}$ through a $110 / 20 \mathrm{kV}$ highvoltage transformer and two $20 \mathrm{kV} / 1.2 \mathrm{kV}$ rectifier transformers feeding through two controlled rectifier systems connected in parallel. Smoothing reactors and protective high-dc, high-speed circuit breakers are arranged at the input of the link circuit. The constant link-circuit voltage is converted by means of two pulse-width-modulated inverter systems into a three-phase voltage system with a meshed output voltage from 0 to $2,027 \mathrm{~V}$ and a variable frequency from 0 to $215 \mathrm{~Hz}$. At motor frequencies from 0 to $55 \mathrm{~Hz}$, this three-phase voltage system is connected directly to the long-stator armature windings. At higher frequer cies, output transformers serve to increase the output voltage to a maximum of 7,800 V. The maximum motor current is $1,200 \mathrm{~A}$. The power-system data are summarized in Table 2.4. ${ }^{9-20}$ 


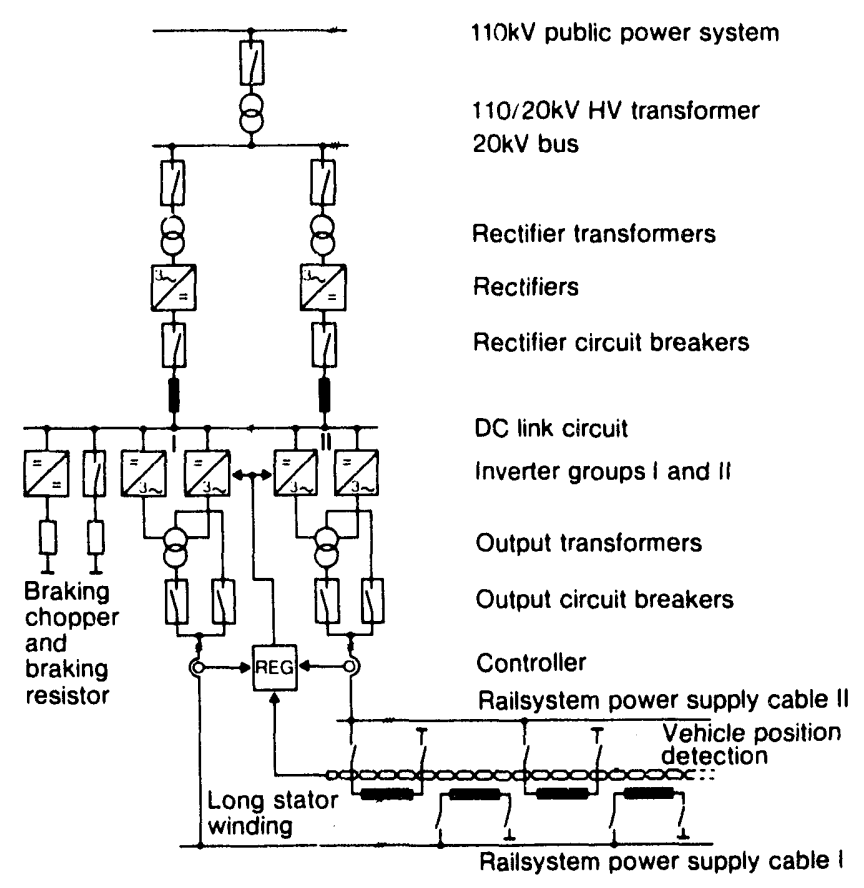

FIGURE 2.16 Basic Circuit Diagram of the Drive System (reproduced from Reference 9 with the permission of the copyright holder)

The propulsion concept of Transrapid TR-06 was realized with a "leapfrog" type of feeder circuit to the motor. By alternating and overlapping the power supply from two inverter groups via separate cable systems, this method avoids any break in the motor thrust as the vehicle passes from one section to the next.

\subsection{Test Facility at Emsland}

The Transrapid Test Track at Emsland, called TVE, is a unique maglev test facility. Sponsored by the Federal Ministry of Research and Technology, TVE was developed and built in two piases by a consortium of prominent industrial companies. The first phase of track built had a length of $20.6 \mathrm{~km}$ and was constructed by the Magnetbahn Transrapid consortium over the years 1979-1984. The second phase of the track, the $10.9 \mathrm{~km}$-long southern loop, was built by Thyssen Henschel (as the general contractor) and became operational at the end of 1987. The facilities of TVE include the Transrapid vehicle family, including the TR 06 and TR 07; well-equipped test center; elevated steel and concrete guideway (Figure 2.17); three bendable steel-beam switches (Figure 2.18); the primary of a long-stator linear motor; and a centrally controlled information and safety system. The test center (Figure 2.19) has a 4,600-m floor and $34,000 \mathrm{~m}^{3}$ of enclosed space. The big hall of the center is used for housing the Transrapid vehicles and facilities for vehicle maintenance and repair. The center houses the operational room for propulsion control, data processing, and system monitoring, as well as other research facilities. ${ }^{9}$ 


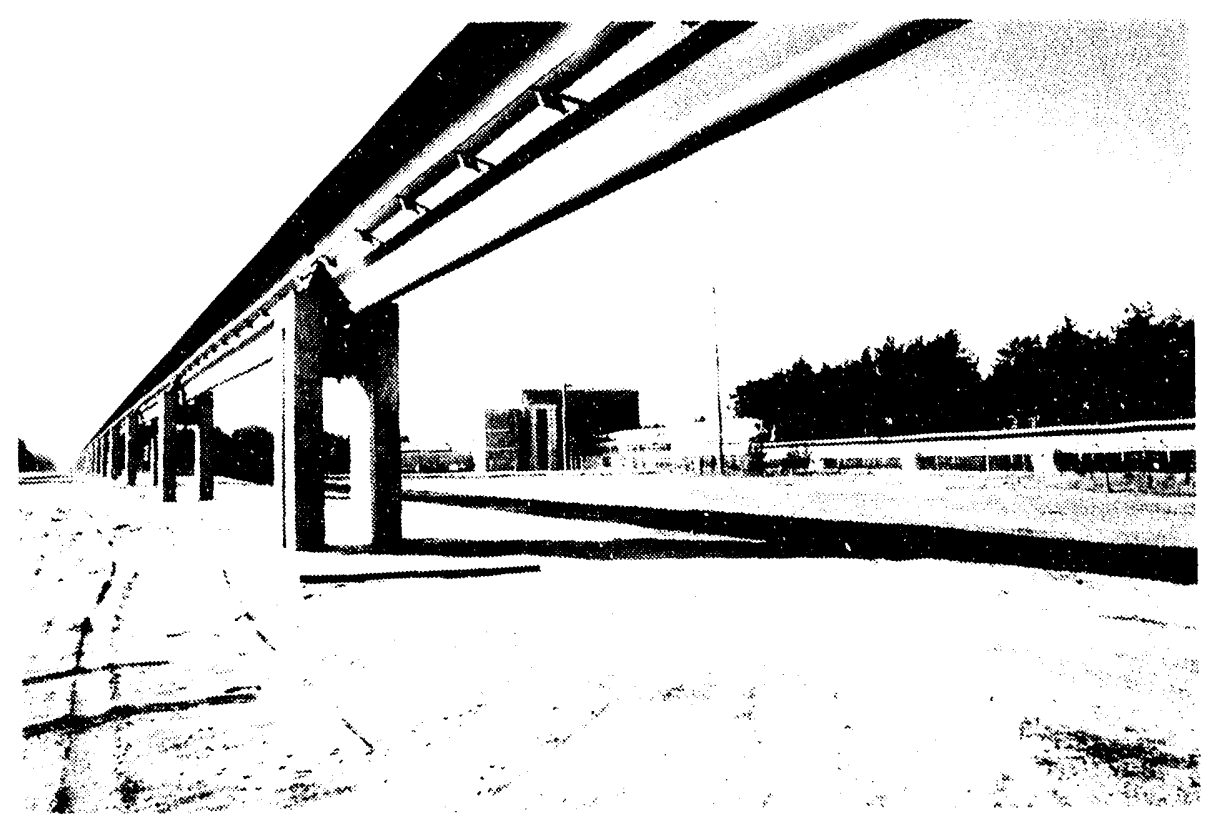

FIGURE 2.17 Transrapid Test Track at Emsland, Showing Steel Guideway Beams with Concrete Pillars (Test Center is in background; reproduced from Reference 9 with the permission of the copyright holder)

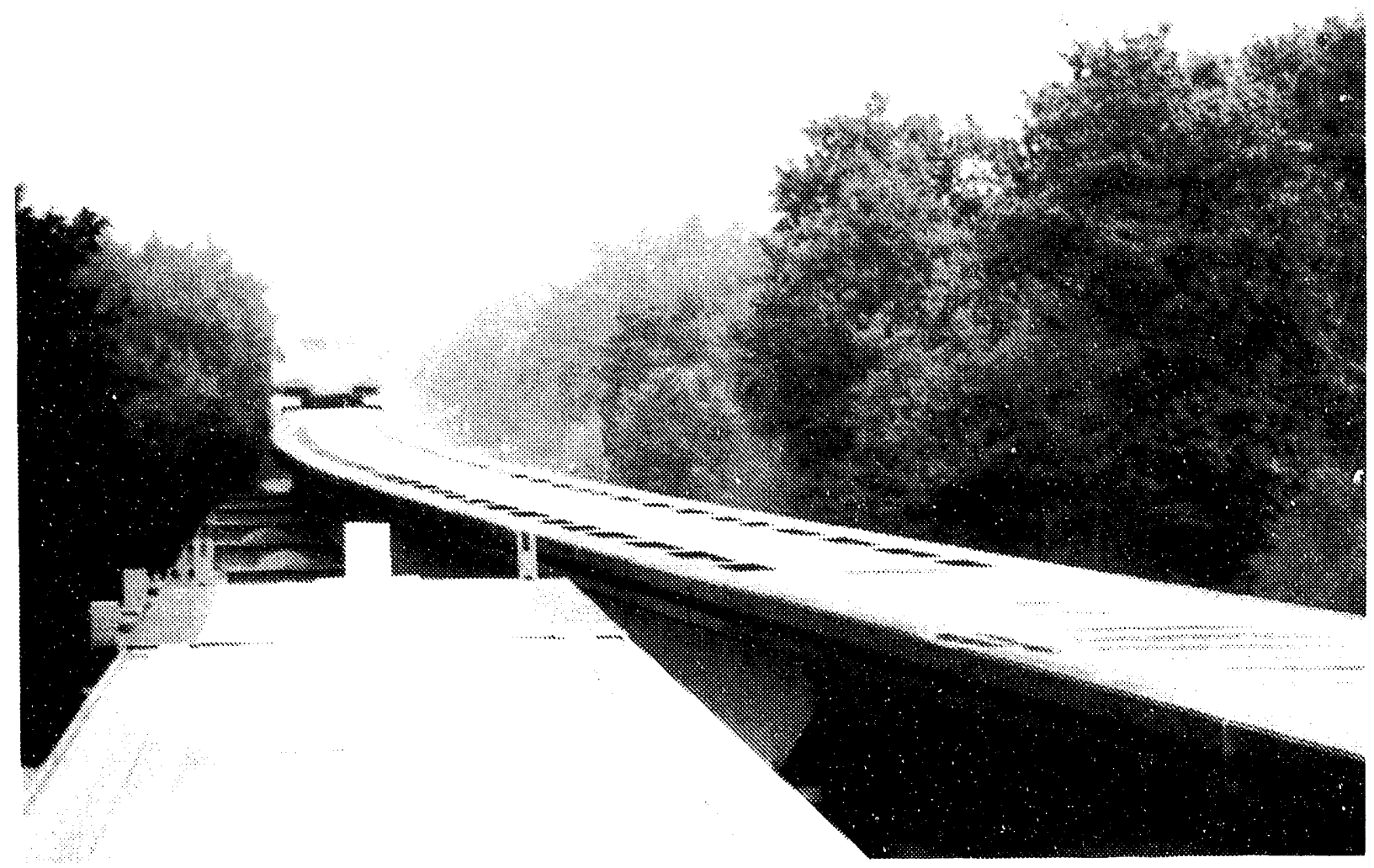

FIGURE 2.18 Transrapid TR 06 Approaching the Bending Switch of the Test Track at Emsland (reproduced from Reference 9 with the permission of the copyright holder) 


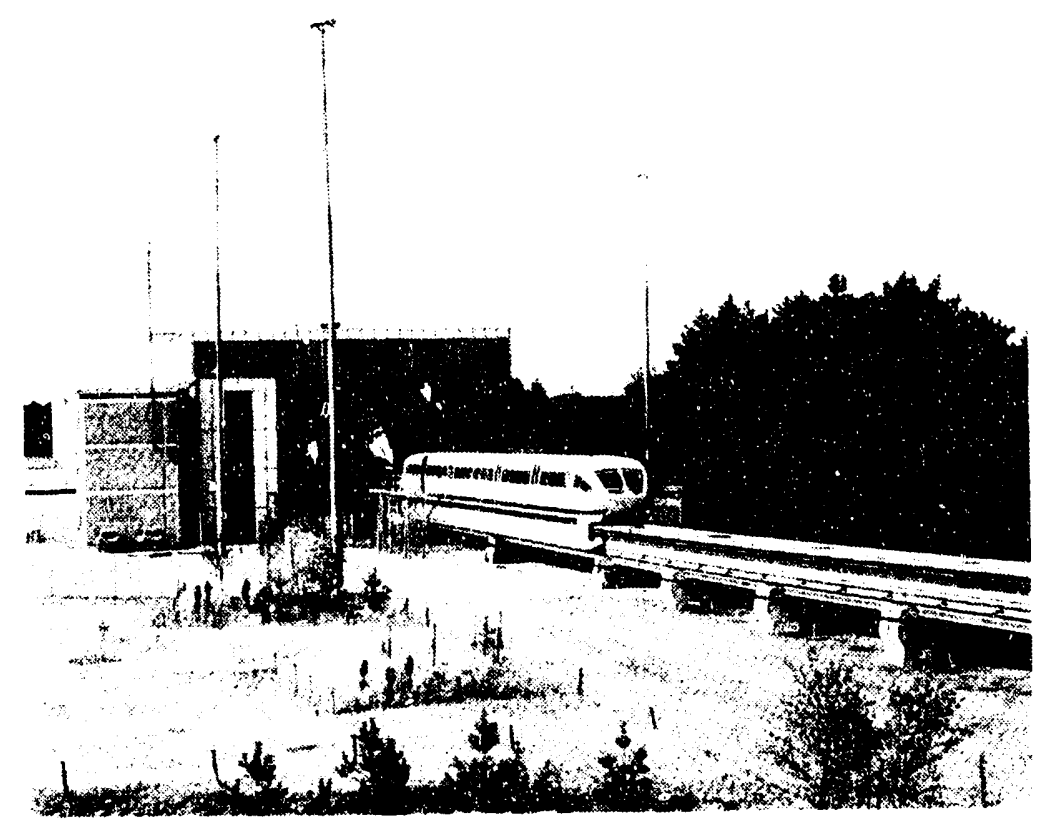

FIGURE 2.19 Test Center of the Transrapid Test Facility at Emsland (reproduced from Reference 9 with the permission of the ccpyright holder)

The TVE guideway has the typical form of a superspeed test facility, as shown in Figure 2.20. Having a total length of $31.5 \mathrm{~km}$, the TVE guideway consists of several speed zones, which permit different test objectives. It has two high-speed switches at the terminal loops and one low-speed switch near the test center. All switches are of flexible steel construction. The radius of curvature of the northern terminal loop is $1,690 \mathrm{~m}$; that of the southern loop is $1,000 \mathrm{~m}$. A summary of data describing TVE is given in Table 2.5 .

Since completion of construction of the first-phase, TVE has played an important role in the development of the maglev program in the Federal Republic of Germany. In particular, on December 12, 1985, the Transrapid TR 06 test vehicle achieved a speed of $355 \mathrm{~km} / \mathrm{h}$ on the first phase of TVE, and on January 22, 1988, the TR 06 attained a speed of $412.6 \mathrm{~km} / \mathrm{h}$ on the completed $31.5-\mathrm{km}$-long guideway, establishing the world speed record for a passenger-carrying maglev vehicle.

\subsection{Present Status and Future Prospects}

At the end of 1991, after about 20 years of research and development, German Federal Railways concluded that the criteria for technical readiness for application of the Transrapid highspeed maglev train were satisfied. This meant that the Transrapid maglev system was officially ready for commercial applications. In fact, of all high-speed maglev systems, the Transrapid could 


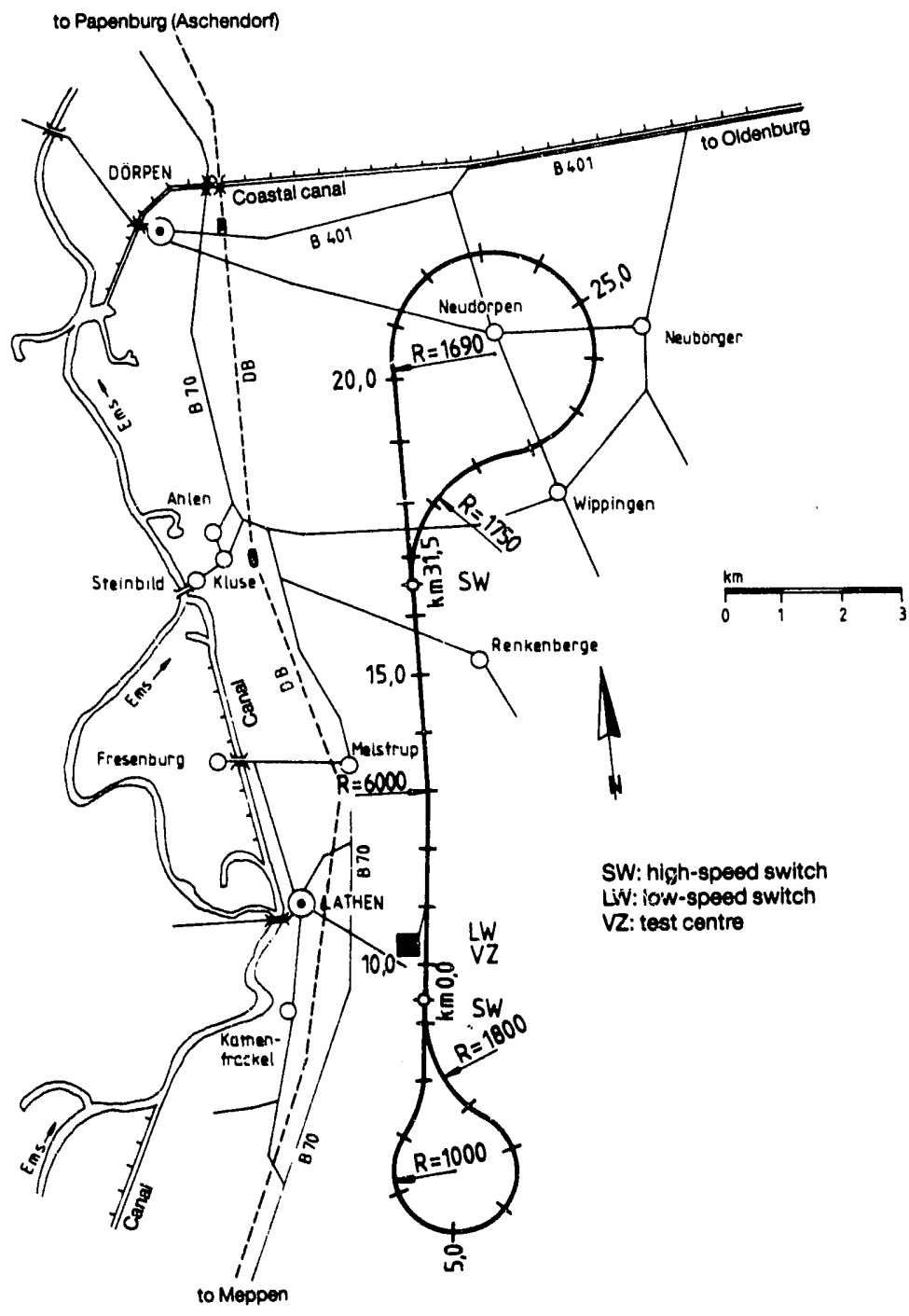

FIGURE 2.20 Site Plan of the Transrapid Test Facility at Emsland (reproduced from Reference 9 with the permission of the copyright holder) 
TABLE 2.5 Summary of Data for the Transrapid Test Facility at Emsland

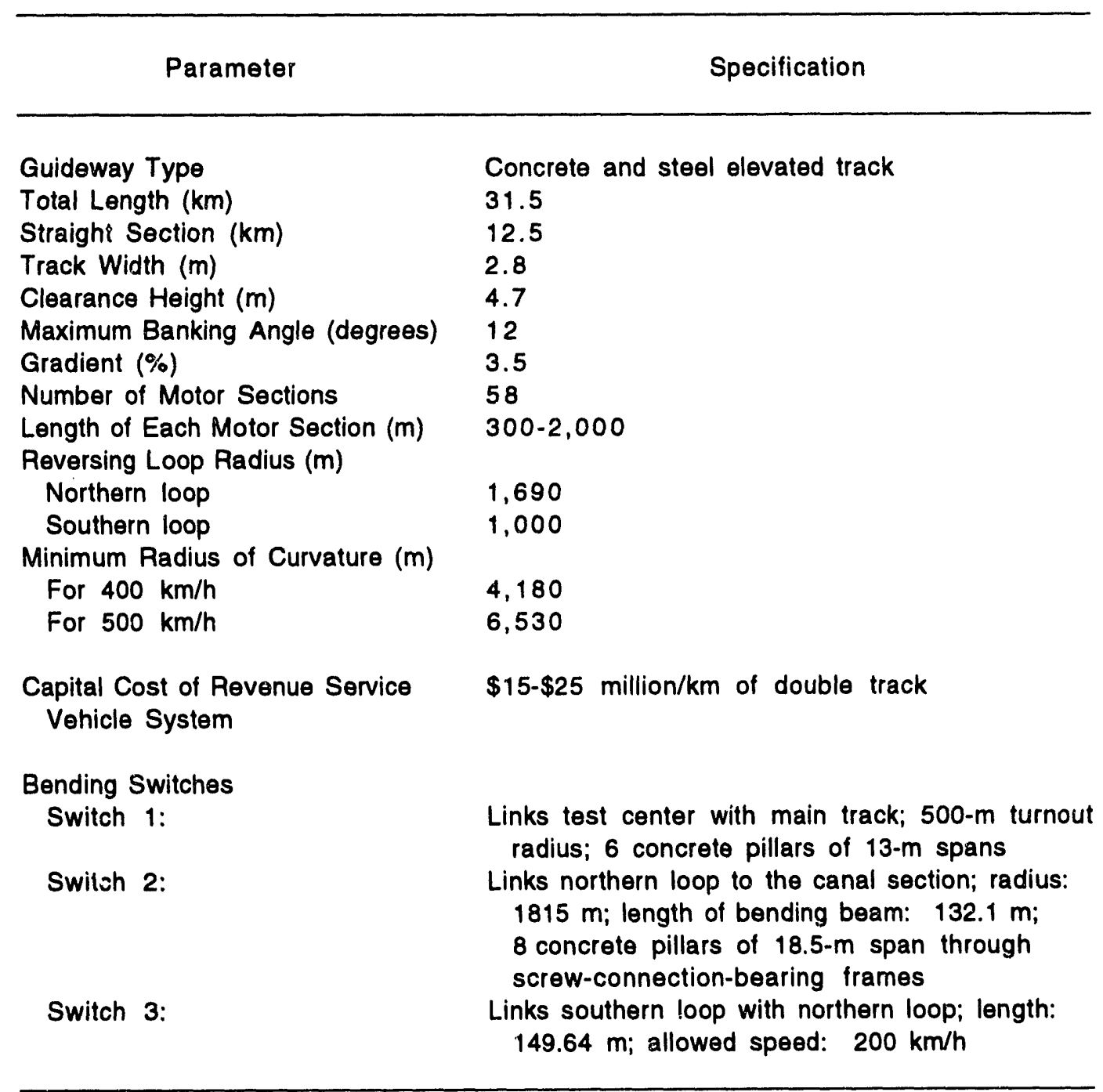

be the first one to be operated commercially. To avoid time gaps between the completion of development and the start of new route construction, two parallel programs on Transrapid maglev are currently being conducted in Germany: (1) the final development program and (2) the application route program. 21,22

The final development program began in 1991 and will end by 1995. During this period, investigation will continue in technological optimization, high-speed aerodynamics, electronic technology, environmental influences, and in other research and development programs on Transrapid, while gaining high-speed operating experience for revenue service.

The application-route planning program, which began in 1992 and will end in 1995, includes the selection of potential maglev system routes to yield overail economic benefit. The 
selected maglev system routes are not expected to conflict with the existing conventional highspeed railroads. Preliminary studies were conducted on two routes: Hamburg-Berlin and BonnBerlin. Hamburg and Berlin are two of the largest cities in Germany, separated by a distance of $287 \mathrm{~km}$. The Transrapid maglev system is expected to serve this route, running every 10 minutes and transporting 15.3 million passenger/yr. The second route studied is between Bonn and Berlin. Several route options are currently being considered, with the shortest one being $582 \mathrm{~km}$ through Kassel. The transportation volume is expected to be 15 million passenger/yr.

Construction work for the maglev system application track in Germany will begin in 1995, and the first revenue-service high-speed maglev system in the world is expected by the year 2000 .

\subsection{References}

1. Schulz, H., 1978, "Technologies for Magnetic Levitation Systems," in Proceedings of the International Seminar on the Superconductive Magnetic Levitated Train, pp. 37-49, held at Miyazaki, Japan, in Nov.

2. Rogg, D., 1982, "Development of Magnetically Levitated High Speed Transport System in the Federal Republic of Germany," in Proceedings of the 2nd International Seminar on the Superconductive Magnetic Levitated Train, pp. 16-24, held at Miyazaki, Japan, in Nov.

3. Rogg, D., 1985, "Development of Magnetic Levitation Transport Systems in the Federal Republic of Germany - Survey, Present State, Prospects, and Reasons," in Proceedings of the International Conference on Maglev Transport '85, published by the Institute of Electrical Engineers of Japan, Tokyo, Japan, pp. 1-11, held at Keidanren Keikan, Tokyo, Japan, in Sept.

4. Rogg, D., 1986, "The Research and Development Program 'Magnetically Suspended High Speed Transport System' in the Federal Republic of Germany," in Proceedings of the International Conference on Maglev and Linear Drives, document $86 \mathrm{CH} 2276-4$, published by the Institute of Electrical and Electronics Engineers, New York, N.Y., pp. 31-39, held at Vancouver, British Columbia, Canada, in May.

5. Raschbichler, H.G., and M. Wackers, 1987, "Status of the Maglev and Linear Drive Technology Program in the Federal Republic of Germany," in Proceedings of the International Conference on Maglev and Linear Drives, document 87CH2443-0, published by the Institute of Electrical and Electronics Engineers, New York, N.Y., pp. 147-154, held at Las Vegas, Nev., in May. 
6. Menden, W., and P. Hartmann, 1987, "The Government-Sponsored Program: Development of the Magnetic Levitation System Transrapid in the Federal Republic of Germany," in Proceedings of the International Conference on Maglev and Linear Drives, document 87CH2443-0, published by the Institute of Electrical and Electronics Engineers, New York, N.Y., pp. 143-146, held at Las Vegas, Nev., in May.

7. Menden, W., W. J. Mayer, and D. Rogg, 1989, "State of Development and Future Prospects of the Maglev-Systems Transrapid, M-Bahn and Starlin," in Proceedings of the 11 th International Conference on Magnetically Levitated Systems and Drives, published by the Institute of Electrical Engineers of Japan, Tokyo, Japan, pp. 11-18, held at Yokohama, Japan, in July.

8. 'Eastham, A.R., and W. F. Hayes, 1988, "Maglev Systems Development Status," IEEE AES Magazine, pp. 21-30, Jan.

9. Heinrich, K., and R. Kretzschmar (editors), 1989, Transrapid Maglev System, HestraVerlag, Darmstadt, Germany.

10. Gaede, P.J., 1985, "The Vehicle Transrapid 06, Specification and Experiences Under Practical Conditions," in Proceedings of the International Conference on Maglev Transport '85, published by the Institute of Electrical Engineers of Japan, Tokyo, Japan, pp. 115-121, held at Keidanren Keikan, Tokyo, Japan, in Sept.

11. Miller, L., 1986, "The Maglev Transportation Systems Transrapid and Ulimas," in Proceedings of the International Conference on Maglev and Linear Drives, document 86CH2276-4, published by the Institute of Electrical and Electronics Engineers, New York, N.Y., pp. 233-242, held at Vancouver, British Columbia, Canada, in May.

12. Bohn, G., and H. Alscher, 1986, "The Magnetic Train Transrapid 06," in Proceedings of the International Conference on Maglev and Linear Drives, document 86CH2276-4, published by the Institute of Electrical and Electronics Engineers, New York, N.Y., pp. 47-52, held at Vancouver, British Columbia, Canada, in May.

13. Meins, J., and L. Miller, 1988, "The High Speed Maglev Transportation System Transrapid," IEEE Transactions on Magnetics MAG 24(2):808-811, March.

14. Raschbichler, H.G., and M. Wackers, 1989, "Application of the Magnetic Levitation Train in the Federal Republic of Germany," in Proceedings of the 11th International Conference on Magnetically Levitated Systems and Drives, published by the Institute of Electrical Engineers of Japan, Tokyo, Japan, pp. 37-46, held at Yokohama, Japan, in July. 
15. Miller, L., and W. Ruoss, 1989, "Performance Analysis of the Transrapid 07," in Proceedings of the 11 th International Conference on Magnetically Levitated Systems and Drives, published by the Institute of Electrical Engineers of Japan, Tokyo, Japan, pp. 85-92, held at Yokohama, Japan, in July.

16. Friedrich, R., K. Dreimann, and R. Leistikow, 1987, "The Long Stator Propulsion System of the Transrapid - Development Prospects Until Service Maturity," in Proceedings of the International Conference on Maglev and Linear Drives, document 87CH2443-0, published by the Institute of Electrical and Electronics Engineers, New York, N.Y., pp. 171-180, held at Las Vegas, Nev., in May.

17. Friedrich, R., et al., 1985, "Propulsion and Power Supply System of the Transrapid 06 Vehicle Design and Test Results, Part 1: Propulsion," in Proceedings of the International Conference on Maglev Transport '85, published by the Institute of Electrical Engineers of Japan, Tokyo, Japan, pp. 75-82, held at Keidanren Keikan, Tokyo, Japan, in Sept.

18. Gottzein, E., and D. Rogg, 1984, "Status of High Speed Maglev Train Development in the FRG," in Proceedings of the International Conference on Maglev Transport, Now and for the Future, Institution of Mechanical Engineers Conference Publication 1984-12, published by Mechanical Engineers Publications, Ltd., London, England, pp. 23-36, held in Oct.

19. Merklinghaus, W., and P. Mnich, 1987, "The Maglev Transrapid System on the Way to Application - Test Results," in Proceedings of the International Conference on Maglev and Linear Drives, document 87CH2443-0, published by the Institute of Electrical and Electronics Engineers, New York, N.Y., pp. 211-214, held at Las Vegas, Nev., in May.

20. Bohn, G., and G. Steinmetz, 1985, "The Electromagnetic Suspension System of the Magnetic Train 'TRANSRAPID'," in Proceedings of the International Conference on Maglev Transport '85, published by the Institute of Electrical Engineers of Japan, Tokyo, Japan, pp. 107-114, held at Keidanren Keikan, Tokyo, Japan, in Sept.

21. Wiescholek, U., and W. Mayer, 1992, "High-Speed Magnetic Levitation Train Transrapid, Planning of the Final Development Program Until 1995 and Prospects of Utilization in Germany," presented at the 6th World Conference on Transportation Research, sponsored by the Laboratoire d'Economie des Transports, Lyon, France, held at Lyon, France, June 29July 3.

22. Miller, L., 1992, "Safety and Availability of the High Speed Transportation System Transrapid," presented at the 6th World Conference on Transportation Research, sponsored by the Laboratoire d'Economie des Transports, Lyon, France, held at Lyon, France, June 29July 3. 


\section{Japanese High-Speed Surface Transport Maglev System}

\subsection{System Description}

The High-Speed Surface Transport (HSST) maglev system uses a single set of iron-core magnets for both attractive-force levitation and guidance and uses a single-sided, short-stator LIM for propulsion. Development and testing of the HSST system was begun in 1974 by Japan Air Lines Co. In 1985, demonstration and marketing of the EMS-type system was assigned to the HSST Corp. The development program included fabrication of six different vehicles: HSST-01, HSST-02, HSST-03, HSST-04, HSST-05, and HSST-100.1-11 The first three were pure test models, while the last three were revenue-application vehicles. A cutaway view of a revenue-type vehicle is shown in Figure 3.1. The HSST-03 vehicle had a design speed of $300 \mathrm{~km} / \mathrm{h}$, whereas the HSST-04 and HSST-05 vehicles have design speeds of $200 \mathrm{~km} / \mathrm{h}$. The basic configuration of the HSST maglev system is shown schematically in Figure 3.2, where the vehicle is assumed to be on a double-beam and double-track guideway. Figure 3.3 shows the levitation and propulsion principle of the HSST in more detail.

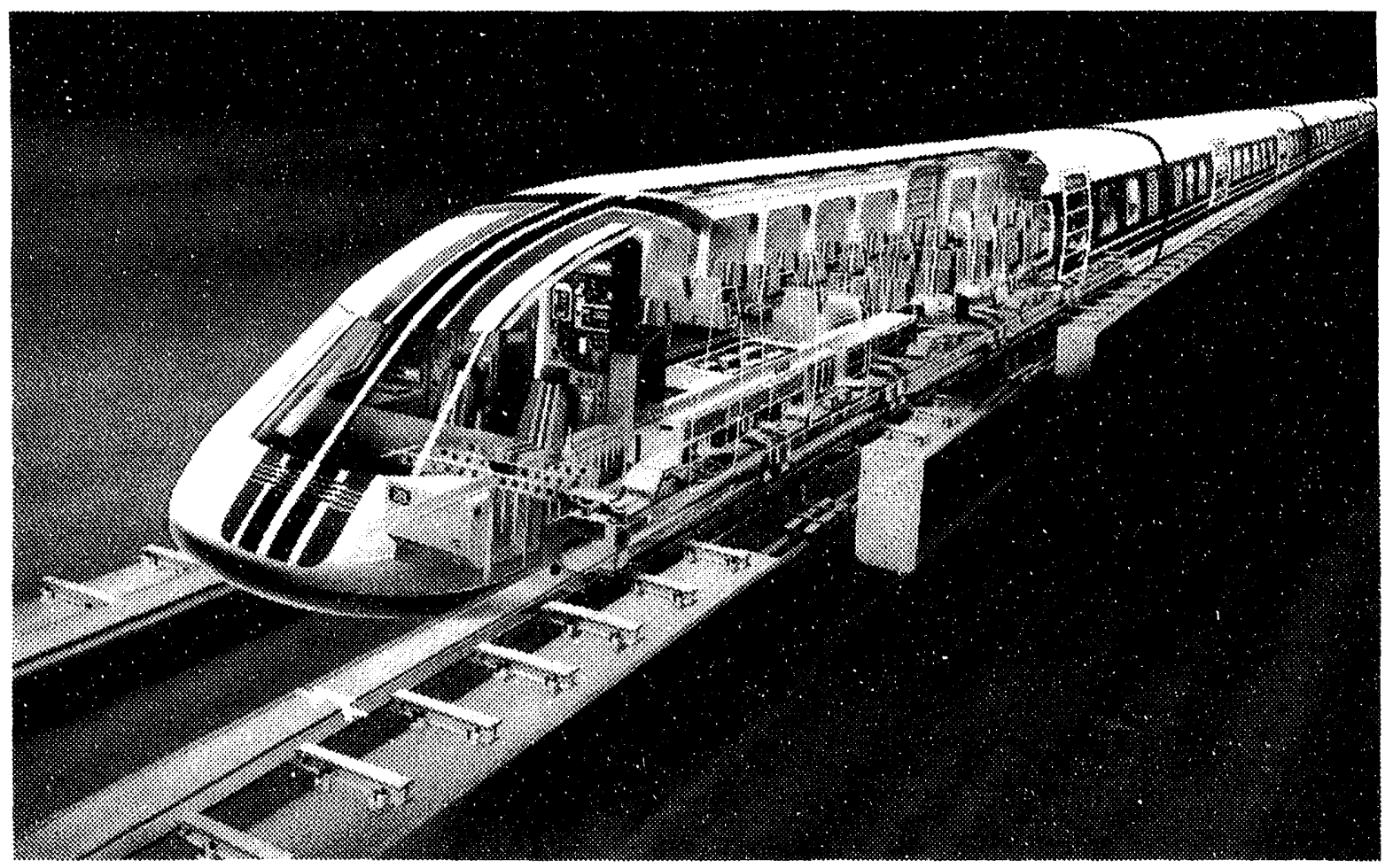

FIGURE 3.1 Cutaway View of an HSST Revenue-Type Maglev Vehicle (reproduced with the permission of the HSST Corporation) 


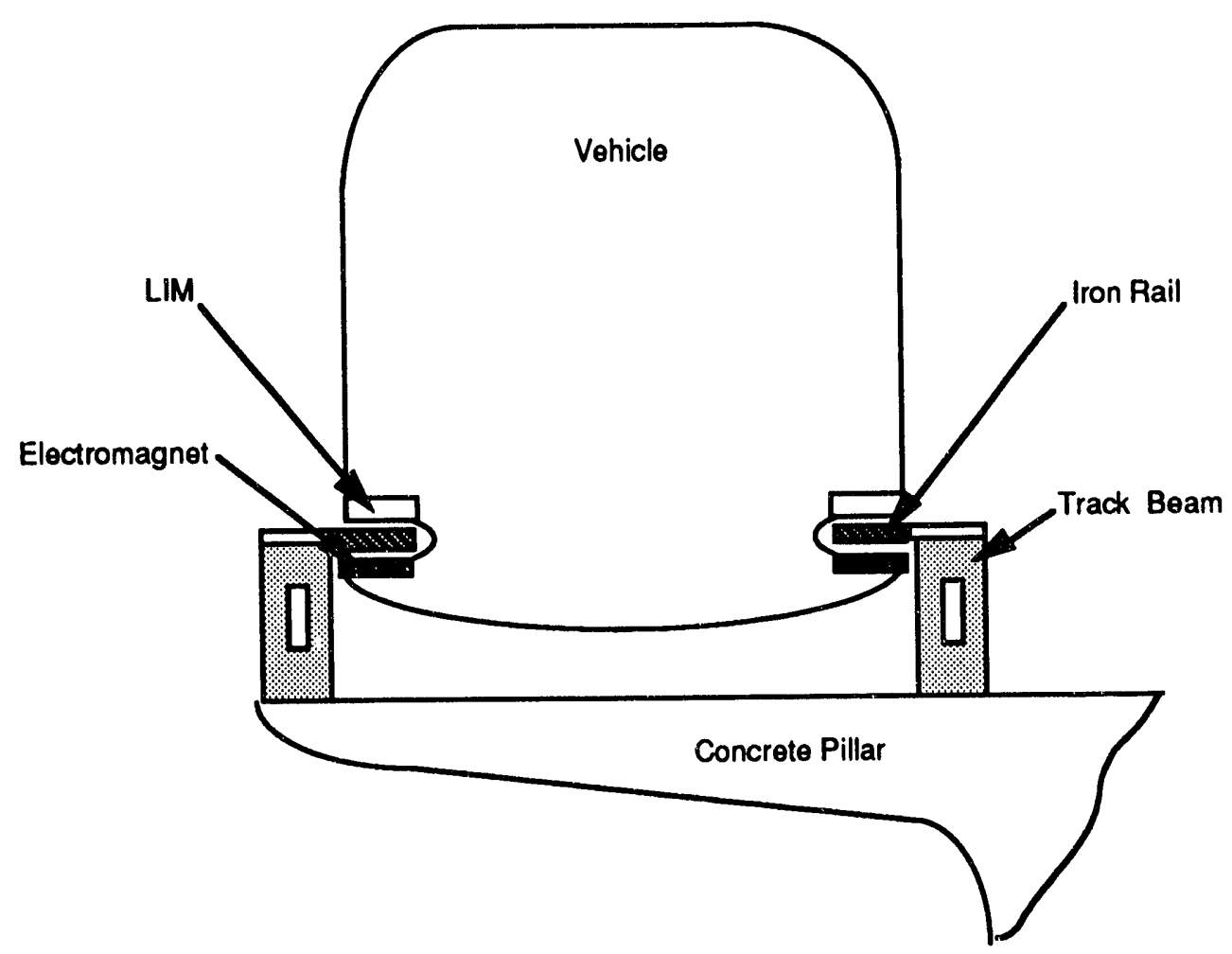

FIGURE 3.2 Schematic Diagram of the HSST Maglev System

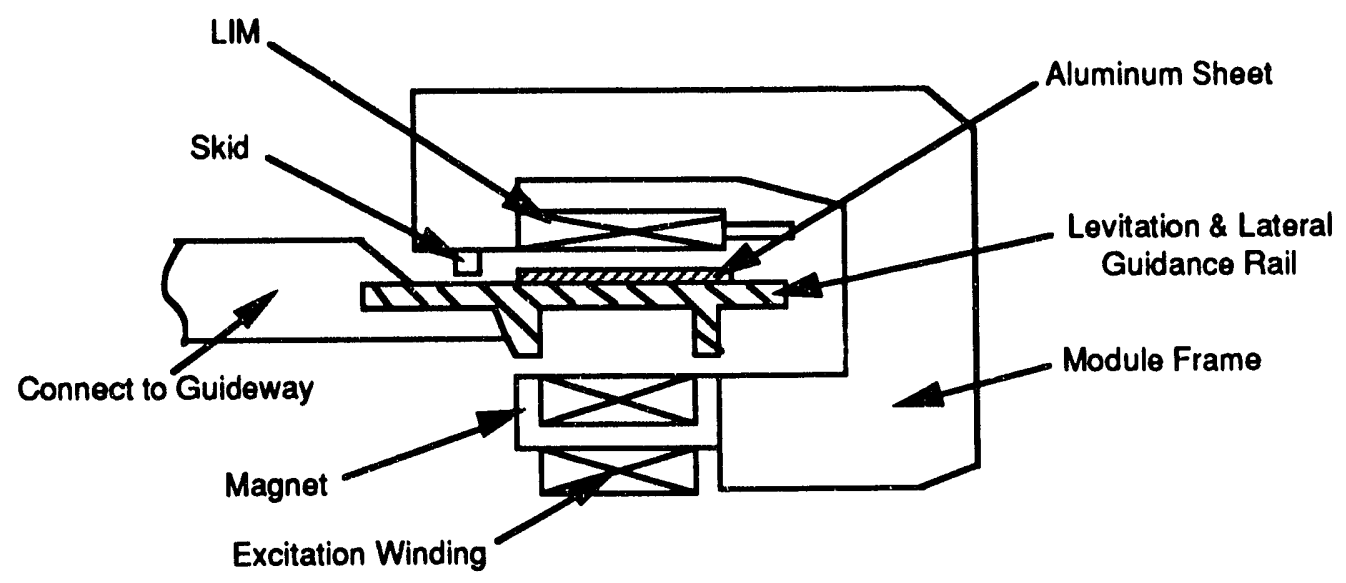

FIGURE 3.3 Schematic Diagram of the Suspension and Propulsion Principles of the HSST Maglev System 
The characteristic features of the HSST maglev system include (1) short-stator, iron-core, LIM propulsion; (2) attractive electromagnetic suspension and guidance; (3) air-spring secondary suspension; (4) simple passive guideway; (5) dc-power sliding-shoe pickup; (6) on-board VVVF power supply for the drive system; and (7) module system for guide-rail maintainability. This system has several advantages:

- Simple passive guideway may greatly reduce system construction and maintenance cost.

- Use of ferromagnetic material reduces magnetic flux density around the vehicle and inside the passenger room, even without magnetic shielding.

- Propulsion by LIM eliminates the requirement of synchronization between vehicle and energized motor section that is necessary for LSM propulsion.

- Concrete or steel may be used in the guideway structure.

- Short-stator system can easily accommodate more than one independent vehicle on the same guideway section, when each vehicle carries its own VVVF power supply.

- Levitation and guidance systems use the same electromagnets.

There are some possible drawbacks of the system:

- Payload efficiency is low due to heavy on-board power conditioning equipment. In particular, as design speed increases, so does the weight of the on-board power-conditioning equipment needed for vehicle propulsion. However, recent information shows that on-board power conditioning equipment is getting lighter, and the weight of the HSST-100 vehicle powerconditioning equipment is about 1.2 metric tons.

- Operating speed is limited due to the use of a power collector. At the least, higher speed operation would require increased maintenance to the power collector and higher costs. Also, electromagnetic interference would be likely, causing further problems.

- Air gap is small, which would require a precisely engineered guideway, especially for high-speed operation. 
- Performance of the LIM at high speeds is poor because of longitudinal endeffects.

\subsection{Overview of the HSST Family}

\subsubsection{HSST-01}

The HSST-01 vehicle, shown in Figure 3.4, was built in 1975. The objective of this model was to evaluate the technical problems of the levitated vehicle in the high-speed region and to collect data on LIM performance during high-speed operation. Table 3.1 shows the detailed system parameters of the HSST- 01 system. The first test with the HSST- 01 was performed in December 1975 on a 200 -m-long guideway. However, because the guideway was so short, the speed recorded was only $35 \mathrm{~km} / \mathrm{h}$. A new, $1300-\mathrm{m}$-long test track was completed in September 1976 in the city of Kawasaki. On February 14, 1978, a maximum speed of $307.8 \mathrm{~km} / \mathrm{h}$ was achieved by the HSST-01 on this guideway, with the aid of eight booster rockets.

\subsubsection{HSST-02}

The second test vehicle, HSST-02, shown in Figure 3.5, was designed for evaluating ride quality and the effect of the secondary suspension on controlled electromagnetic levitation. The

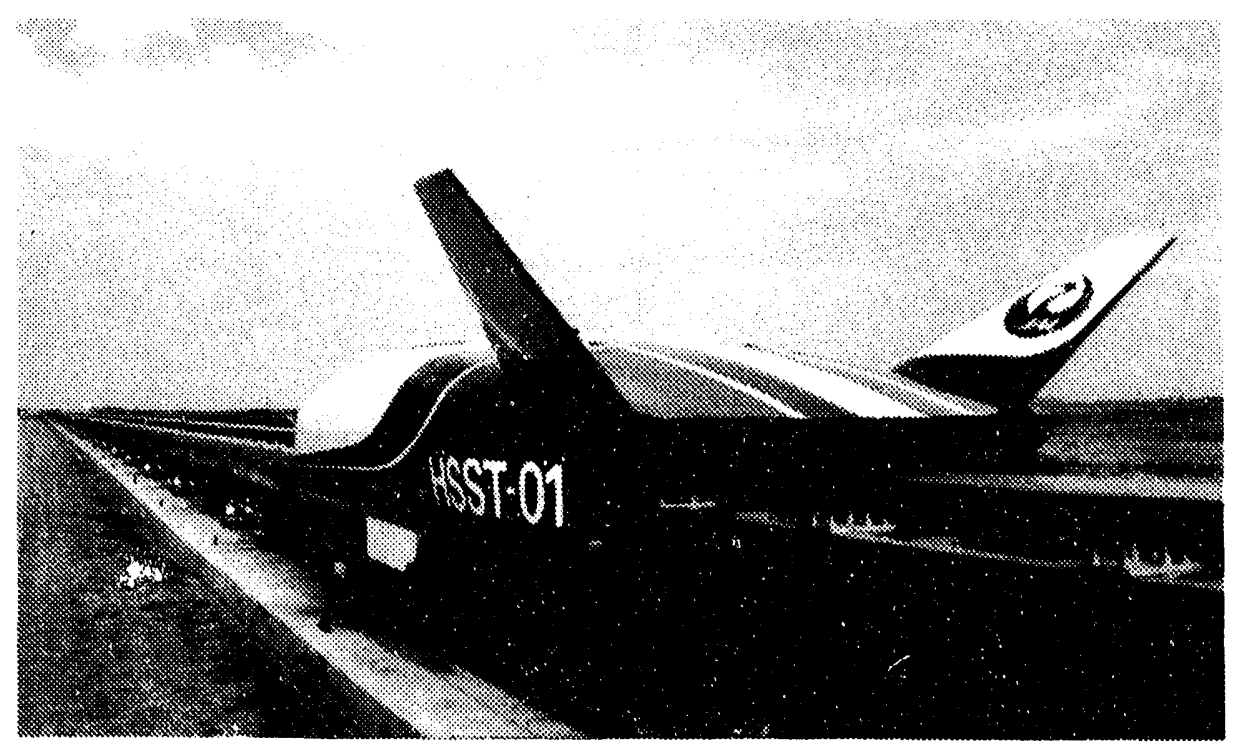

FIGURE 3.4 HSST-01 Test Vehicle, Built in 1975, for Which a Speed of $307.8 \mathrm{~km} / \mathrm{h}$ on a $1,300-\mathrm{m}$-Long Guideway Was Recorded on February 14, 1978 (reproduced with the permission of the HSST Corporation) 
TABLE 3.1 Operating Data for the HSST-01 Maglev System

\begin{tabular}{ll}
\multicolumn{1}{c}{ Parameter } & \\
& \\
& \\
& \\
Vehicle General Information & \\
Length (m) & 4.2 \\
Width (m) & 2.6 \\
Height (m) & 1.1 \\
Weight (metric tons) & 1.0 \\
Seats & 0 \\
& \\
Operating Information & \\
Maximum speed (km/h) & 307.8 \\
Suspension and Levitation & \\
Levitation and guidance & Controlled electromagnet \\
Levitation air gap (mm) & 13 \\
Power supply & $168-\mathrm{V}$ battery (12 $x$ 14 in series) \\
Chopping frequency (kHz) & 2
\end{tabular}


HSST-02 was completed at the end of 1977 and tested in January 1978. The major difference between HSST-01 and HSST-02 was that the magnets of HSST-01 were directly mounted on the body, whereas the magnets and LIM of HSST-02 were mounted on a flexible chassis supported by springs and dampers. Detailed information about the HSST-02 is given in Table 3.2.

\subsubsection{HSST-03}

The HSST-03 test vehicle, shown in Figures 3.6 and 3.7, was the third stage of the HSST system development. ${ }^{6-11}$ The main objectives included advancement of the HSST concept to the commercial application stage and acquisition of data on the combination of electromagnetic levitation with other technologies. In the HSST-03 vehicle, the concept of modular design was introduced. On the track side of the system, the rails used for propulsion, levitation, and guidance were combined, which reduced the overall cost. In addition, new technology, such as an optical communication system, was also tested. Table 3.3 gives more detailed technical information on the HSST-03 maglev system. The HSST-03 operated successfully at EXPO'85, held at Tsukuba, Japan, and EXPO'86, held at Vancouver, British Columbia, Canada, for a total of 349 days and $15,792 \mathrm{~km}$, carrying about one million passengers. The system was also demonstrated at Okazaki City, Japan.

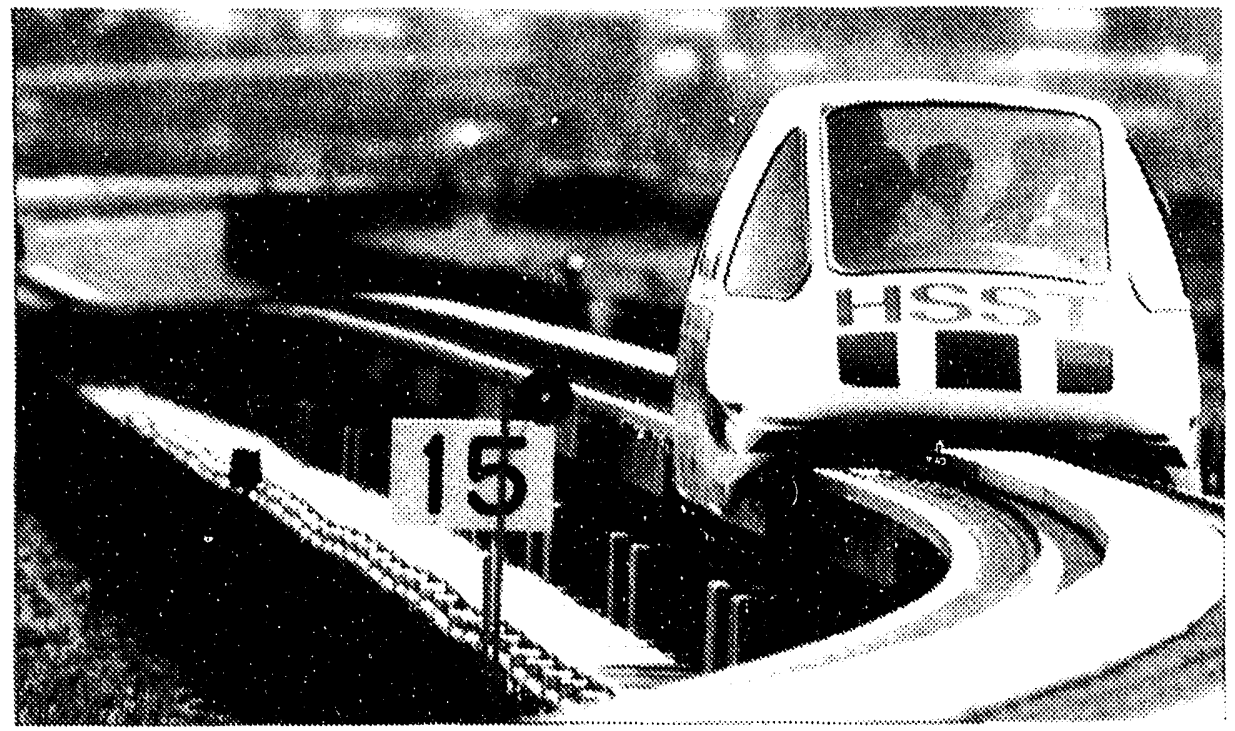

FIGURE 3.5 HSST-02 Test Vehicle, Built in 1977 (reproduced with the permission of the HSST Corporation) 
TABLE 3.2 Operating Data for the HSST-02 Maglev System

\begin{tabular}{|c|c|}
\hline Parameter & Specification \\
\hline \multicolumn{2}{|l|}{ Vehicle General Information } \\
\hline Length $(m)$ & 6.84 \\
\hline Width $(m)$ & 2.0 \\
\hline Height (m) & 1.75 \\
\hline \multicolumn{2}{|l|}{ Weight (metric tons) } \\
\hline Unloaded & 1.8 \\
\hline Loaded & 2.4 \\
\hline Seats & $6-8$ \\
\hline \multicolumn{2}{|l|}{ Operating Information } \\
\hline Maximum speed $(\mathrm{km} / \mathrm{h})$ & 110 \\
\hline Normal cruising speed $(\mathrm{km} / \mathrm{h})$ & 110 \\
\hline Number of operations & 1,456 \\
\hline Number of passengers & 3,000 \\
\hline \multicolumn{2}{|l|}{ Suspension and Levitation } \\
\hline Secondary suspension & Air spring \\
\hline Levitation air gap (mm) & $8-10$ \\
\hline Power supply & $\begin{array}{l}120-V \text { battery with } \\
\text { on-board charger }\end{array}$ \\
\hline Chopping frequency $(\mathrm{kHz})$ & 2 \\
\hline \multicolumn{2}{|l|}{ Propulsion } \\
\hline Mode & LIM \\
\hline Thrust (N) & 3,400 \\
\hline \multicolumn{2}{|l|}{ Power Supply } \\
\hline Type & Ground-based VVVF \\
\hline Capacity (KVA) & 208 \\
\hline Voltage (V, line to line) & 0.600 \\
\hline Frequency $(\mathrm{Hz})$ & $0-120$ \\
\hline Phase & 3-phase ac \\
\hline \multicolumn{2}{|l|}{ Braking } \\
\hline Mechanical brake & Hydraulic \\
\hline Track Structure & Single beam on ground \\
\hline
\end{tabular}




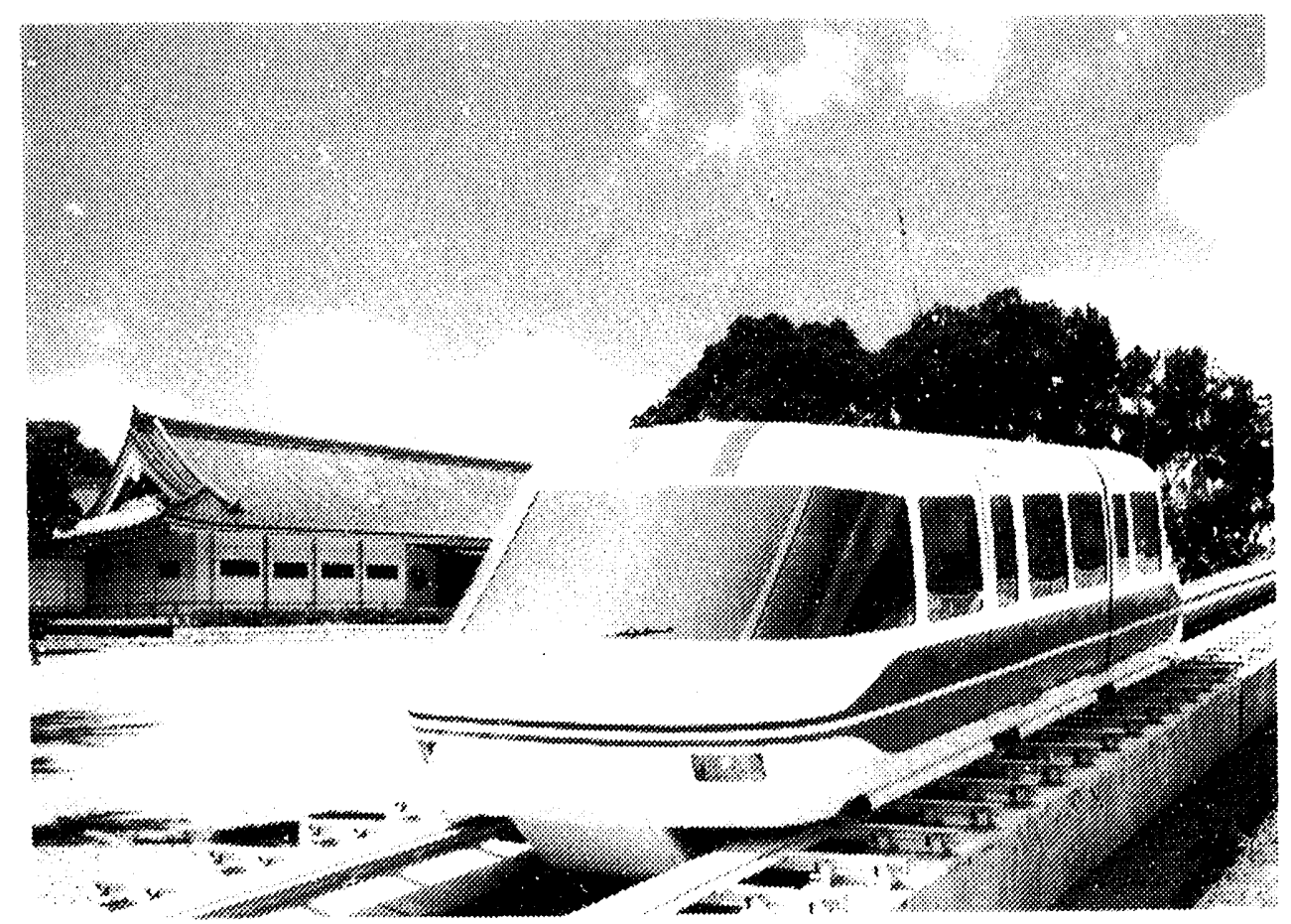

FiGURE 3.6 HSST-03 Operating at the EXPO'85 in Tsukuba, Japan (reproduced with the permission of the HSST Corporation)

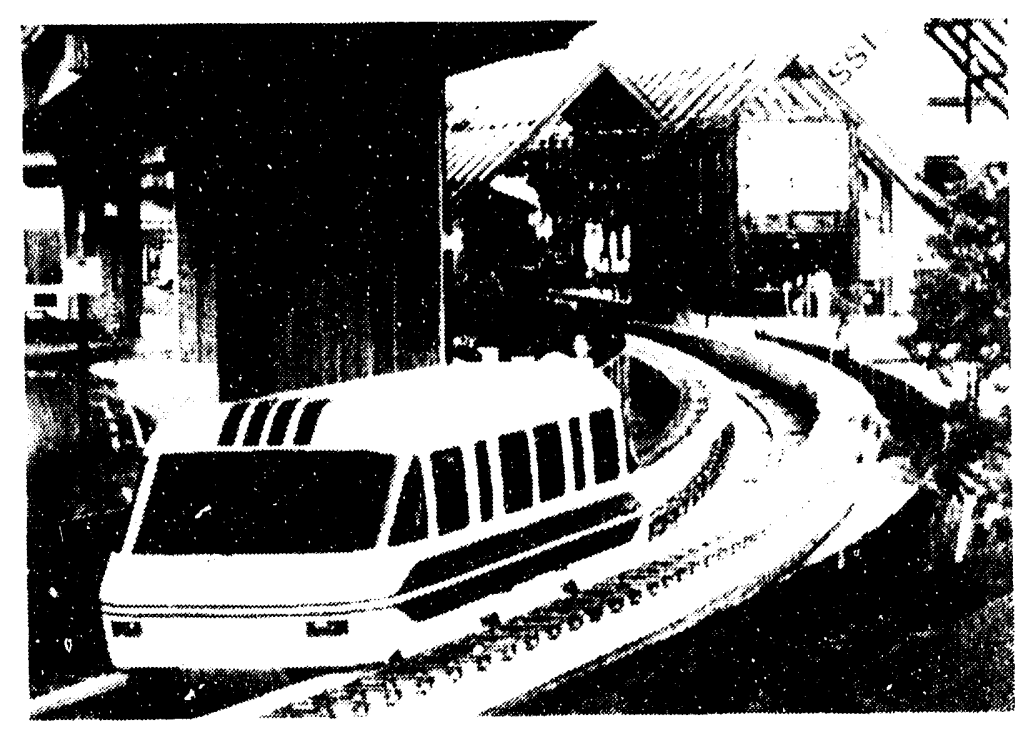

FIGURE 3.7 HSST-03 Operating at the EXPO'86 in Vancouver, British Columbia, Canada (reproduced from Reference 1 with the permission of the copyright holder) 
TABLE 3.3 Operating Data for the HSST-03 Maglev System

\begin{tabular}{ll}
\hline \multicolumn{1}{c}{ Parameter } & \multicolumn{1}{c}{ Specification } \\
& \\
\hline & \\
Vehicle General Information & 13.8 \\
Length (m) & 2.95 \\
Width (m) & 3 \\
Haight (m) & \\
Weight (metric tons) & 12.3 \\
Unloaded & 18 \\
Loaded & 50 \\
Seats & \\
Operating Information & \\
Maximum speed (km/h) & 60 \\
Normal cruising speed (km/h) & 40 \\
Number of operations & 24,644 \\
Number of passengers & 1 million \\
Track Structure &
\end{tabular}




\subsubsection{HSST-04 and HSST-05}

The HSST-04 (Figure 3.8) is a revenue-type vehicle using a mono-beam track. The first public operation of the HSST-04 was at the Saitama Expo in Japan. The HSST-05 (Figure 3.9) was also designed for demonstration and commercial applications. 2,4,5 Constructed in 1988, the HSST-05 was operated as a means of transportation at an exposition held in Yokohama, Japan (the YES 89 exposition). The design speed for both the HSST-04 and the HSST-05 vehicles was $200 \mathrm{~km} / \mathrm{h}$. Cruising speed actually reached at YES 89 was in the range of 50 to $60 \mathrm{~km} / \mathrm{h}$. Ride quality, as observed by author Rote, was good, except that the deceleration phase had some noticeable, relatively suiden, rate changes. The design of the HSST-05 is basically the same as that oi the HSST-04; however, improvements were made on the HSST-05 in the areas of ride quality and system reliability. The HSST-05 system, a two-car train called the "YES'89 Line" at the Yokoilama exposition, has been approved as the first Japanese commercial magnetic levitation railway system. Detailed technical parameters for the HSST-04 maglev system are given in Table 3.4, and those for the HSST-05 are given in Table 3.5.

\subsection{Present Status and Future Prospects}

To speed up the commercial application of the HSST maglev system, a neu organization called the Chubu-HSST Development Corporation was established in August 1989 by the HSST Corporation, the Aichi Prefectural Government, and the Nagoya Railroad Co. A new test track located in Nagoya was completed by Chubu-HSST Development Corporation in May 1991. Since then, operational tests have been conducted at the Nagoya site with an HSST-100 test vehicle. According to Chubu-HSST, these tests will continue until 1993.12-14

The length of the Nagoya Test Track is $1,566 \mathrm{~m}$, which is sufficient for a vehicle to attain a speed of $100 \mathrm{~km} / \mathrm{h}$. The track incorporates lateral and vertical curves, switching with a branch line, and all other features that a vehicle might face in practical operation. The newest test vehicle, designated HSST-100, consists of two cars with a total loaded weight of 30 metric tons. Each car is supported by six levitation modules and has a maximum capacity of 67 passengers with 22 seats. Detailed information on the HSST-100 vehicle and the Nagoya Test Track is shown in Table 3.6. 


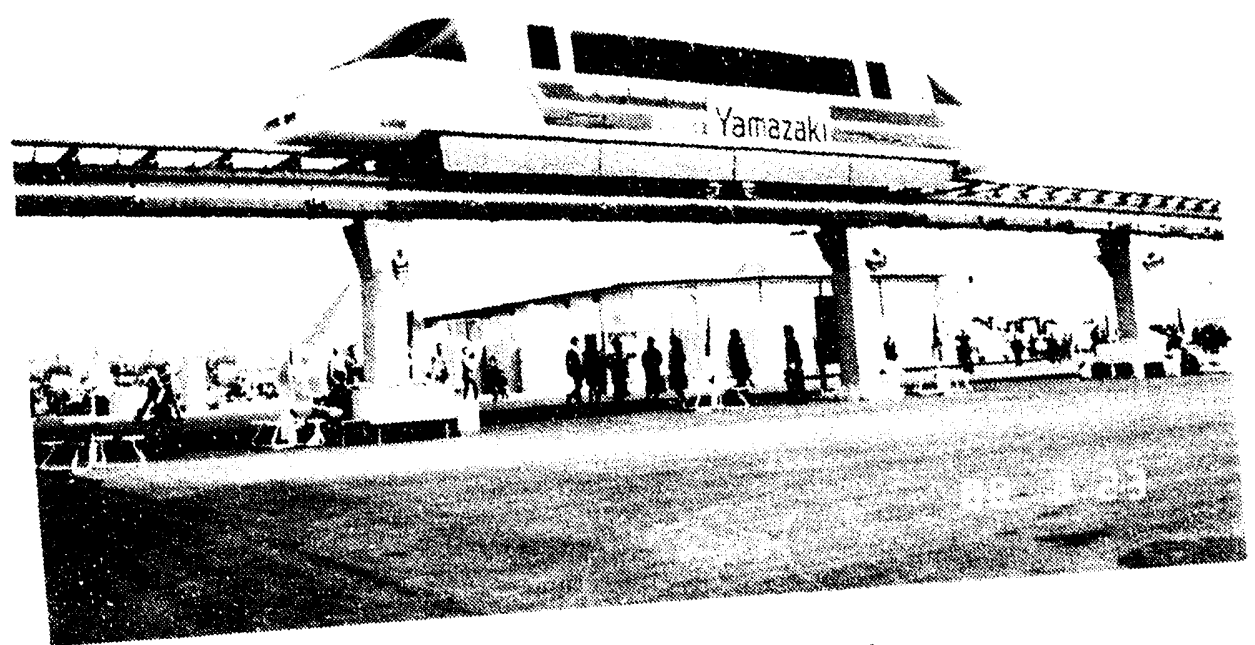

FIGURE 3.8 HSST-04 Operating at the Saitama Expo
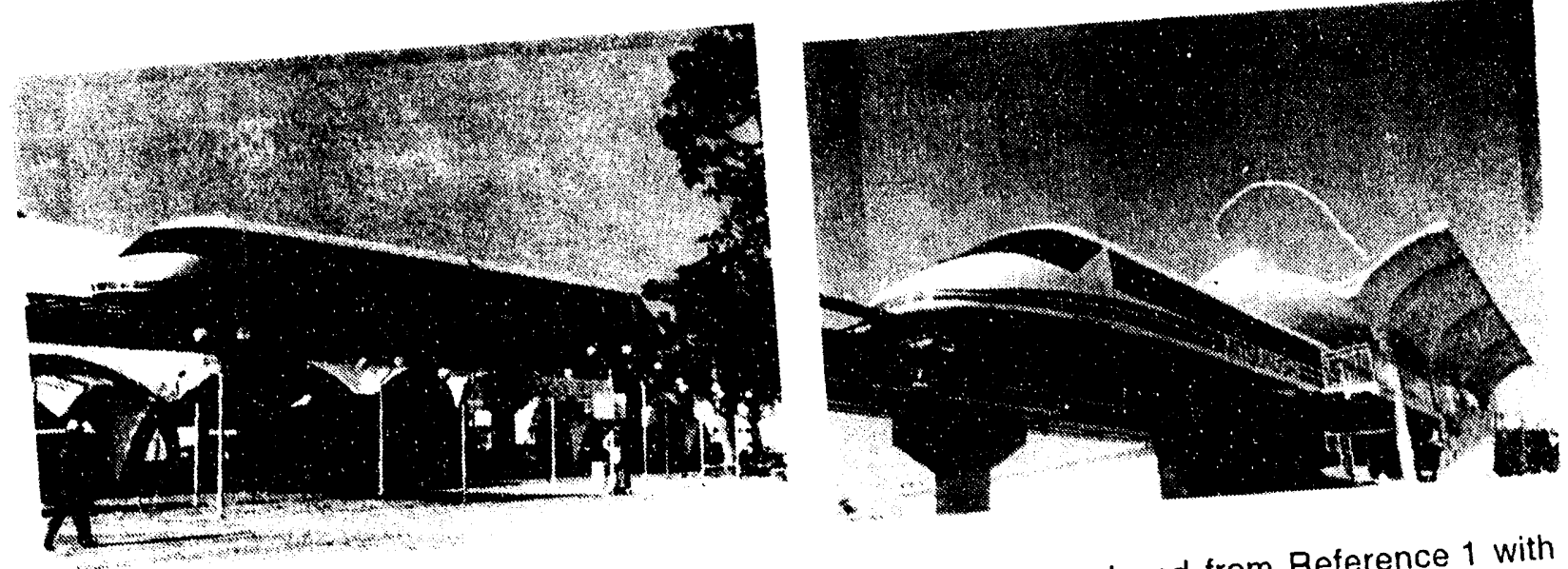

FIGURE 3.9 HSST-05 Operating at the YES'89 Exposition (reproduced from Reference 1 with the permission of the copyright holder) 
TABLE 3.4 Operating Data for the HSST-04 Maglev System

\begin{tabular}{|c|c|}
\hline Parameter & Specification \\
\hline \multicolumn{2}{|l|}{ Vehicle General Information } \\
\hline Length $(m)$ & 19.4 \\
\hline Width $(\mathrm{m})$ & 3 \\
\hline Height $(m)$ & 3.6 \\
\hline \multicolumn{2}{|l|}{ Wright (metric tons) } \\
\hline Unloaded & 19.8 \\
\hline Loaded & 27 \\
\hline Seats & 70 \\
\hline \multicolumn{2}{|l|}{ Operating Information } \\
\hline Maximum speed $(\mathrm{km} / \mathrm{h})$ & 43 \\
\hline Normal cruising speed $(\mathrm{km} / \mathrm{h})$ & 30 \\
\hline Number of operations & 3,781 \\
\hline Number of passengers & 241,203 \\
\hline \multicolumn{2}{|l|}{ Suspension and Levitation } \\
\hline Secondary suspension & 8 modules, air spring \\
\hline Levitation air gap (mm) & \\
\hline Power supply & $280-V$ dc from on-board converter \\
\hline Chopping frequency $(\mathrm{kHz})$ & 2 \\
\hline \multicolumn{2}{|l|}{ Propulsion } \\
\hline Mode & 8 short-stator LIMs \\
\hline Thrust per motor $(\mathrm{N})$ & 2,646 \\
\hline \multicolumn{2}{|l|}{ Power Supply } \\
\hline Type & On-board VVVF \\
\hline Capacity (kVA) & 760 \\
\hline Voltage $(V$, line to line $)$ & $0-550$ \\
\hline Current (A) & 800 \\
\hline Frequency $(\mathrm{Hz})$ & 0.70 \\
\hline Phase & 3-phase ac \\
\hline Power feeding & $750-V$ dc power rail \\
\hline \multicolumn{2}{|l|}{ Braking } \\
\hline $\begin{array}{l}\text { Electric brake } \\
\text { Mechanical brake }\end{array}$ & $\begin{array}{l}\text { Phase-reversing } \\
\text { Hydraulic }\end{array}$ \\
\hline Track Structure & Single beam, elevated, span $12 \mathrm{~m}$ and $16 \mathrm{~m}$ \\
\hline
\end{tabular}


TABLE 3.5 Operating Data for the HSST-05 Maglev System

\begin{tabular}{|c|c|}
\hline Parameter & Specification \\
\hline \multicolumn{2}{|l|}{ Vehicle General Information ${ }^{a}$} \\
\hline Length $(m)$ & 36.3 \\
\hline Width $(m)$ & 3 \\
\hline Height $(m)$ & 3.6 \\
\hline \multicolumn{2}{|l|}{ Weight (metric tons) } \\
\hline Unloaded & 39.5 \\
\hline Loaded & 50 \\
\hline Seats & 160 \\
\hline \multicolumn{2}{|l|}{ Operating Information } \\
\hline Maximum speed $(\mathrm{km} / \mathrm{h})$ & $55^{b}$ \\
\hline Design speed $(\mathrm{km} / \mathrm{h})$ & 200 \\
\hline Normal cruising speed $(\mathrm{km} / \mathrm{h})$ & 42 \\
\hline \multicolumn{2}{|l|}{ Suspension and Levitation } \\
\hline Secondary suspension & 8 modules/car, air spring \\
\hline Levitation air gap (mm) & \\
\hline Power supply & $280-V$ dc from on-board converter \\
\hline Chopping frequency $(\mathrm{kHz})$ & 2 \\
\hline \multicolumn{2}{|l|}{ Lateral Guidance } \\
\hline \multicolumn{2}{|l|}{ Passive system } \\
\hline \multicolumn{2}{|l|}{ Minimum magnetic reluctance } \\
\hline \multicolumn{2}{|c|}{ Alternating magnet lateral offsets } \\
\hline \multicolumn{2}{|l|}{ Propulsion } \\
\hline Mode & 16 short-stator LIMs per car \\
\hline Thrust per motor $(\mathrm{N})$ & 2,646 \\
\hline \multicolumn{2}{|l|}{ Power Supply } \\
\hline Type & On-board VVVF \\
\hline Capacity per car (kVA) & 760 \\
\hline Voltage (V, line to line) & 0.550 \\
\hline Current (A) & 800 \\
\hline Frequency $(\mathrm{Hz})$ & 0.70 \\
\hline Phase & 3-phase ac \\
\hline Power feeding & $750-V$ dc power rail \\
\hline \multicolumn{2}{|l|}{ Braking } \\
\hline $\begin{array}{l}\text { Electric brake } \\
\text { Mechanical brake }\end{array}$ & $\begin{array}{l}\text { Phase-reversing and regenerative } \\
\text { Hydraulic }\end{array}$ \\
\hline Track Structure & Single beam, elevated, span $12 \mathrm{~m}$ and $16 \mathrm{~m}$ \\
\hline
\end{tabular}


TABLE 3.6 Operating Data for the HSST-100 Maglev System

\begin{tabular}{|c|c|}
\hline Parameter & Specification \\
\hline \multicolumn{2}{|l|}{ Vehicle General Information } \\
\hline Length (m) & 17.6 \\
\hline Width $(m)$ & 2.6 \\
\hline Height $(m)$ & 3.3 \\
\hline \multicolumn{2}{|l|}{ Weight (metric tons) } \\
\hline Unloaded & 21.2 \\
\hline Loaded & 30 \\
\hline Seats & 44 \\
\hline No. of Cars & 2 \\
\hline \multicolumn{2}{|l|}{ Operating Information } \\
\hline Maximum speed $(\mathrm{km} / \mathrm{h})$ & 110 \\
\hline Normal cruising speed $(\mathrm{km} / \mathrm{h})$ & 100 \\
\hline Start of operating test & May 1991 \\
\hline \multicolumn{2}{|l|}{ Suspension and Levitation } \\
\hline Secondary suspension & 6 modules/car, air spring \\
\hline Levitation air gap (mm) & 8 \\
\hline Power supply & $280-\mathrm{V}$ dc from on-board converter \\
\hline Chopping frequency $(\mathrm{kHz})$ & 4 \\
\hline \multicolumn{2}{|l|}{ Suspension magnet } \\
\hline No. of magnets per module & 4 (with 2 magnets in series) \\
\hline Rated current (A) & 29 \\
\hline Turns per magnet & 304 \\
\hline Force per magnet $(\mathrm{kg})$ & 625 \\
\hline \multicolumn{2}{|l|}{ Propulsion } \\
\hline Mode & 12 short-stator LIMs \\
\hline Thrust per motor $(N)$ & 3,000 \\
\hline \multicolumn{2}{|l|}{ Power Supply } \\
\hline Type & On-board VVVF \\
\hline Capacity (kVA) & 1,560 \\
\hline Voltage $(V, \operatorname{lin} \theta$ to $\operatorname{lin} \theta)$ & $0-1,130$ \\
\hline Current (A) & 800 \\
\hline Frequency $(\mathrm{Hz})$ & 0.90 \\
\hline Phase & 3-phase ac \\
\hline \multicolumn{2}{|l|}{ Braking } \\
\hline $\begin{array}{l}\text { Electric brake } \\
\text { Mechanical brake }\end{array}$ & $\begin{array}{l}\text { Phase-reversing and regenerative } \\
\text { Hydraulic }\end{array}$ \\
\hline \multicolumn{2}{|l|}{ Guideway } \\
\hline Structure & Single beam, elevated, span of 12 to $40 \mathrm{~m}$ \\
\hline Length $(m)$ & 1,566 \\
\hline Minimum curve radius $(\mathrm{m})$ & 25 \\
\hline Maximum gradient & $7 \%$ \\
\hline Switch & 3-segment horizontal swing-type switch \\
\hline
\end{tabular}




\subsection{References}

1. Nagaike, T., and H. Takatsuka, 1989, "Present Status and Prospect of HSST," in Proceedings of the 11 th International Conference on Magnetically Levitated Systems and Drives, published by the Institute of Electrical Engineers of Japan, Tokyo, Japan, pp. 29-35, held at Yokohama, Japan, in July.

2. Ohishi, A., 1989, "HSST-05 System General and Operational Outline at Yes'' 89 ," in Proceedings of the 11 th International Conference on Magnetically Levitated Systems and Drives, published by the Institute of Electrical Engineers of Japan, Tokyo, Japan, pp. 93-10), held at Yokohama, Japan, in July.

3. Nagata, K., H. Sekimoto, and M. Murai, 1989, "Levitation Magnet Driver for HSST Controlled by SI Thyristors," in Proceedings of the 11th International Conference on Magnetically Levitated Systems and Drives, published by the Institute of Electrical Engineers of Japan, Tokyo, Japan, pp. 257-262, held at Yokohama, Japan, in July.

4. Iwaya, M., 1989, "Dynamic Behaviour of the Module \& Suspension System on HSST-05," in Proceedings of the 11 th International Conference on Magnetically Levitated Systems and Drives, published by the Institute of Electrical Engineers of Japan, Tokyo, Japan, pp. 263-268, held at Yokohama, Japan, in July.

5. Hashimoto, F., 1989, "Signal and Communication System of HSST-05," in Proceedings of the 11 th International Conference on Magnetically Levitated Systems and Drives, published by the Institute of Electrical Engineers of Japan, Tokyo, Japan, pp. 303-308, held at Yokohama, Japan, in July.

6. Suzuki, S., M. Murai, and M. Kawashima, 1987, "Operational Experience of HSST-03 System at Expo'85 and Expo'86," in Proceedings of the International Conference on Maglev and Linear Drives, document $87 \mathrm{CH} 2443-0$, published by the Institute of Electrical and Electronics Engineers, New York, N.Y., pp. 129-132, held at Las Vegas, Nev., in May.

7. Suzuki, S., M. Murai, M. Kawashima, and Y. Hosoda, 1986, "HSST-03 System Operational Summary at Expo'85 and Operational Outline at Expo'86," in Proceedings of the International Conference on Maglev and Linear Drives, document $86 \mathrm{CH} 2276-4$, published by the Institute of Electrical and Electronics Engineers, New York, N.Y., pp. 27-30, held at Vancouver, British Columbia, Canada, in May.

8. Suzuki, S., et al., 1986, "Power Supply System to Drive HSST-Expo'86," in Proceedings of the International Conference on Maglev and Linear Drives, document $86 \mathrm{CH} 2276-4$, published by the Institute of Electrical and Electronics Engineers, New York, N.Y., pp. 25I256, held at Vancouver, British Columbia, Canada, in May. 
9. Masada, E., et al., 1985, "Short-Stator Propulsion System of HSST-()3," in Proceedings of the International Conference on Maglev Transport '85, published by the Institute of Electrical Engineers of Japan, Tokyo, Japan, pp. 61-68, held at Keidanren Kaikan, Tokyo, Japan, in Sept.

10. Kawashima, M., et al., 1985, "Ground Facilities and Operational Experience of HSSTExpo'85," in Proceedings of the International Conference on Maglev Transport '85, published by the Institute of Electrical Engineers of Japan, Tokyo, Japan, pp. 263-27(), held at Keidanren Kaikan, Tokyo, Japan, in Sept.

11. Masada, E., 1984, "Present Status of Maglev Development in Japan and HSST-(13 Project," in Proceedings of the International Conference on Maglev Transport, Now and for the Future, Institution of Mechanical Engineers Conference Publication 1984-12, published by Mechanical Engineers Publications, Ltd., London, England, pp. 9-22, held in Oct.

12. Japanese Rolling Stock Exporters' Association, 1989, "HSST - High Speed Surface Transport," Japanese Railway Information, Railway Systems and Components, No. 42, October.

13. Japanese Rolling Stock Exporters' Association, 1992, "Magnetic Levitated Linear Motor Car HSST-100 for Urban Transport," Japanese Railway Information, Railway Systems and Components, No. 51, January.

14. Iwaya, M., and M. Fujino, 1992, "HSST-100 System Experiments in Nagoya Test Site," presented at the 6th World Conference on Transportation Research, sponsored by Laboratoire d'Economie des Transports, Lyon, France, held at Lyon, France, June 29-July 3. 


\section{Japanese Maglev Systems with Electrodynamic Suspension}

\subsection{Introduction}

The Japanese have devoted a great amount of effort to developing an electrodynamicsuspension (EDS) system that uses superconducting magnets aboard the maglev vehicle to perform three different functions: levitation, guidance, and propulsion. Development of the EDS system was begun in the 1960s by Japanese National Railways (JNR). At the present time, the Railway Technical Research Institute (RTRI) is responsible for this maglev program.

JNR demonstrated the first superconductive magnetically levitated vehicle, ML-100, in 1972 at the RTRI, using a short section of linear test-guideway. Following the favorable results achieved with the ML-100, JNR also successfully tested the air-core LSM propulsion system with the ML-100A vehicle in 1975 at the RTRI. A large-scale test facility was opened at Miyazaki on Kyushu Island in April 1977, and tests began on a 1.3-km section with the ML-500 test vehicle supported by wheels. Testing of the magnetically suspended ML-500 vehicle commenced in July 1977 on a $3.1-\mathrm{km}$ section. The full $7.0-\mathrm{km}$ length of the test guideway was completed in August 1979, and in December 1979, the ML-500 reached a speed of $517 \mathrm{~km} / \mathrm{h}$ on the completed guideway. Testing began on the MLU001 and the MLU002 in 1980 and 1987, respectively. The MLU001 reached a speed of $400.8 \mathrm{~km} / \mathrm{h}$ in a manned test run in February 1987, and the MLU002 achieved a speed of $394.3 \mathrm{~km} / \mathrm{h}$ in November $1989.1-13$

The principal features of the latest version of JNR's EDS system can be summarized as follows: (1) lightweight, multifunction, superconducting magnets aboard the vehicle to perform the functions of levitation, propulsion, and guidance; (2) figure-eight-shaped null-flux coil suspension with cross-cornection for the null-flux guidance; and (3) active track, air-core LSM propulsion. The U-share $\mathrm{I}$ EDS test track in Miyazaki was first used with a "facing" levitation configuration, as show $\mathrm{n}$ in Figure $4.1 \mathrm{a}$, in which the levitation force was obtained from the interaction between the vertically arranged superconducting coils aboard the vehicle and the horizontally arranged loop coils on the guideway; externally powered coils on the sidewall of the guideway were cross-connected to produce both propulsion and guidance forces. The latest version of the Japanese EDS system uses cross-connected, figure-eight-shaped, null-flux coils mounted on the sidewalls to form a combined null-flux sidewall suspension and guidance system as shown in Figure 4.1b. In this latest configuration, the levitation force is obtained from the interaction between the superconducting coils aboard the vehicle and the null-flux coils mounted on the sidewall, whereas the guidance force is obtained from the interaction between superconducting magnet pairs arranged on both sides of the vehicle and the cross-connected, figure-eight-shaped, null-flux coils mounted on both sidewalls of the guideway. The propulsion coils overlapping with the figure-eight-shaped null-flux coils on the sidewalls produce propulsion force only. The nullflux EDS maglev system has several advantages:

- Very high lift-to-drag ratio, typically several hundreds depending upon system design, has the potential to make the system very energy-efficient. 


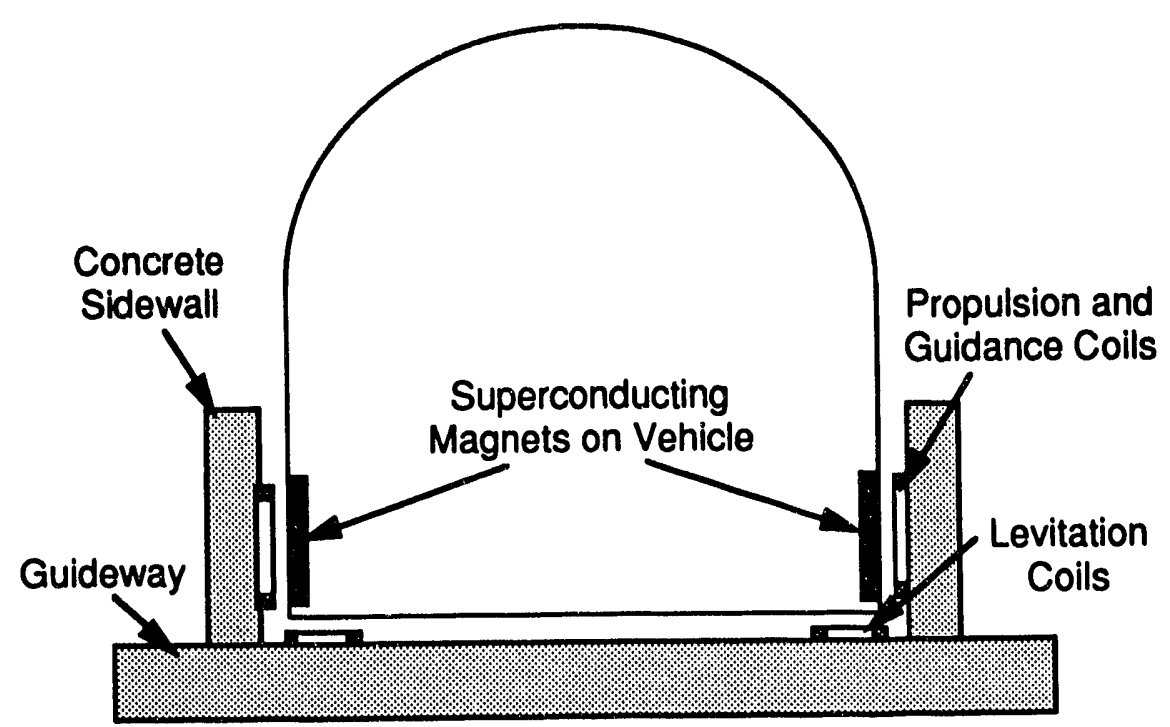

(a) Facing Suspension System

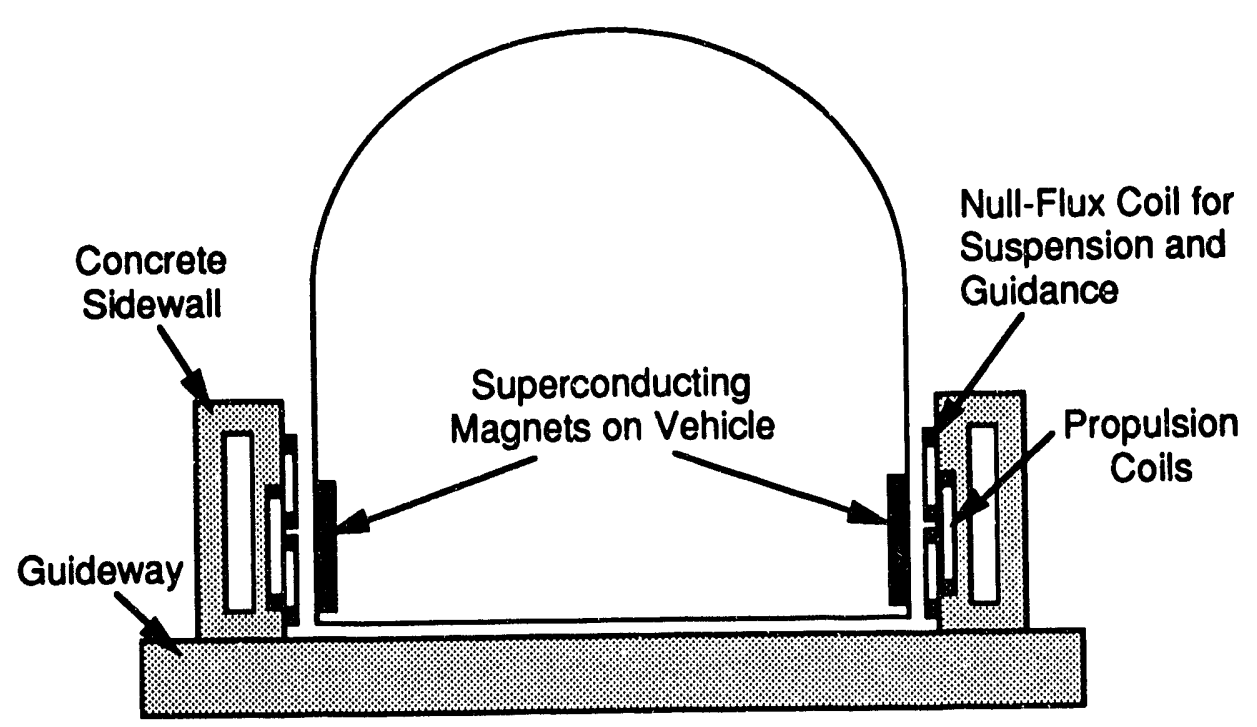

(b) Sidewall, Null-Flux Suspension System

FIGURE 4.1 Operating Principle and Coil Arrangement for the Japanese Electrodynamic-Suspension Systems 
- High lift and guidance stiffness provides good dynamic stability, but special secondary or tertiary suspension systems may be required to soften the ride quality.

- High payload efficiency may be achieved due to the use of lightweight superconducting magnets.

- The EDS system is intrinsically stable at high speeds and does not require excitation of the vehicle-borne magnets with dc power controlled by a feedback system, as is the case with the EMS system.

- Large clearance, typically $10 \mathrm{~cm}$, allows the vehicle to run safely at high speeds and allows a soft, comfortable ride.

- Large clearance permits the system to accommodate large guideway irregularities, thus providing an extra margin of safety and, in principle, providing an opportunity to minimize construction and maintenance costs.

- Large clearance also implies that the guideway of an EDS system may withstand a wide range of adverse weather conditions, such as snow and icing, and still maintain normal operation.

- Power factor and efficiency of the propulsion system may improve because of the use of powerful superconducting magnets that allow relatively small excitation currents to be used in the stator windings.

- Vehicle is in contact-free operation because no power collection is required for levitation and propulsion. This can reduce noise and substantially decrease guideway and vehicle maintenance. (Some power collection is required for cooling the magnet and for such on-board power needs as lighting, air conditioning, and monitoring and control functions.)

There are some possible drawbacks of the system:

- Shielding may be required to reduce the magnetic field strength inside the passenger compartment of the vehicle. This could increase the vehicle weight.

- Dynamic stability of the system and acceptable ride quality may require additional damping and vibration control. 
- The vehicle must be suspended by a landing gear at low speeds. In the case of the MLU002 system, the lift-off speed is about $170 \mathrm{~km} / \mathrm{h}$. With alternative EDS-system designs, the lift-off speed can be reduced to the range of $50-100 \mathrm{~km} / \mathrm{h}$.

- Performance testing has been limited to very-large-radius curves $(10,000 \mathrm{~m})$. How the vehicle will perform over smaller-radius curves or in negotiating banked curves has not been addressed. The present design of nontilting vehicles and relatively small angles of superelevation may restrict applications to relatively straight route alignments.

- The present test vehicle design is subject to resonant effects that lead to quenching of the superconducting magnets above a critical speed of about $300 \mathrm{~km} / \mathrm{h}$. Technical solutions to this problem are feasible but will require testing and evaluation.

\subsection{Overview of Japanese Electrodynamic-Suspension Maglev Systems}

\subsubsection{ML-500}

The ML-500 test vehicle employing the EDS system was the first vehic $a$ be tested at the Miyazaki test facility (Figure 4.2). This vehicle, built in 1977, was a nonpassenger-carrying test vehicle that had the following dimensions: length, $13.5 \mathrm{~m}$; width, $3.72 \mathrm{~m}$; height, $2.85 \mathrm{~m}$; and weight, 10 metric tons. The inverted-T-shaped guideway was utilized in the test. Aboard the vehicle were four L-shaped cryostats, each of which contained four superconducting coils: two for propulsion and guidance, and two for levitation. The helium refrigerator and compressor were installed on the ground, and liquid helium was supplied to the cryostats before each test run.

During the three-year test period, the maximum speed of the ML-500 increased as the length of the guideway increased. The ML-500 attained $132 \mathrm{~km} / \mathrm{h}$ on the $1.3-\mathrm{km}-\mathrm{long}$ guideway in $1977,301 \mathrm{~km} / \mathrm{h}$ on the $3.1-\mathrm{km}$-long guideway in 1978 , and $517 \mathrm{~km} / \mathrm{h}$ on the $7-\mathrm{km}-$ long guideway in 1979. Three objectives were met by the ML-500 vehicle tests: (1) high-speed operation up to $517 \mathrm{~km} / \mathrm{h}$ in 1979 , (2) measurement of vehicle dynamic response to guideway irregularities, and (3) operation in a simulated tunnel. From these experiments, the principle of operation and the design of the LSM propulsion system, the EDS system, the superconducting magnet technology, and the po ver-supply system were verified. 


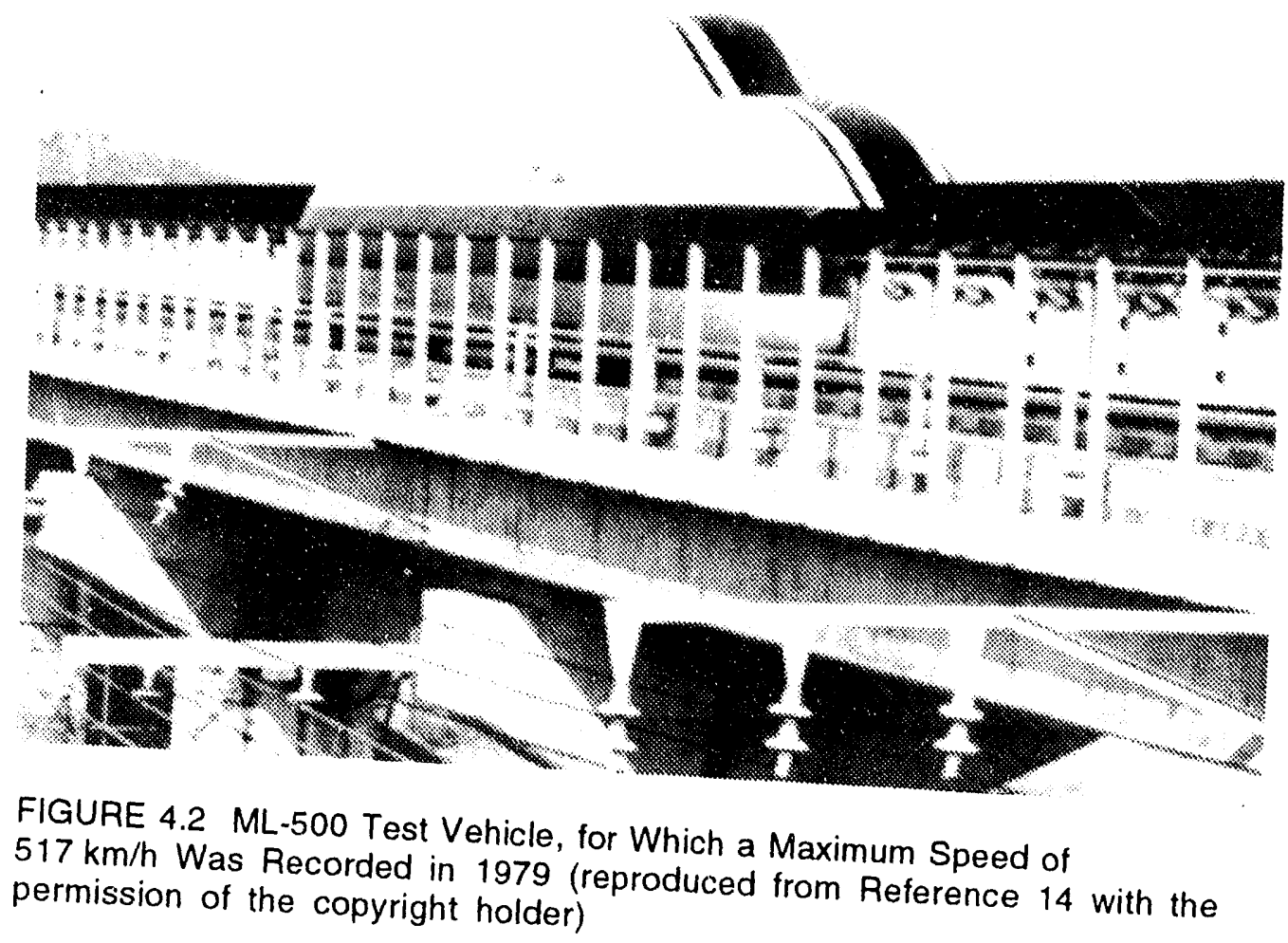

\subsubsection{MLU001}

The MLU001, a three-car train with a total weight of about 30 metric tons and a total The test objective for this vehicle was to (Figure 4.3). It began operation in November 1980 ). coupled operation. The cars had about the investigate the running characteristics of vehicles in a total of 32 seats in the three cars. Superconducting section as a commercial vehicle. There were $700 \mathrm{kA}$, were located throughout the bottom of the magnets, each with a magnetomotive force of with four poles in each row. The I-shaped supercond bodies; each car had eight coils in two rows performed three functions: levitation, propulsion, anding coils, installed vertically in the cars, systems were tested with this vehicle. The reliability guidance. Various types of cryogenic verified; however, reliable on-board reliquefaction of vap of the on-board cryogenic system was

\subsubsection{MLU002}

The MLU002, shown in Figure 4.4, is an application prototype vehicle with a weight of 17 metric tons and a length of $22 \mathrm{~m}$ constructed in 1987 (see Table 4.2 for detailed technical 


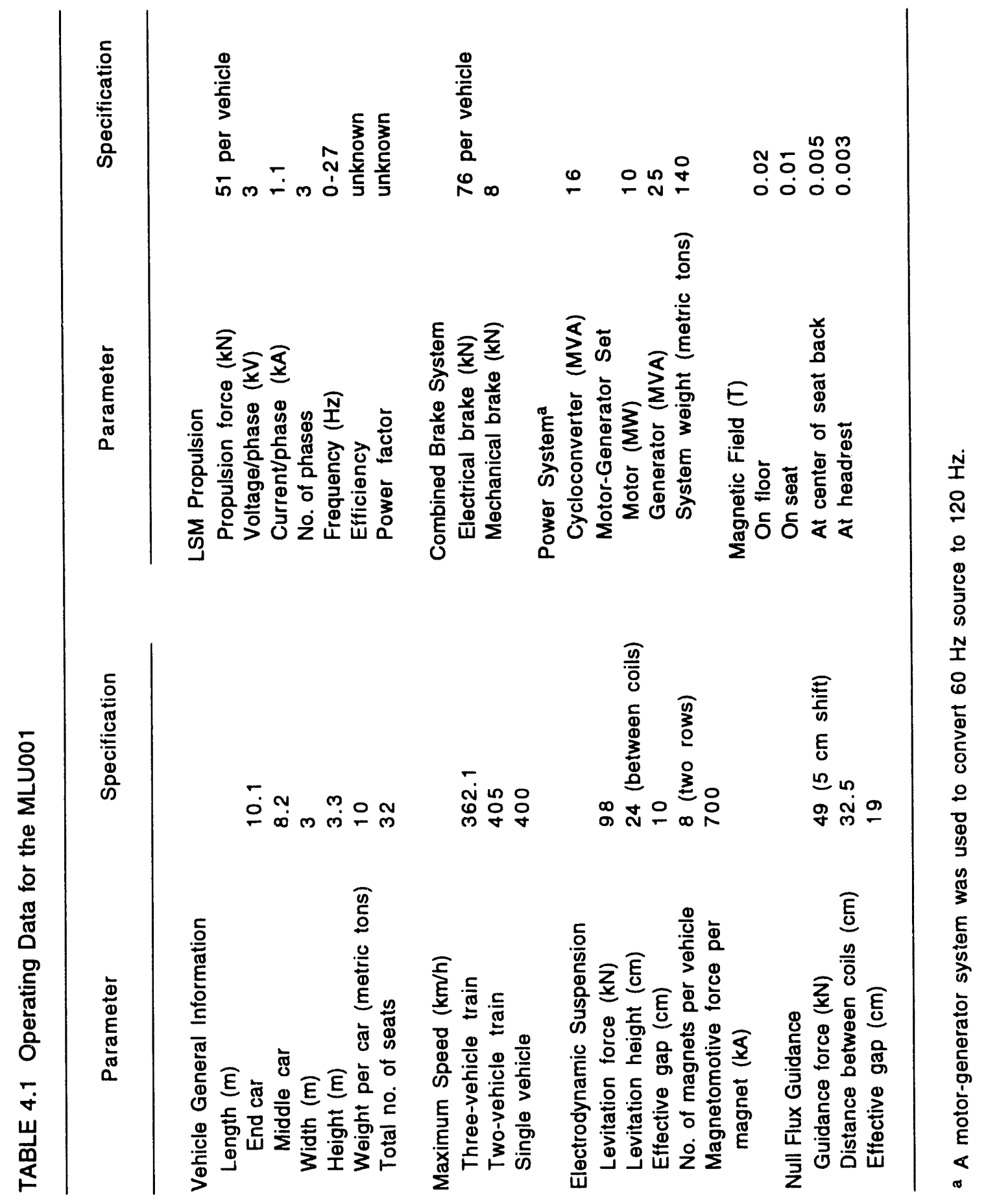




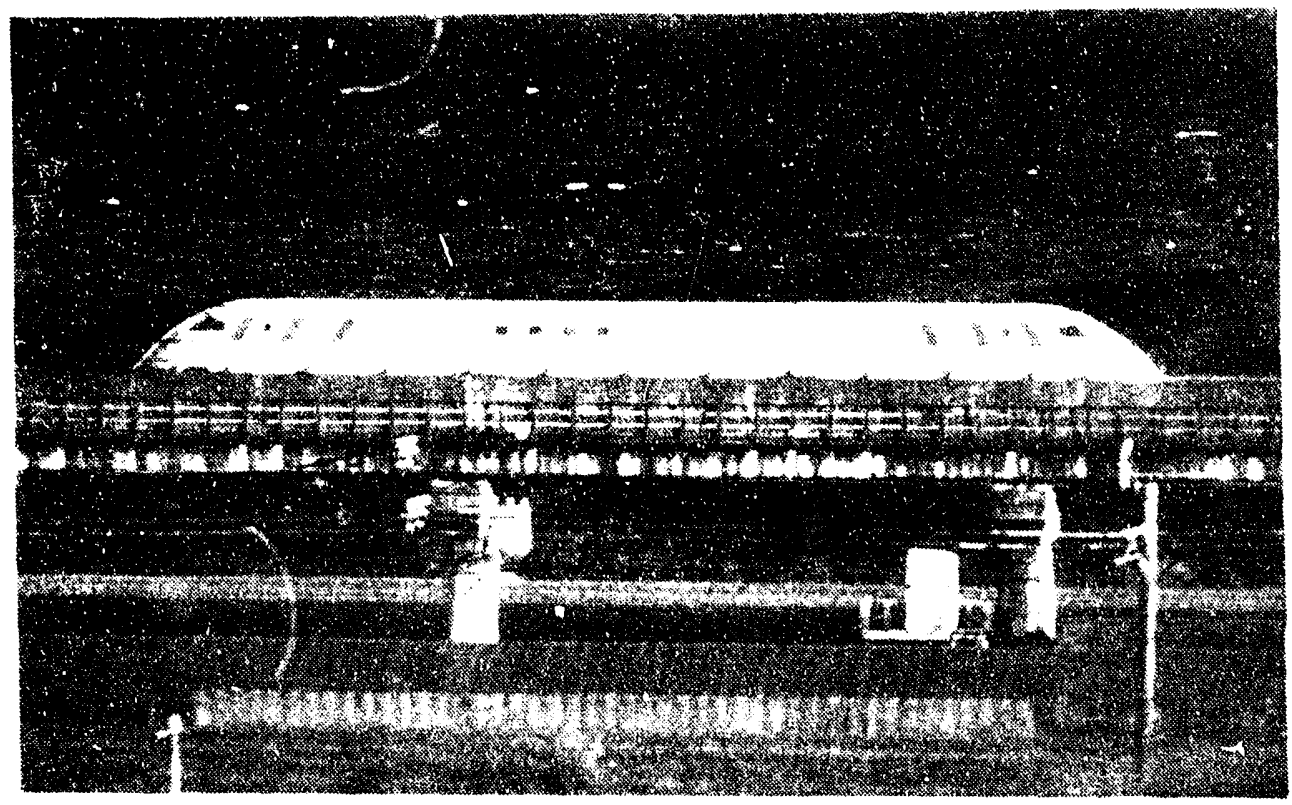

FIGURE 4.3 MLUDo1, a Three-Car Train Built in 1980

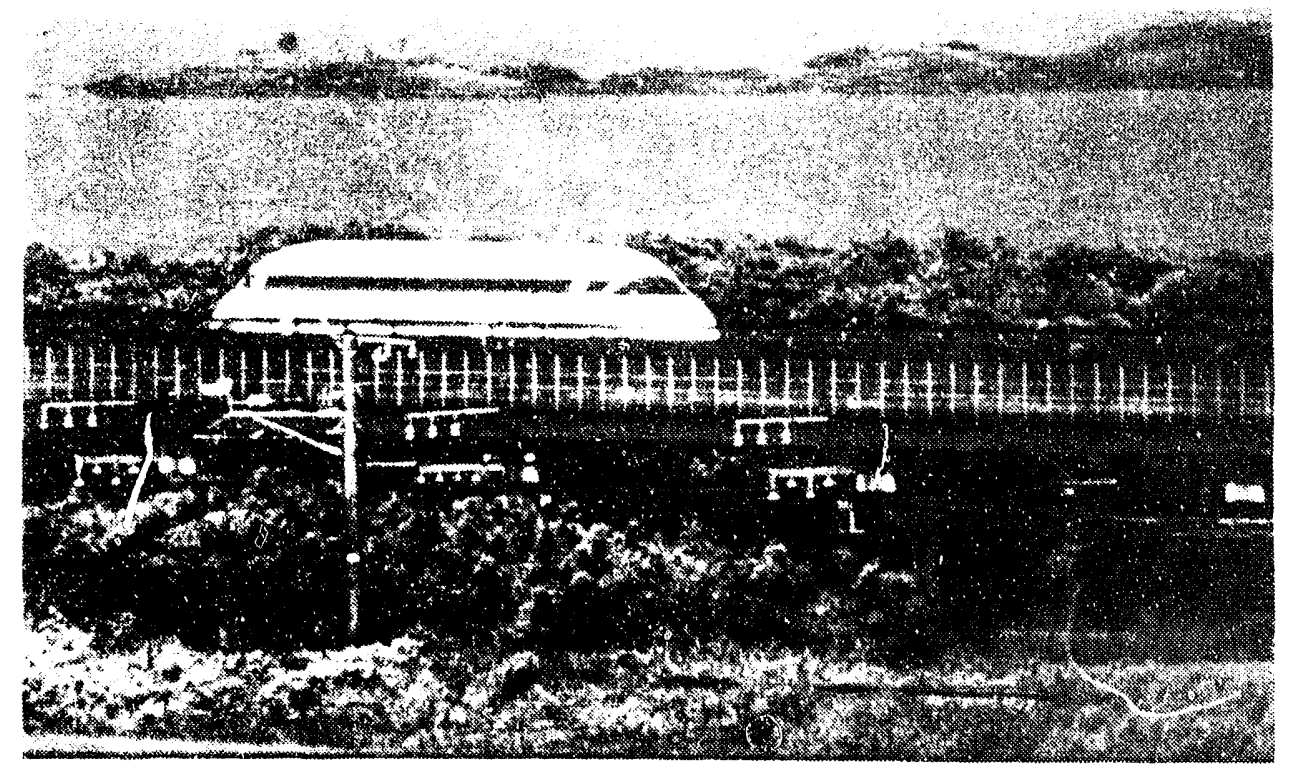

FIGURE 4.4 MLU002, an Application-Prototype Vehicle Built in 1987 


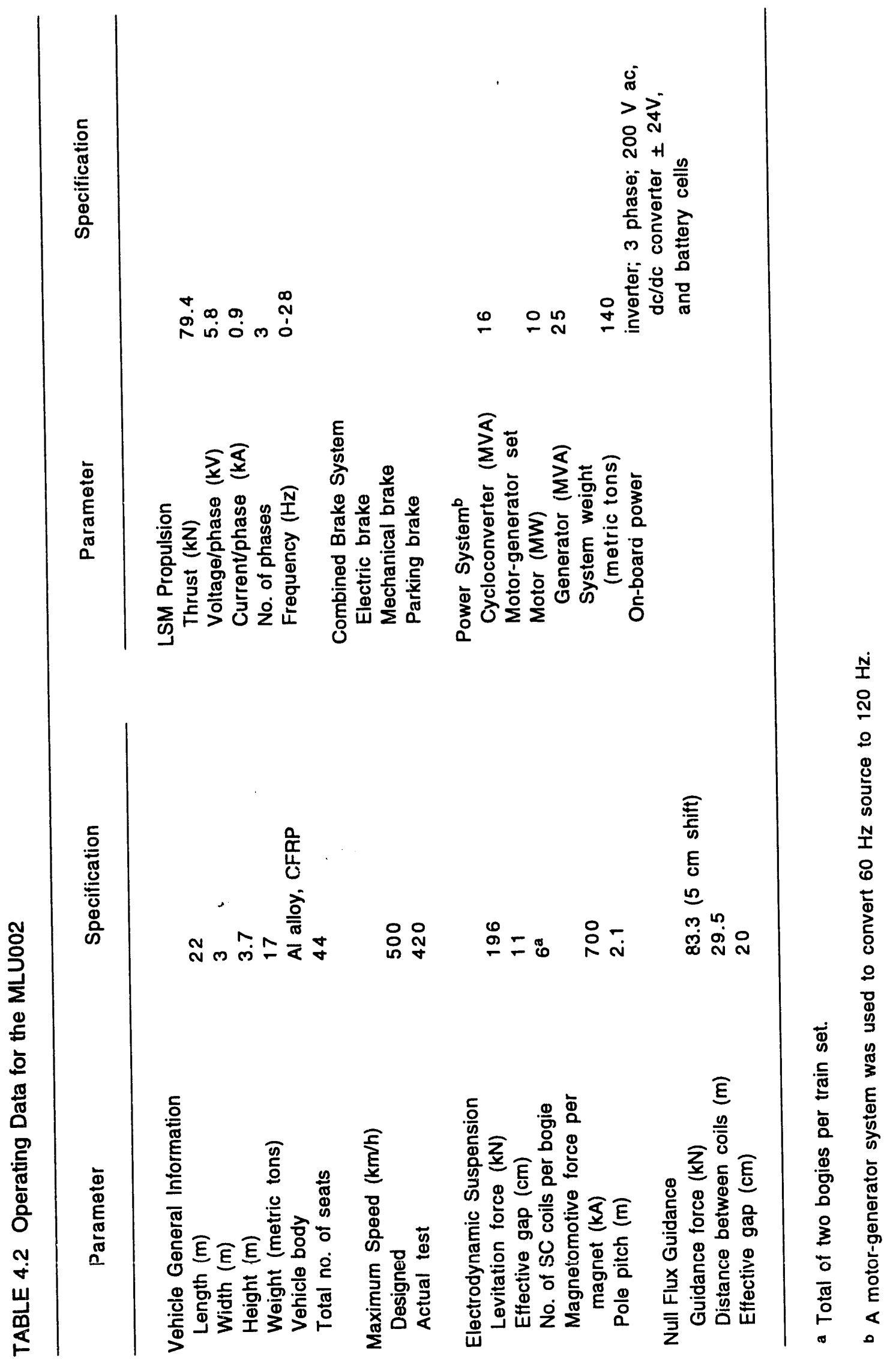


parameters). The major difference between the MLU002 and the MLU001 was that the superconducting coils on the MLU002 were concentrated on separately suspended bogies (similar to those used on conventional rolling stock), instead of being continuously distributed along the car bodies, as was the case for the MLU001. In addition, the number of superconducting magnets was reduced, reflecting the greatly increased field strength of the magnets. This resulted in a reduction of vehicle weight and, therefore, in an increase in payload efficiency. Figure 4.5 shows the different arrangements of the superconducting magnets on the MLU001 and MLU002. The maximum speed of the MLU002 is designed to be $500 \mathrm{~km} / \mathrm{h}$; however, actual speed was limited to $420 \mathrm{~km} / \mathrm{h}$ because of the length of the test track. Both the MLU001 and the MLU002 use the U-shaped guideway configuration shown in Figure 4.1a.

It should be noted that the same guideway structure that was used for the ML-500 was also used for the MLU001 and MLU002 vehicles. The center structure used to support the LSM windings of the ML-500 system (the inverted-T-shaped guideway superstructure) was replaced by outside walls that supported the LSM windings of the MLU001 and MLU002 vehicles (U-shaped guideway superstructure).

\subsubsection{Commercial Vehicle}

On the basis of data obtained from tests on the MLU001 and MLU002 vehicles, Japanese engineers have designed a new commercial-type vehicle. In this design, the superconducting magnets are arranged on the bogies at the ends of each car and at the articulation points between the cars of the maglev train (also shown in Figure 4.5). Thus, the passenger compartments can be located at a distance from the superconducting magnets, where the magnetic flux density will be considerably reduced. The design specifications of a commercial EDS system are given in Table 4.3. The new commercial vehicle is discussed further in Section 4.3.
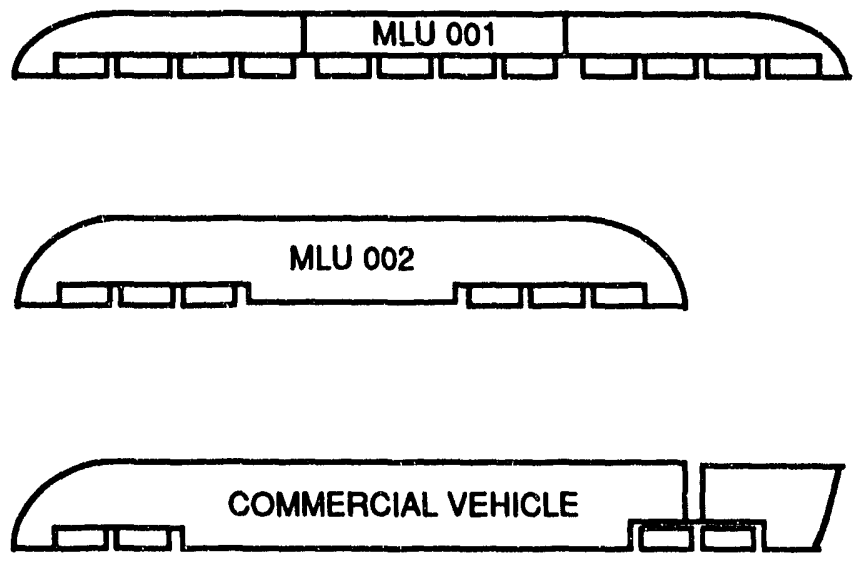

FIGURE 4.5 Arrangement of Superconducting Magnets on Various Maglev Vehicles (not to scale) 


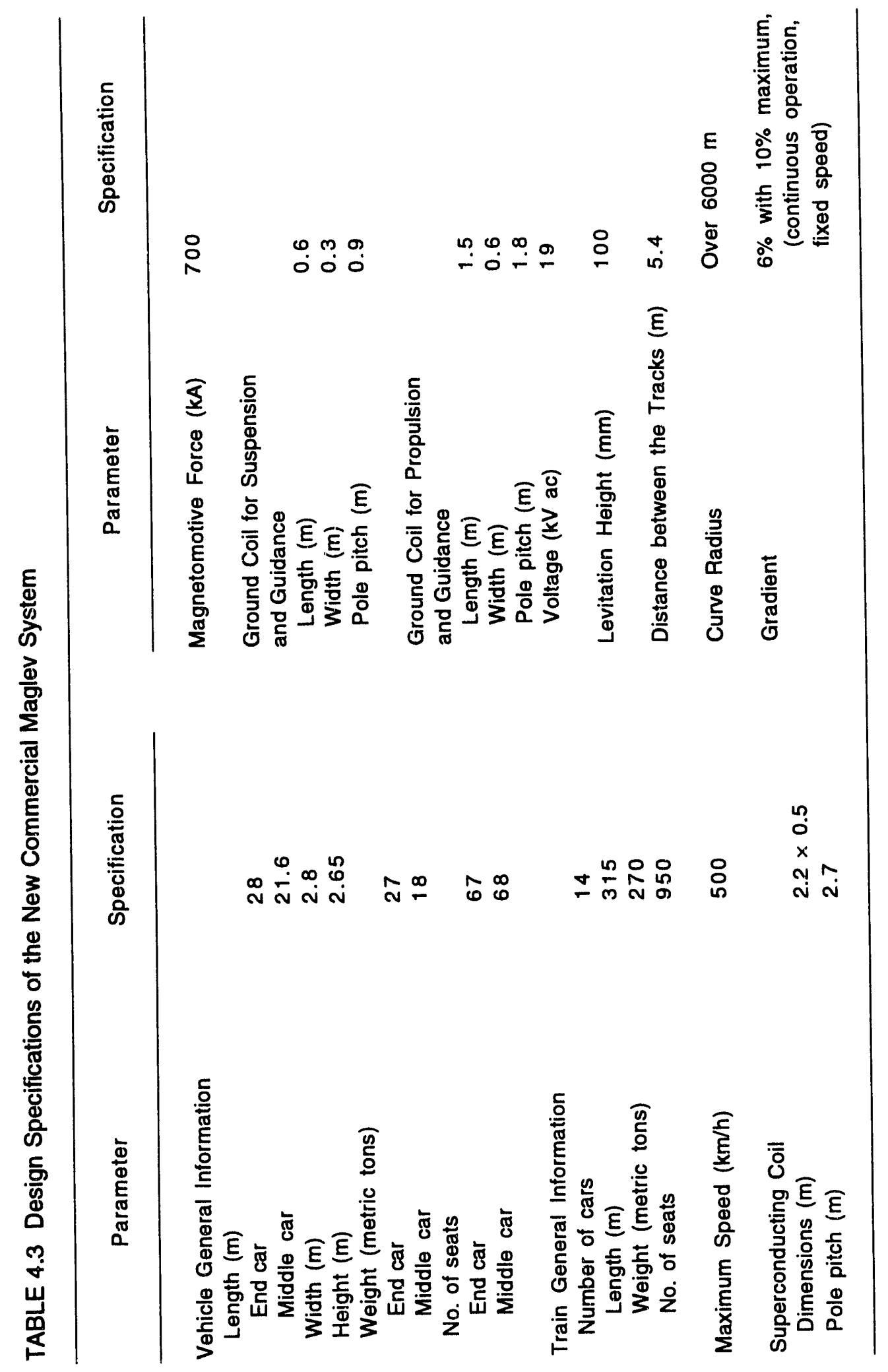




\subsection{Superconducting Magnets}

One of the major research areas for the EDS maglev system is the development of reliable superconducting magnets (SCMs). The Japanese have devoted a great amount of effort since the 1960s to developing high-quality SCMs for their EDS maglev system. Basic features of SCMs are light-weight, compact design; high magnetomotive force; and high current density. The major progress made in Japan recently in this area can be seen from a comparison of the values in Table 4.4, where parameters for the superconducting magnet in each of the three different types of EDS maglev systems have been listed. One can see that considerable improvement has been made on the new system, such as the increase in the ratio of lift force to magnet weight and the reduction of heat leakage.

Because of the improvement in SCMs, the Japanese have proposed a new commercial EDS system in which the SCMs are placed on bogies only at the ends and at the articulation points of the maglev train, as shown in Figure 4.5. Concentrating the magnets on bogies that cut into the vehicle body reduces the overall vehicle cross section, which reduces aerodynamic drag and permits smaller-size tunnels - a major consideration in Japan. This design approach uses fewer magnets, which improves the payload efficiency and reduces the magnetic field intensity in the passenger compartments, by displacing the compartment from the bogies. The use of very large magnets on bogies does have some disadvantages, including possible large local magnetic fields at the ends of the passenger compartments that may require shielding, lack of redundancy in the suspension system, and poor utilization of the energized portion of the propulsion motor stator windings. Further research work has been suggested on SCMs in the following areas:

- Developing compact, light-weight, high lift-to-mass ratio SCMs;

- Characterizing long-span superconducting coils and establishing massproduction technology for SCMs;

- Verifying superconducting-coil stability under the increased electromagnetic force due to the concentrated magnet arrangement and the presence of harmonics in the propulsion windings; and in

- Confirming the reliability of the on-board refrigeration system in long-term operation. 
TABLE 4.4 Main Specifications of Superconducting Magnets for the Japanese Electrodynamic-Suspension Maglev Systems

\begin{tabular}{|c|c|c|c|}
\hline Parameter & MLU001 & MLU002 & $\begin{array}{c}\text { New } \\
\text { Commercial } \\
\text { System }\end{array}$ \\
\hline Cross Section & I-shaped & I-shaped & I-shaped \\
\hline \multicolumn{4}{|l|}{ Composition } \\
\hline No. of coils per cryostat & 2 (or 1) & 1 & 1 \\
\hline No. of cryostats/helium tank & 1 & 3 & 2 \\
\hline Dimensions of SCM (m) & $4 \times 1.15$ & $6.1 \times 0.885$ & $5.18 \times 1$ \\
\hline Magnetomotive Force (kA) & 700 & 700 & 700 \\
\hline \multicolumn{4}{|l|}{ Dimensions of Superconducting } \\
\hline Coil $(m)$ & $1.7 \times 0.5$ & $1.7 \times 0.5$ & $2.3 \times 0.5$ \\
\hline Copper Ratio & 2 & 1.0 & 1.0 \\
\hline \multicolumn{4}{|l|}{ Persistent Current Switch Off-State } \\
\hline Resistance $(\Omega)$ & 0.8 & 50 & 100 \\
\hline Support & FRP column & FRP column & FRP column \\
\hline Heat Leakage to Inner Vessel (W) & 2.5 & 3 & 3 \\
\hline Mass (without refrigerator) (kg) & 650 & 950 & 895 \\
\hline On-Board Refrigerator & separate & built-in & built-in \\
\hline Refrigeration Capacity at $4.4 \mathrm{~K}(\mathrm{~W})$ & 5 & 5 & 5 \\
\hline Force per Magnet (kN) & 24.5 & 41.7 & 88.3 \\
\hline Heat Leakage per Force (W/kN) & 0.1 & 0.07 & 0.03 \\
\hline Lift Force per Magnet Mass & 3.85 & 4.5 & 10 \\
\hline
\end{tabular}




\subsection{Electrodynamic-Suspension Maglev-System Guideway}

\subsubsection{Miyazaki Test Track}

For the development of the EDS maglev system, JNR constructed a test track at Miyazaki. The first section of $1.3 \mathrm{~km}$ (completed in 1977) was extended in three stages until in 1979 the track reached a total length of $7.0 \mathrm{~km}$. Some of its features include a downhill section with a gradient of $0.5 \%$ at about $1 \mathrm{~km}$ from the test center and a curve with a radius of $10,000 \mathrm{~m}$ with $0.115 \mathrm{rad}$ of cant. Operational tests began in July 1977 with the ML-500 vehicle on the inverted$\mathrm{T}$-shaped guideway. In 1980 , the guideway was converted into a U-shaped configuration, with ground-based coils for levitation and sidewall coils for propulsion and guidance. The guideway contains about 20,000 suspension coils and 10,000 propulsion coils. Both the MLU001 and MLU002 vehicles were tested on the U-shaped guideway. Portions of the guideway superstructure were deliberately misaligned to test the dynamic response of the system to such misalignments. Recently, short sections of the guideway have been used to test vertical figureeight-shaped, null-flux coils for suspension (Figure 4.1b), in place of the discrete short-turn horizontal coils usually located on the floor of the guideway. A mechanical directional switch was installed in the test track in 1990. Short portions of the guideway have also been recently replaced with alternative structural designs.

\subsubsection{New Test Track}

A new test-track is under construction in Yamanashi Prefecture about $100 \mathrm{~km}$ west of Tokyo. The planned length is about $43 \mathrm{~km}$, with a portion of that length double-tracked. There will be some gradient sections and tunnel sections. The new track is scheduled for completion in FY1994, with operational testing beginning around mid-FY1993. The track is planned to permit a speed of $500 \mathrm{~km} / \mathrm{h}$ on the gradient sections and speeds up to $550 \mathrm{~km} / \mathrm{h}$ on the flat, straight sections. Two test vehicles will be able to pass each other on the double-tracked section. It is expected that the test results obtained from the new track will be immediately reflected in the commercial system design.

\subsection{Propulsion and Power-Supply Systems}

The propulsion system of the Miyazaki Maglev Test Track employs a long-stator LSM, which consists of superconductive field coils aboard the vehicle and an array of armature coils connected across the guideway. The interaction between the superconductive coils and armature coils yields a null-flux guidance system. The power-supply system, a high-capacity cycloconverter, energizes only the motor section in which the vehicle is running, for a block length 
about 58.8-m long. A contact-free power-collection system utilizing the reaction flux of the ground-based levitation coils supplies on-board power.

Prior to 1986, the Miyazaki power system included a motor-generator (MG) set, which converted the $60 \mathrm{~Hz}$ line power to $120 \mathrm{~Hz}$, and a pair of cycloconverters, which produced VVVF (0-34 Hz) output prower for the LSM stator windings. In 1986, the power system was changed, and the MG set was eliminated. New circulating-current-type cycloconverters were installed, which were capable of converting the $60-\mathrm{Hz}$ line current directly into VVVF output power at frequencies up to two-thirds the line frequency.

In the propulsion-control system of the test track, a central controller transmits propulsion commands to the substation in accordance with vehicle information obtained through a leakage coaxial cable. In response to the propulsion command, cycloconverters feed an alternating current to the propulsion coils, in synchronization with the vehicle field phase detected by cross-inductive wires strung along the guideway. A section changeover control for a pair of cycloconverters alternately feeds current to the propulsion coils along which the vehicle is passing. In emergencies, resistors for dynamic braking can be applied. The control system can be classified into current control, synchronization control, and speed control through thrust calculations.

\subsection{Braking Systems}

In normal and emergency service, the MLU002 vehicle uses a regenerative braking system that is incorporated into the power-supply system of the LSM. If the power-supply system fails, three alternative braking systems are possible. A dynamic brake that feeds electrical energy into a resistor bank is regarded as the first backup braking system. It is operational over the entire vehicle-speed range. In the lower-speed range (below about $350 \mathrm{~km} / \mathrm{h}$ ), a friction brake may be used if the dynamic system fails, but at speeds above $350 \mathrm{~km} / \mathrm{h}$, mechanical friction brakes are not effective. However, aerodynamic drag force is the dominant drag force at high speeds. Consequently, it can be effectively used to provide safe, strong, reliable braking action in the higher speed range if both the regenerative and dynamic brakes fail.

Both scale-model tests in a wind tunnel and full-scale tests of aerodynamic braking systems have been conducted in Japan. The system tested on the MLU001 vehicle at the Miyazaki Test Track consisted of hydraulically actuated panels that open on the top and sides of each car in the train set. Tests conducted at speeds up to $350 \mathrm{~km} / \mathrm{h}$ with the three-car MLU001 train, in both wheel-supported and levitated modes, were reported to show satisfactory results. No instabilities were observed, and the transition from the closed to open panel configuration did not result in abrupt jerking motions. The change in drag force occurred over an interval of about one second. The accompanying small change in deceleration resulted in a smooth change in velocity. Tests included normal panel deployments in various combinations on the three cars and also panel deployment failures, in which only c,ne of three panels opened (for example, the right side opened while the top and left-side panels remained closed). Time delays between opening panels on the first and last cars were found to have no adverse effects. However, the braking forces were 
somewhat smaller in the field tests than had been predicted from the wind-tunnel tests. Also, some interference that reduced the effectiveness of the rear aerodynamic brake panels was observed during the field tests, in contrast to the wind-tunnel tests, which had indicated no interference.

\subsection{Present Status and Future Prospects}

The MLU002 test vehicle burned on October 3, 1991, due to an accident at the Miyazaki Test Track. 15,16 Investigation showed that the accident was not related to the operating principle of the maglev system, but that one of the tires went flat and its rotation locked. The vehicle was being towed back to the high-bay building when excessive friction between the flat tire and concrete guideway generated flames that ignited oil and the magnesium wheels. Subsequently, the entire vehicle was burned.

A new test vehicle, called the MLU002N, is in development and will replace the MLU002. The new vehicle will be made of fireproof material and have other improved features, including a new secondary suspension system. However, detailed technical information on the MLU002N has not yet been released. Test runs with the new vehicle will begin in January 1993 on the Miyazaki Test Track (outfitted with figure-eight, null-flux suspension coils). Later, tests will be conducted on the Yamanashi Test Track.

Development of the new high-speed test track in Yamanashi Prefecture is on schedule, and preliminary tests may start as early as $1994 .{ }^{17}$ The new test track will be used for many important tests associated with high-speed operation, such as the high-speed test up to $550 \mathrm{~km} / \mathrm{h}$ with safety and ride comfort; reliability and durability of vehicles, including on-board superconducting magnets and ground facilities; guideway switching; multiple train operating control; and vehicle operating performance associated with a tunnel.

The Japanese Government is planning to build a one-day-trip network across the entire country, in which one can travel between any two principal cities within three hours. Maglev systems are being considered to serve part of the network. For instance, the Chuo Shinkansen will employ maglev to connect three major metropolitan areas (Tokyo to Osaka through Nagoya). It takes about one hour to make this $500-\mathrm{km}$ distance trip, and the traffic density is expected to be about 100,000 to 150,000 passengers per day.

In addition to the long-distance trip between major cities, several short-distance projects utilizing maglev systems are currently under consideration. A 45-km long Shin Chitose AirportSapporo route, located in northern Japan, will use maglev vehicles to transport 10 million passengers annually at a speed of $500 \mathrm{~km} / \mathrm{h}$. Similarly, the Omiya-Narita Airport route in Saitama Prefecture is expected to use maglev vehicles to transport foreign travelers. 


\subsection{References}

1. Nakao, H., et al., 1989, "New Type Superconducting Magnet for EDS System," in Proceedings of the 11 th International Conference on Magnetically Levitated Systems and Drives, published by the Institute of Electrical Engineers of Japan, Tokyo, Japan, pp. 229-234, held at Yokohama, Japan, in July.

2. Seki, A., and T. Simomae, 1989, "Electric Equipment of the Chuo Linear Express," in Proceedings of the 11 th International Conference on Magnetically Levitated Systems and Drives, published by the Institute of Electrical Engineers of Japan, Tokyo, Japan, pp. 135-139, held at Yokohama, Japan, in July.

3. Seki, A., S. Kato, and T. Kawakami, 1989, "Concept of the Operational Safety System for the Chuo Linear Express," in Proceedings of the 11 th International Conference on Magnetically Levitated Systems and Drives, published by the Institute of Electrical Engineers of Japan, Tokyo, Japan, pp. 287-290, held at Yokohama, Japan, in July.

4. Fujie, J., 1989, "Current Status of EDS System in Japan," in Proceedings of the 11 th International Conference on Magnetically Levitated Systems and Drives, published by the Institute of Electrical Engineers of Japan, Tokyo, Japan, pp. 81-83, held at Yokohama, Japan, in July.

5. Japan Rolling Stock Exporters' Association, 1988, Japanese Railway Information, Railway Systems and Components, No. 35, pp. 1-7, Jan.

6. Hara, Y., K. Terada, and K. Miyairi, 1988, "Structure of the MLU002 Maglev Vehicle," Hitachi Review 37(6):357-363.

7. Kyotani, Y., 1988, "Recent Progress by JNR on Maglev," IEEE Transactions on Magnetics MAG-24(2):804-807, March.

8. Kyotani, Y., and H. Tanaka, 1986, "Present Status of JNR Maglev Development," in Proceedings of the International Conference on Maglev and Linear Drives, document 86CH2276-4, published by the Institute of Electrical and Electronics Engineers, New York, N.Y., pp. 41-45, held at Vancouver, British Columbia, Canada, in May.

9. Masada, E., 1985, "The Development of Maglev Transport and Related Systems in Japan," in Proceedings of the International Conference on Maglev Transport '85, published by the Institute of Electrical Engineers of Japan, Tokyo, Japan, pp. 21-28, held at Keidanren Keikan, Tokyo, Japan, in Sept. 
10. Jizo, Y., and Y. Furuta, 1985, "Superconducting Magnet for Maglev Train," in Proceedings of the International Conference on Maglev Transport '85, published by the Institute of Electrical Engineers of Japan, Tokyo, Japan, pp. 185-192, held at Keidanren Keikan, Tokyo, Japan, in Sept.

11. Ohguma, H., et al., 1985, "On-board Refrigeration System of Magnetically Levitated High Speed Trains MLU001," in Proceedings of the International Conference on Maglev Transport '85, published by the Institute of Electrical Engineers of Japan, Tokyo, Japan, pp. 193-198, held at Keidanren Keikan, Tokyo, Japan, in Sept.

12. Tanaka, H., 1985, "Present Conditions of Maglev Test in JNR," Japanese Railway Engineering, No. 96, pp. 8-11, Dec.

13. Nakamura, K., et al., 1985, "LSM Propulsion of the Miyazaki Maglev Test Track," in Proceedings of the International Conference on Maglev Transport '85, published by the Institute of Electrical Engineers of Japan, Tokyo, Japan, pp. 91-98, held at Keidanren Keikan, Tokyo, Japan, in Sept.

14. Kyotani, Y., 1982, "Outline of JNR Maglev Development," in Proceedings of the 2nd International Seminar on the Superconductive Magnetic Levitated Train, pp. 4-11, held at Miyazaki, Japan, in Nov.

15. Swinbanks, K., 1991, "Maglev Burns out in Japan," Nature 353:592.

16. Takagi, H., and S. Miyata, 1992, "Status Quo of Research and Development of Superconductive Magnetically Levitated Train," presented at the 6th World Conference on Transportation Research, sponsored by Laboratoire d'Economie des Transports, Lyon, France, held at Lyon, France, June 29-July 3.

17. Yamada, K., and N. Nakayama, 1992, "Introduction of the Maglev System to Mass Tansportation," presented at the 6th World Conference on Transportation Resarch, sponsored by Laboratoire d'Economie des Transports, Lyon, France, held at Lyon France, June 29-July 3 . 


\section{German M-Bahn Maglev System}

\subsection{System Description}

M-Bahn is a low-speed, short-distance, rapid-transit maglev system built by the Federal Republic of Germany in 1986. The system, shown in Figure 5.1, has been running as a revenueservice transit system in West Berlin since June 1988. The basic features of the M-Bahn are longstator, iron-core LSM propulsion; permanent-magnet attractive levitation; and mechanical-roller guidance and air-gap control. The vehicle-borne permanent magnets perform two functions: excitation for the LSM and attractive levitation, which is controlled by mechanical means through guidance rollers (Figure 5.2). ${ }^{1-4}$

The M-Bahn maglev system has many advantages when compared with conventional transportation systems. The system permits a fully automatic, driverless operation with small headway. This leads to economical and efficient passenger transport. In addition, the system is relatively inexpensive to build, because the M-Bahn guideway is simple and the vehicle is light and has a small cross section. These characteristics also lead to low energy consumption, relatively low noise, and low system maintenance cost. The main disadvantage of the M-Bahn system may be the mechanical guidance system, which involves a certain degree of contact mechanical friction and eventual wear of moving parts. Because the M-Bahn is not a purely contact-free maglev system, the speed of the M-Bahn vehicle is limited to a few tens of kilometers per hour, as are most people-mover systems. However, as a low-speed transport system, the M-Bahn maglev system is economical and efficient. Some of its applications could be as feeder lines for existing

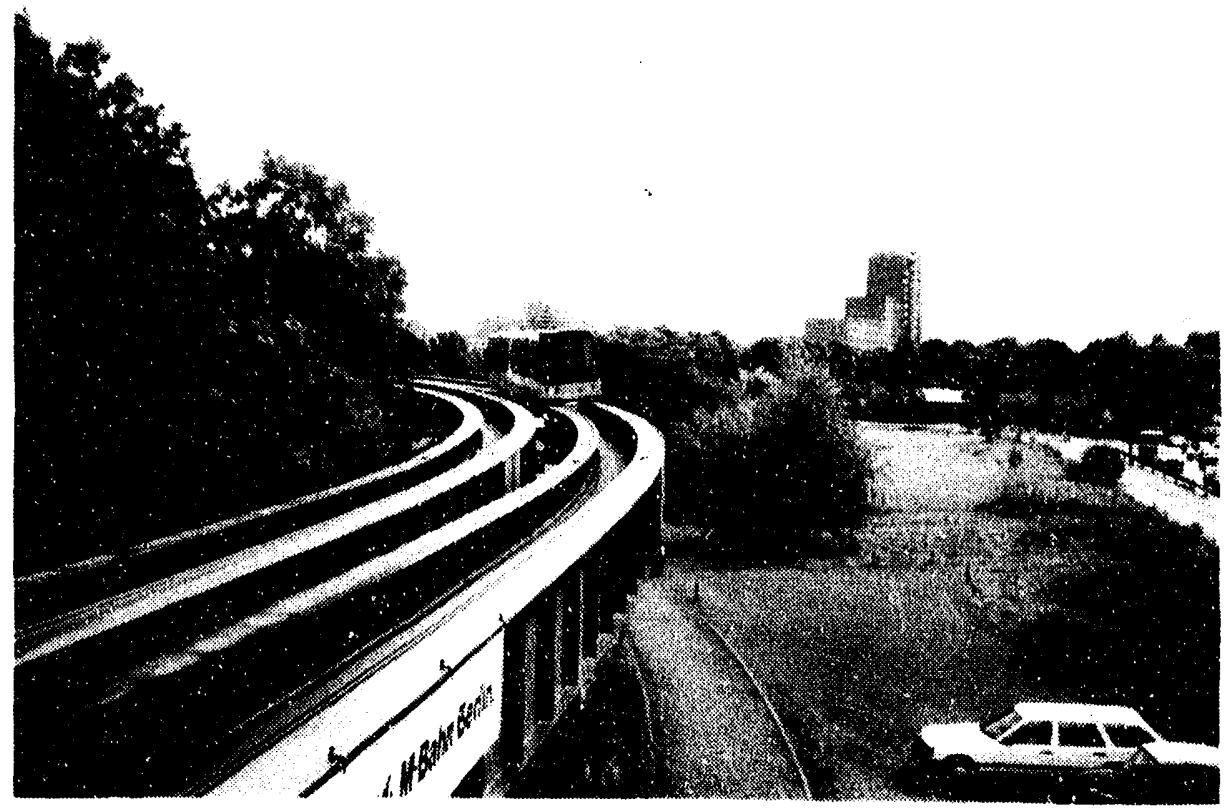

FIGURE 5.1 M-Bahn Maglev System Operating in West Berlin 


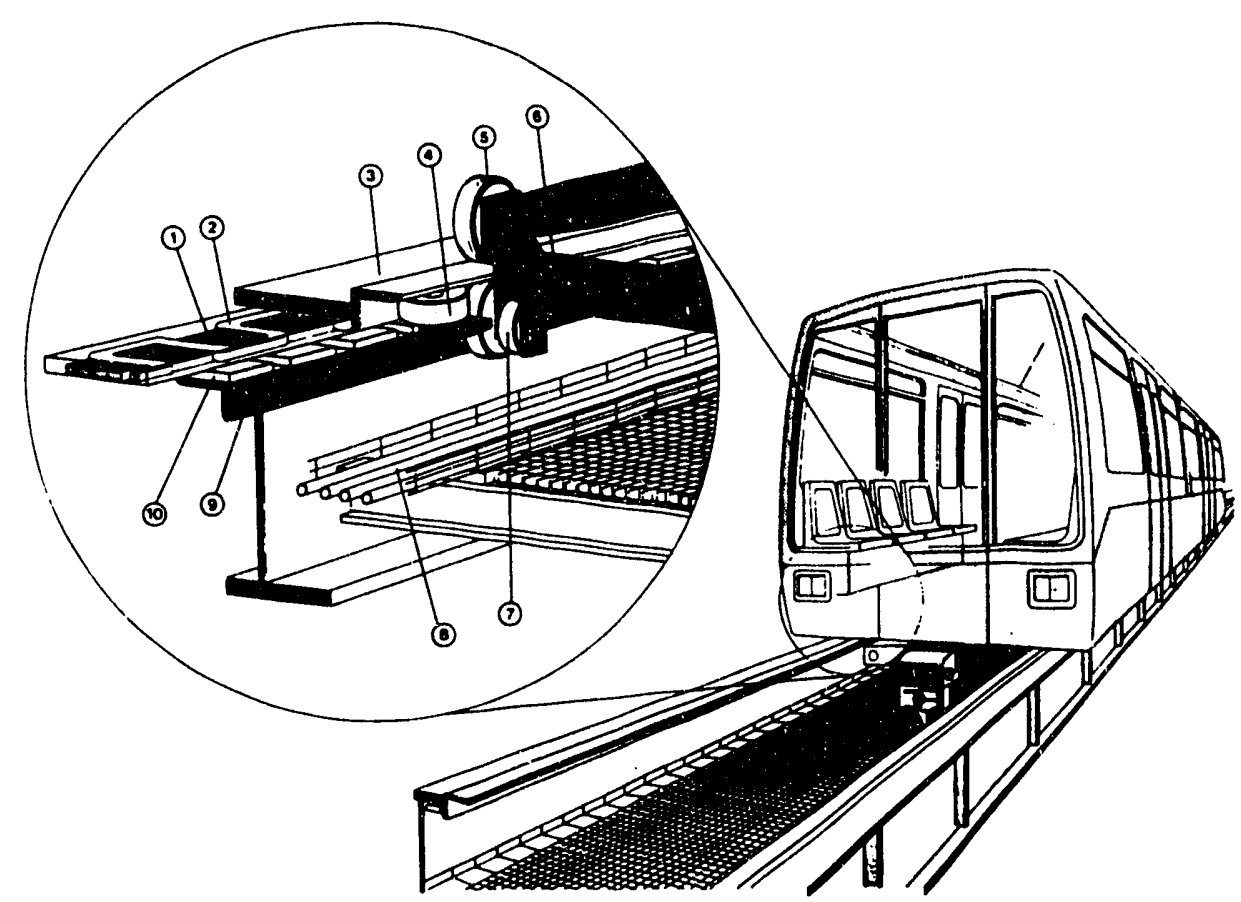

1. Laminated Iron Core

2. Armature Windings of LSM

3. Guideway

4. Horizontal Guide Rollers

5. Vertical Guide Rollers
6. Bogie

7. Switch Guidance Rollers

8. Cable

9. Magnet Support (part of vehicle)

10. Permanent Magnets

FIGURE 5.2 Basic Features of the M-Bahn Guideway and Vehicle (reproduced from Reference 1 with the permission of the copyright holder)

heavy mass-transport systems in large cities, as transit systems for medium-size downtowns (such as subway systems), and as point-to-point connection systems in such activity centers as airports, parks, or shopping centers.

The M-Bahn maglev development program is supported by funding from the Ministry of Research and Technology of the Federal Republic of Germany and from the city of Berlin. Tests of the major components, in particular the magnetic levitation and propulsion systems, began in 1973. A full-scale test facility was constructed in 1976 in Braunschweig, where different types of guideways and vehicle configurations were evaluated. The construction of Phase I of the demonstration line in Berlin began in 1983. Phase II, forming the full length of $1,600 \mathrm{~m}$ with three stations of the Berlin reference line, was completed in 1986. The objectives of the program are to prove the transportation and environmental feasibility of the M-Bahn system and to demonstrate the advantages and the technical reliability of the new system. M-Bahn has been in public operation since June 1988. 


\subsection{Propulsion and Power-Supply Systems}

The excitation field of the LSM is provided by the on-board permanent magnets. This field produces the attractive force necessary to levitate the vehicle. Thus, the propulsion force is controlled by the current in the stator windings, not by the excitation field. The propulsion force can also be changed by connecting the stator windings in series or in parallel. The LSM has a pole pitch of $0.12 \mathrm{~m}$, which corresponds to a maximum frequency of $92 \mathrm{~Hz}$, in order to obtain a maximum speed of $80 \mathrm{~km} / \mathrm{h}$.

The inverter, a condenser-forced commutator type, is equipped with the AEG-thyristor $\mathrm{T} 670 \mathrm{~F}$ and an antiparallel diode, one power semiconductor device per branch. The pulse-width inverter has dc link voltage of $970 \mathrm{~V}$, ac phase voltage of 0-440 V, ac line current of 550 A, and frequency of $0-95 \mathrm{~Hz}$. The guideway is divided into sections and is energized section by section. There is a 20 -ms power interruption during the transition between the sections. Detailed information is given in Table 5.1.

\subsection{References}

1. Dreimann, K., 1989, "M-Bahn Maglev Transit System Experience, Status, Application," in Proceedings of the 11 th International Conference on Magnetically Levitated Systems and Drives, published by the Institute of Electrical Engineers of Japan, Tokyo, Japan, pp. 101-104, held at Yokohama, Japan, in July.

2. Dreimann, K., 1987, "The M-Bahn Maglev Rapid Transit System - Technology, Status, Experience," in Proceedings of the International Conference on Maglev and Linear Drives, document $87 \mathrm{CH} 2443-0$, published by the Institute of Electrical and Electronics Engineers, New York, N.Y., pp. 113-118, held at Las Vegas, Nev., in May.

3. Eck, M.G., 1987, "The M-Bahn Demonstration Line in Berlin - Project, Status and Artistic Implementation," in Proceedings of the International Conference on Maglev and Linear Drives, document $87 \mathrm{CH} 2443-0$, published by the Institu:- of Electrical and Electronics Engineers, New York, N.Y., pp. 119-124, held at Las Vegas, Nev., in May.

4. Menden, W'., W.J. Mayer, and D. Rogg, 1989, "State of Development and Future Prospects of the Maglev Systems - Transrapid, M-Bahn and Starlin," in Proceedings of the 11th International Conference on Magnetically Levitated Systems and Drives, published by the Institute of Electrical Engineers of Japan, Tokyo, Japan, pp. 11-17, held at Yokohama, Japan, in July. 


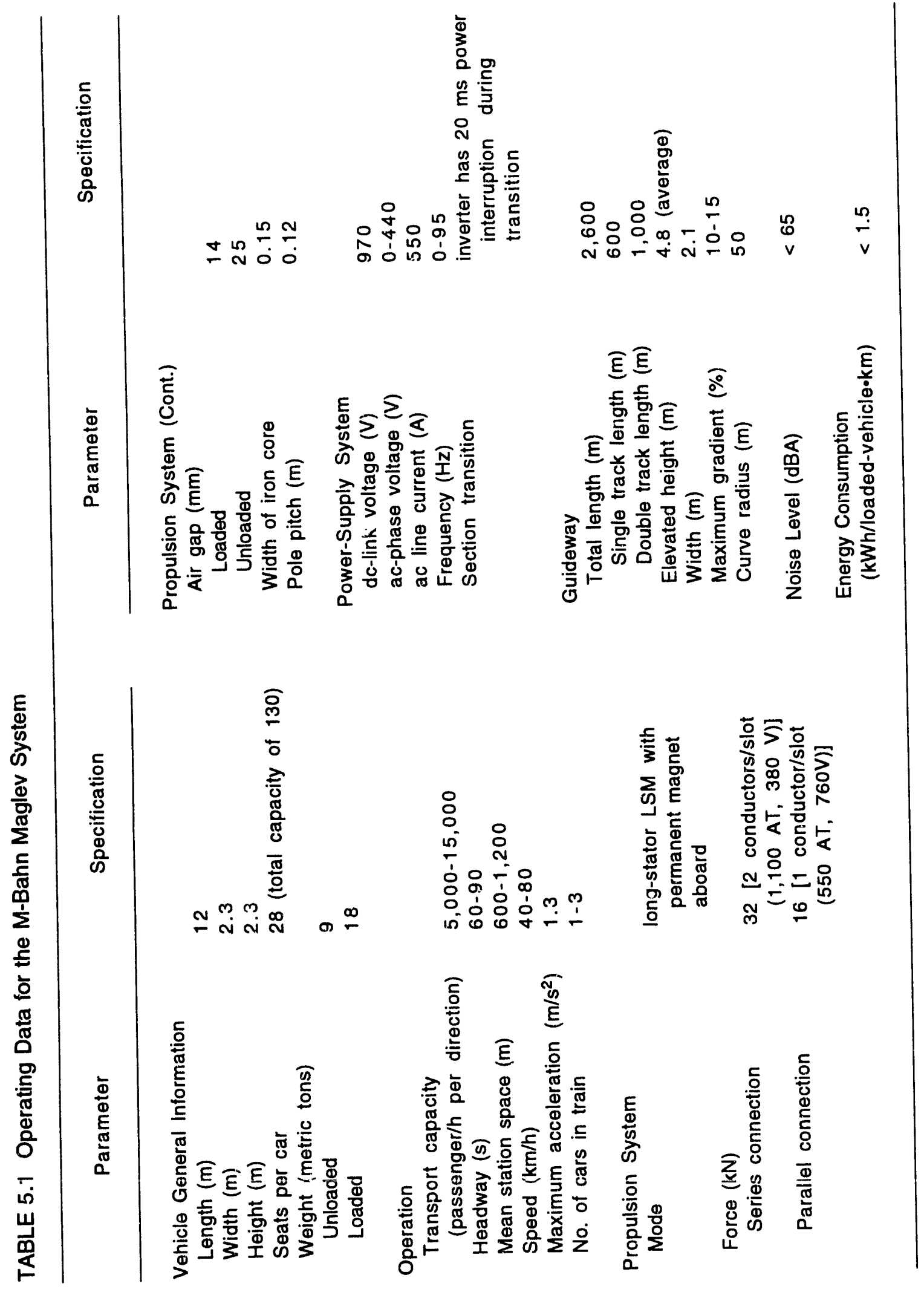




\section{Maglev-System Research and Development in the United Kingdom}

\subsection{Introduction}

Maglev research and development in the United Kingdom was carried out in the 1970s at private industries, at various universities, and by British Rail.1-3 The efforts focused on four separate concepts: (1) the EMS system, involving the use of controlled dc electromagnets, under the direction of Prof. B.V. Jayawant at Sussex University; (2) the EDS system, involving superconducting magnets and the split-track guidew'ay, under the direction of Prof. R.G. Rhodes at Warwick University; (3) the "magnetic river" concept, in which ac-excited magnets provide propulsion, guidance, anc repulsive-force levitation, under the direction of Prof. E.R. Laithwaite at Imperial College; and (4) the "mixed mu" system, in which materials having magnetic permeabilities of less than one (diamagnetic) and greater than one (paramagnetic and ferromagnetic) are combined to produce levitation and guidance even at zero speed, at Rutherford and Culham Laboratories.

Of these four concepts, the efforts at Warwick University were notable in that they progressed to the stage where a split aluminum track was attached to the rim of a 3-m-diameter wheel test rig. Subsequently, a small-scale test vehicle was fabricated and tested on a 550-m linear track. The split continuous track system had several important advantages. First, levitation, guidance, and propulsion could all be provided with a single set of on-board superconducting magnets. Second, only a single set of ground-based windings was needed to complete the propulsion motor. Third, the guideway itself was quite simple, consisting of two parallel aluminum strips for levitation and guidance, and a single set of windings for the propulsion motor stator. Tests on the $550-\mathrm{m}$ guideway were conducted by pulling the test vehicle along the guideway with a continuous cable. (No LSM windings were installed in the test guideway.)

\subsection{Birmingham Maglev System}

The Birmingham maglev system, built by a consortium of leading British companies in 1981 , is a low-speed (up to $54 \mathrm{~km} / \mathrm{h}$ ) maglev people-mover system (Figure 6.1). The system provides a link between the Birmingham Airport and the Birmingham International Rail Station, with a total track length of $640 \mathrm{~m}$, and has been in continuous public use since 1984.4-13

The basic features of the Birmingham maglev system include two parallel tracks running on a single elevated guideway, a group of controlled magnets providing attractive levitation and guidance forces, and a short-stator, single-sided, iron-core LIM propelling the vehicle (Figure 6.2). The advantages of the system, as compared with conventional transportation systems, include short transfer time and frequent service; reliability, safety, and flexibility; allweather operation; ease of maintenance; good compatibility with the public buildings served; and 


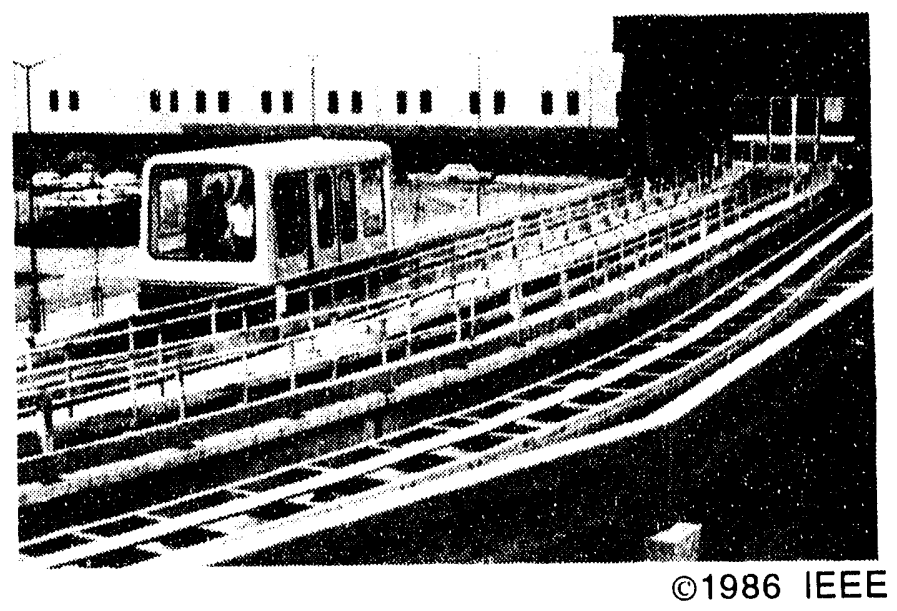

FIGURE 6.1 Birmingham Maglev Vehicle Approaching Airport Station (reproduced from Reference 10 with the permission of the copyright holder

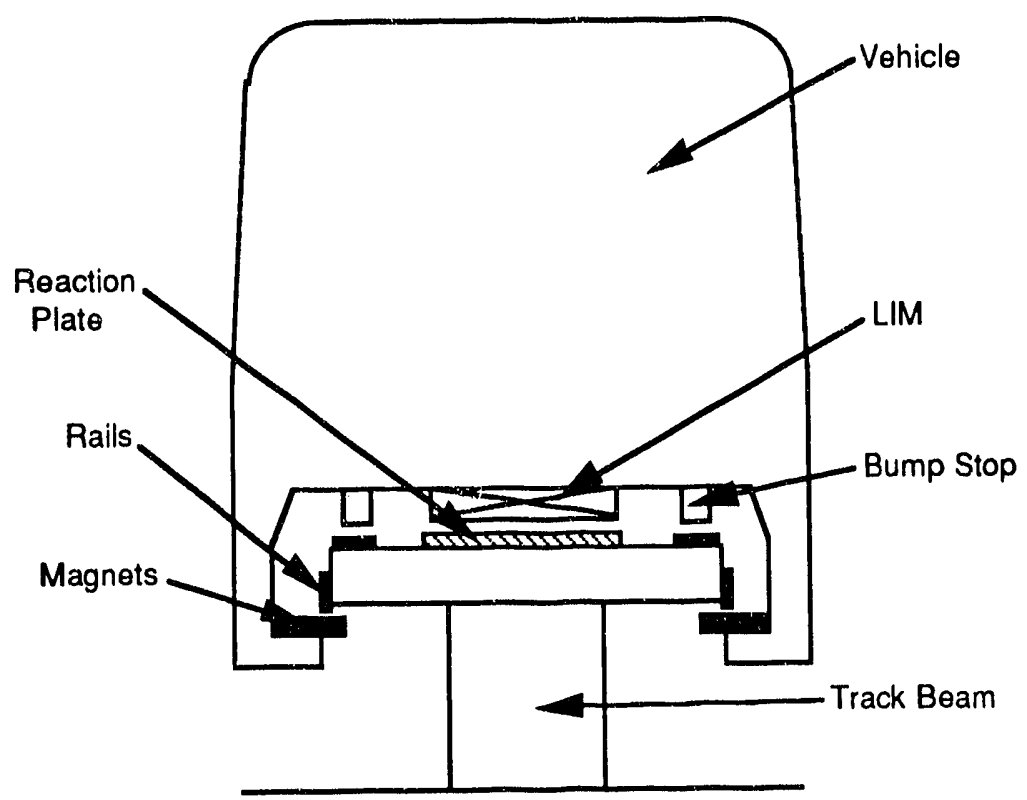

FIGURE 6.2 Schematic Diagram of the Birmingham Maglev System 
low capital and operation cost. The system is suitable for automated people-mover systems in major activity centers where special requirements exclude conventional mass transit and light rail systems. These may include shopping centers, sport and entertainment centers, airports, and downtown centers, where people wish to move quickly between points a few hundred meters to several kilometers apart.

The design of the propulsion system is based on many specifications, such as a one-way travel time of $90 \mathrm{~s}$ and a total vehicle weight of 8 tons. The motor output was designed to be $4 \mathrm{kN}$ thrust up to $54 \mathrm{~km} / \mathrm{h}(15 \mathrm{~m} / \mathrm{s})$ both in the motoring and braking modes. The normal air gap is $20 \mathrm{~mm}$. Because the system does not have a secondary suspension, the three-phase supply from the inverter is continuously monitored and modified in response to the air-gap variation to maintain constant thrust output from the motor; this results in a high degree of riding comfort. However, due to the large air gap, the system has a relatively low power factor and efficiency. Typically, both are lower than $50 \%$ for a vehicle speed of $43.2 \mathrm{~km} / \mathrm{h}(12 \mathrm{~m} / \mathrm{s})$. Operating data for the system are shown in Table 6.1.

The LIM is energized by an on-board three-phase, VVVF inverter system. This system, consisting of three power-switching modules that constitute the three phases, is transistorized to keep vehicle weight to a minimum. Each module contains a total of 16 main transistors and provides a complete switch for one phase of the inverter.

The dc power is fed from a central supply to the vehicle through a track-side filter inductor by means of collector rails positioned under the guideway. Two sets of current-collector shoes for each vehicle are used for power pickup to on-board equipment. The power rails under the guideway, rated 1000-A current, are centrally fed by the $600-\mathrm{V}$ dc power supply. These power rails are made of extruded aluminum with a stainless-steel running surface and are covered by a polyvinylchloride shroud to avoid accidental contact.

\subsection{References}

1. Rhodes, R.G., 1978, "Research and Development of Maglev Systems in the U.K.," in Proceedings of the International Seminar on the Superconductive Magnetic Levitated Train, pp. 50-58, held at Miyazaki, Japan, in Nov.

2. Laithwaite, E.R., and J.F. Eastham, 1971, "Linear Motors with Transverse Flux," Proceedings of the Institution of Electrical Engineers 118(12):1761-1767, Dec.

3. Laithwaite, E.R., 1977, Transport Without Wheels, Paul Elek (Scientific Books) Ltd., London, England. 
TABLE 6.1 Operating Data for the Birmingham Maglev System

\begin{tabular}{|c|c|}
\hline Parameter & Specification \\
\hline \multicolumn{2}{|l|}{ Vehicle General Information } \\
\hline Length $(m)$ & 6 \\
\hline Width $(m)$ & 2.25 \\
\hline Height $(\mathrm{m})$ & 3.08 \\
\hline \multicolumn{2}{|l|}{ Weight (tons) } \\
\hline Loaded & 8 \\
\hline Unloaded & 5 \\
\hline Capacity & 32 passengers and luggage \\
\hline Maximum speed $(\mathrm{km} / \mathrm{h})$ & 54 \\
\hline \multicolumn{2}{|l|}{ Suspension } \\
\hline Type & EMS with axial flux \\
\hline Number of magnets & 8 (E-shaped core) \\
\hline Air gap $(\mathrm{mm})$ & $15-20$ \\
\hline \multicolumn{2}{|l|}{ Propulsion System } \\
\hline Type & single-sided LIM \\
\hline Rated thrust (kN) & 4 \\
\hline Core width (mm) & 202 \\
\hline Core length (mm) & 1,853 \\
\hline Core depth (mm) & 90 \\
\hline Number of poles & 7 \\
\hline Number of phases & 3 \\
\hline Slots per pole & 12 \\
\hline Pole pitch & 240 \\
\hline Motor winding & double layer diamond \\
\hline Insulation & class $\mathrm{H}$ \\
\hline Cooling & forced air \\
\hline Motor weight (kg) & 440 \\
\hline Air-gap flux density $(T)$ & 0.8 \\
\hline \multicolumn{2}{|l|}{ Inverter } \\
\hline Maximum overcurrent (A) & 850 \\
\hline Maximum switching frequency $(\mathrm{Hz})$ & 540 \\
\hline Normal source voltage (V) & 600 \\
\hline Continuous output current (A) & 335 \\
\hline Continuous output (kVA) & 240 \\
\hline Cooling by natural ventilati & \\
\hline \multicolumn{2}{|l|}{ Guideway } \\
\hline Type & $\begin{array}{l}\text { double steel tracks on single } \\
\text { concrete supports; tracks } \\
\text { separated by walkway }\end{array}$ \\
\hline Length $(m)$ & 640 \\
\hline Elevated height (m) & 6 \\
\hline
\end{tabular}


4. Benussi, J., et al., 1984, "Birmingham Airport Maglev - System Development, Guideway Design and Construction," in Proceedings of the International Conference on Maglev Transport, Now and for the Future, Institution of Mechanical Engineers Conference Publication 1984-12, published by Mechanical Engineers Publications, Ltd., London, England, pp. 211-218, held in Oct.

5. McGeough, P.A., and A. Sutton, 1984, "Birmingham Airport Maglev Vehicle Construction," in Proceedings of the International Conference on Maglev Transport, Now and for the Future, Institution of Mechanical Engineers Conference Publication 1984-12, published by Mechanical Engineers Publications, Ltd., London, England, pp. 177-183, held in Oct.

6 Nenadovic, V., 1984, "Maglev Transit Link for Birmingham Airport Systems Engineering," in Proceedings of the International Conference on Maglev Transport, Now and for the Future, Institution of Mechanical Engineers Conference Publication 1984-12, published by Mechanical Engineers Publications, Ltd., London, England, pp. 169-174, held in Oct.

7. Barnard, R.E.B., 1984, "Birmingham Maglev - Automatic Control and Communications," in Proceedings of the International Conference on Maglev Transport, Now and for the Future, Institution of Mechanical Engineers Conference Publication 1984-12, published by Mechanical Engineers Publications, Ltd., London, England, pp. 203-210, held in Oct.

8. Taylor, D.R.D., 1984, "Theoretical and Practical Considerations in the Design of the Suspension System for Birmingham Maglev," in Proceedings of the International Conference on Maglev Transport, Now and for the Future, Institution of Mechanical Engineers Conference Publication 1984-12, published by Mechanical Engineers Publications, Ltd., London, England, pp. 185-192, held in Oct.

9. Linacre, H., 1984, "Birmingham Airport Maglev Propulsion System," in Proceedings of the International Conference on Maglev Transport, Now and for the Future, Institution of Mechanical Engineers Conference Publication 1984-12, published by Mechanical Engineers Publications, Ltd., London, England, pp. 193-201, held in Oct.

10. Dalgleish, E.H., and E. E. Riches, 1986, "A Review of Birmingham Maglev After One Year in Public Service," in Proceedings of the International Conference on Maglev and Linear Drives, document $86 \mathrm{CH} 2276-4$, published by the Institute of Electrical and Electronics Engineers, New York, N.Y., pp. 1-5, held at Vancouver, British Columbia, Canada, in May.

11. Mustow, S.N., 1985, "Operational Experience of Birmingham Maglev," in Proceedings of the International Conference on Maglev Transport '85, published by the Institute of Electrical Engineers of Japan, Tokyo, Japan, pp. 255-262, held at Keidanren Kaikan, Tokyo, Japan, in Sept. 
12. Jayawant, B.V., 1981, Electromagnetic Levitation and Suspension Techniques, Edward Arnold, Ltd., London, United Kingdom.

13. Rhodes, R.G., and B.E. Mulhall, 1981, Magnetic Levitation for Rail Transport, Clarendon Press, Oxford, England. 


\section{Maglev-System Research and Development in Canada}

\subsection{Introduction}

Canadian scientists and engineers have been involved in maglev research since 1968 . The long-term objective of the Canadian maglev program can be described as the operational deployment of a high-speed guided ground-transportation system, within the framework of Canadian requirements. The program has been supported by the Transport Canada Research and Development Center with additional sponsorship by the National Reseirch Council of Canada (NRC). A formal research group was formed in 1970, consisting of several universities (Queen's, Toronto, and McGill), the NRC, and private industry. A maglev research institute, the Canadian Institute of Guided Ground Transport (CIGGT), was established at Queen's University at the same time. The CIGGT has played an important role in the Canadian maglev program and in some maglev feasibility studies in the United States. For the past 20 years, the Canadian maglev group has engaged in various research ' ctivities, including basic feasibility studies, small-scale modeling, detailed analysis, large-scale testing of system components, engineering design studies, and economic assessment studies. ${ }^{1-8}$ However, no actual prototypes, either in reduced or full scale, have been built.

The Canadian maglev group has conducted two detailed design studies for an EDS maglev system that has been proposed as a future transportation alternative for the $600-\mathrm{km}$ TorontoOttawa-Montreal traffic corridor. Due to financial and other reasons, however, Canada has not been able to build a maglev system. The historical evolution of the Canadian maglev program is summarized in Table 7.1.

\subsection{Conceptual Design of the Canadian Maglev System}

Based on substantial technical and economic feasibility studies, the Canadian maglev group proposed an EDS maglev system that could be the most suitable for Canadian requirements, and in particular, for the $600-\mathrm{km}$-long Toronto-Ottawa-Montreal corridor. The first design of the system was made in the 1970s; later, this version was revised. In the updated Canadian maglev system design, the vehicle consists of a 59.2-ton, two-car train set, and the guideway has a rectangular box shape, as shown in Figure 7.1. Two air-core LSM stators, vertically arranged on either side of the guideway, interact with 36 vertically arranged on-board SCMs to produce propulsion force. The nonoverlapped stator windings are also cross-connected to produce null-flux guidance force (as in the Japanese SCM-based system). The levitation force is obtained from the interaction between 12 horizontally arranged on-board SCMs and the eddy currents induced in the conductor strips on the guideway. Tables 7.2 and 7.3 give the design parameters for the original design and the revised version, respectively. 
TABLE 7.1 Milestones of the Canadian Maglev Program

Year Activities

1968 Conception of Canadian maglev program

1970 Preliminary design and analysis completed

Formation of CIGGT at Queen's University

Formation of Canadian maglev group

Test facility concept developed

Detailed analysis and design of subsystem

1973 7.6-m diameter test whe日l design completed

1974 Test facility fabricated and commissioned LSM propulsion demonstrated and tested

LSM test completed and control model evaluated

1976 EDS tests completed

1977 Detailed system conceptual design initiated Engineering studies of maglev system completed

Economic assessment initiated

1978 Modeling of levitation coil moments and forces

1979 Economic assessment completed Industrial participation initiated

1980 Isochoric cooling study completed

1983 Vehicle design concept revised

Levitation magnet design study completed

1984 Technical assessment completed

Superconducting magnet development initiated

Los Angeles-Las Vegas maglev system assessment initiated 


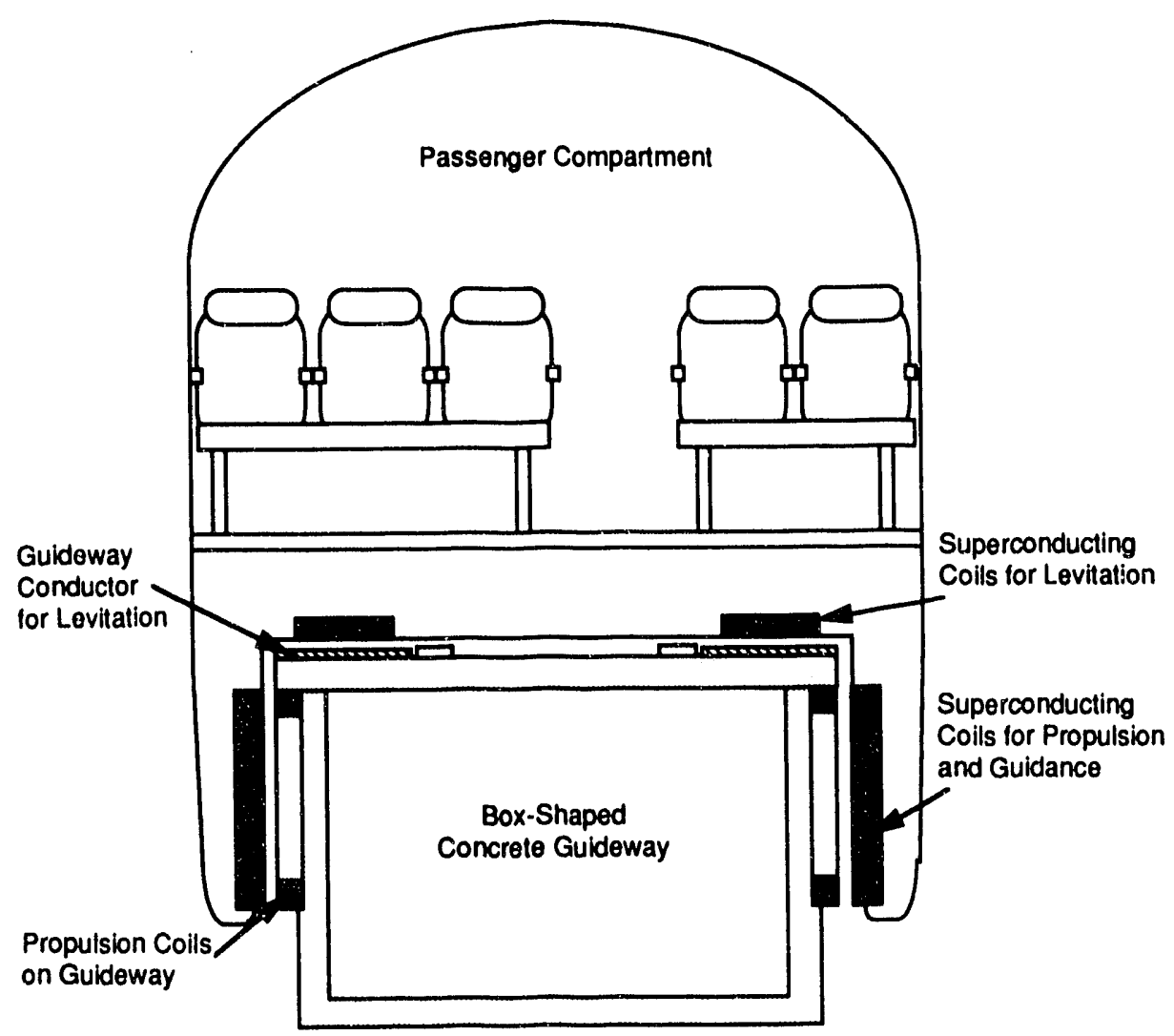

FIGUPE 7.1 Cross-Sectional View of the Revised Canadian Maglev-System Design

The Canadian conceptual design has several unique features when compared with other EDS maglev systems:

- A large number of on-board SCMs are used for the propulsion system, which means better LSM performance, a longer energized motor-section length (typically $5 \mathrm{~km}$ ), and a simpler power control subsystem;

- The vertically arranged SCMs for the propulsion system are relatively far from the passenger compartment, which reduces the magnetic-field shielding problems;

- The box-shaped guideway can provide better mechanical performance and should be relatively inexpensive, compared with the U-shaped guideway used in the Japanese MLU system; and

- Two LSM stator windings are cross-connected to form a null-flux guidance system, which simplifies guideway electrical components and reduces guideway cost. 
TABLE 7.2 Parameters for the Original-Design Canadian Electrodynamic-Suspension Maglev System

\begin{tabular}{|c|c|}
\hline Parameter & Specification \\
\hline \multicolumn{2}{|l|}{ Vehicles } \\
\hline Operation & single vehicle, unidirectional \\
\hline Seating capacity & 145 (2×3 seating) \\
\hline Overall length $(\mathrm{m})$ & 36.5 \\
\hline Overall width (m) & 3.2 \\
\hline Overall height (m) & 3.2 \\
\hline Estimated weighi (tons) & 34.2 \\
\hline Maximum cruise speed $(\mathrm{km} / \mathrm{h})$ & 480 \\
\hline Levitation clearance $(\mathrm{cm})$ & 15 (above $50 \mathrm{~km} / \mathrm{hr}$ ) \\
\hline Aerodynamic drag (kN) & 29 \\
\hline \multicolumn{2}{|l|}{ Specific total drag at cruise speed } \\
\hline Magnetic shielding weight (tons) & 3.2 (passive, 80 gauss limit) \\
\hline Payload-to-gross weight ratio & 0.42 \\
\hline Emergency lateral restraint means & $\begin{array}{l}\text { wheel-set development over } \\
\text { guideway edges }\end{array}$ \\
\hline \multicolumn{2}{|l|}{ Guideway } \\
\hline Guideway beam cross-section & trapezoidal \\
\hline Top $(m)$ & 3.2 \\
\hline Bottom (m) & 1.5 \\
\hline Deep $(m)$ & 1.4 \\
\hline Nominal beam span length $(m)$ & 25 \\
\hline \multicolumn{2}{|l|}{ Propulsion System } \\
\hline Type & long-stator, air-core LSM \\
\hline Stator windings & $\begin{array}{l}\text { overlapped ( } 2 \text { windings/phase), } \\
\text { horizontally oriented }\end{array}$ \\
\hline Number of SCMs & 50 \\
\hline Magnetomotive force (kA.turn) & 500 \\
\hline SCM length (m) & 0.53 \\
\hline SCM width (m) & 1.7 \\
\hline Pole pitch (m) & 1.14 \\
\hline Thrust at cruise speed (kN) & 45.5 \\
\hline Output power at cruise speed (MW) & 5.98 \\
\hline Motor section length $(\mathrm{km})$ & 5 \\
\hline Efficiency & $75 \%$ \\
\hline Power factor & 0.93 \\
\hline $\begin{array}{l}\text { Stator magnetomotive force per } \\
\text { phase (A.turn) }\end{array}$ & 490 (at cruise speed) \\
\hline \multicolumn{2}{|l|}{ EDS Levitation System } \\
\hline Number of levitation magnets & 10 \\
\hline Magnetomotive force (kA.turn) & 308 \\
\hline Magnet length $(\mathrm{m})$ & 1.06 \\
\hline Magnet width (m) & 0.3 \\
\hline Magnet suspension height $(\mathrm{cm})$ & 22 \\
\hline
\end{tabular}


TABLE 7.2 (Cont.)

\begin{tabular}{|c|c|}
\hline Parameter & Specification \\
\hline \multicolumn{2}{|l|}{ EDS Levitation System (Cont.) } \\
\hline Guideway strip length (m) & 0.6 \\
\hline Guideway strip thickness $(\mathrm{cm})$ & 1 \\
\hline Magnetic drag at cruise speed (kN) & 16.4 \\
\hline \multicolumn{2}{|l|}{ Guidance System } \\
\hline Type & $\begin{array}{l}\text { EDS, null-flux plus edge-effect } \\
\text { due to levitation strip }\end{array}$ \\
\hline Null-flux loop (m) & 0.57 square \\
\hline Null-flux loop pitch (m) & 0.315 \\
\hline Aerodynamic lateral load (kN) & 70 (at $100 \mathrm{~km} / \mathrm{h}$ cross wind) \\
\hline $\begin{array}{l}\text { Maximum lateral guidance force } \\
\text { (kN) }\end{array}$ & $\begin{array}{l}270 \text { (at } 30 \mathrm{~cm} \text { lateral } \\
\text { displacement) }\end{array}$ \\
\hline \multicolumn{2}{|l|}{ Superconducting magnets } \\
\hline Superconductor wire & $\mathrm{Nb}_{3} \mathrm{Sn}$ \\
\hline Liquid $\mathrm{He}$ cooling operation & isochoric \\
\hline Cryogenic cooling & $\begin{array}{l}\text { intermittent (from wayside } \mathrm{He} \\
\text { liquefier when train is } \\
\text { stationary in terminal) }\end{array}$ \\
\hline
\end{tabular}


TABLE 7.3 Parameters for the Revised-Design Canadian ElectrodynamicSuspension Maglev System

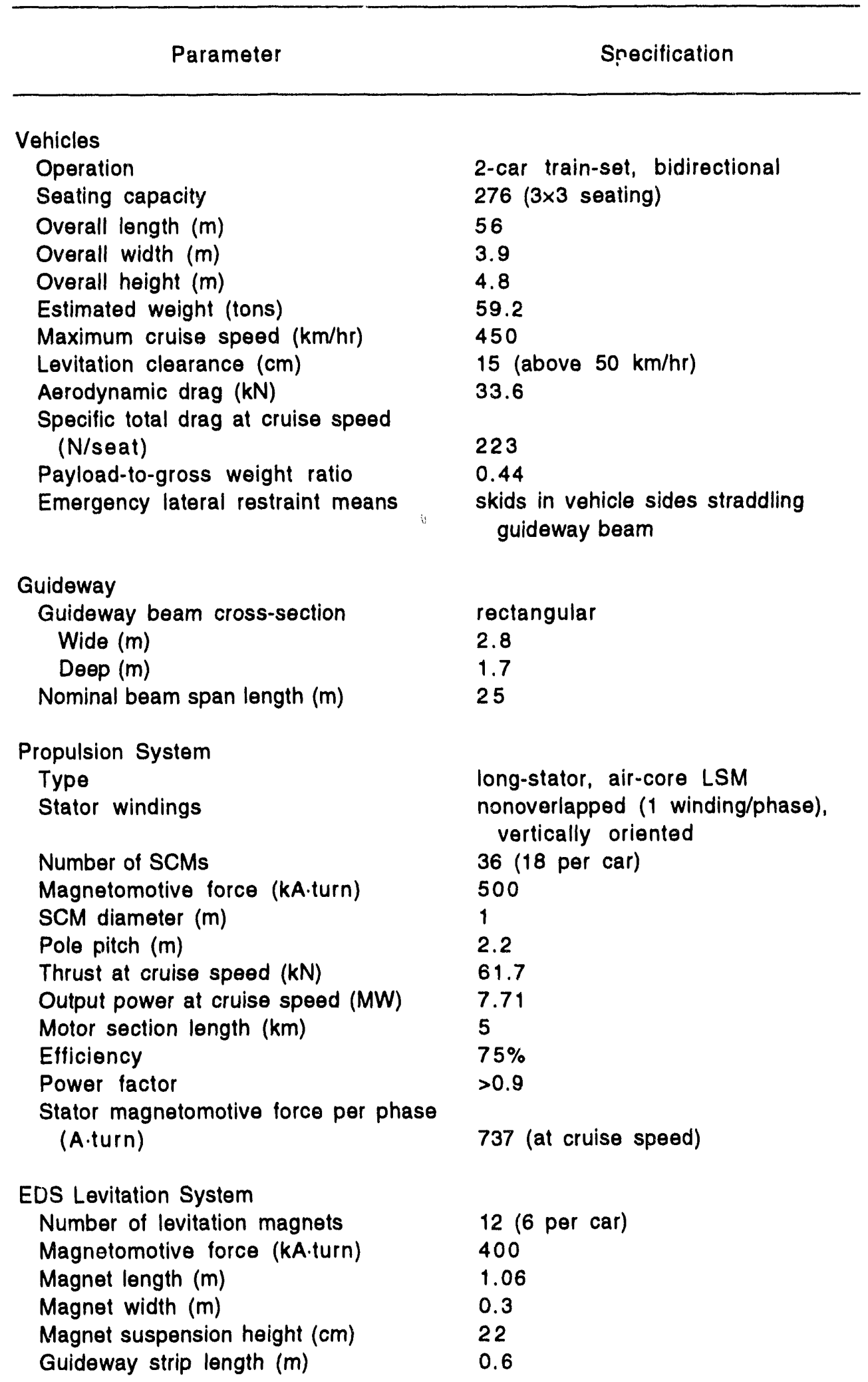


TABLE 7.3 (Cont.)

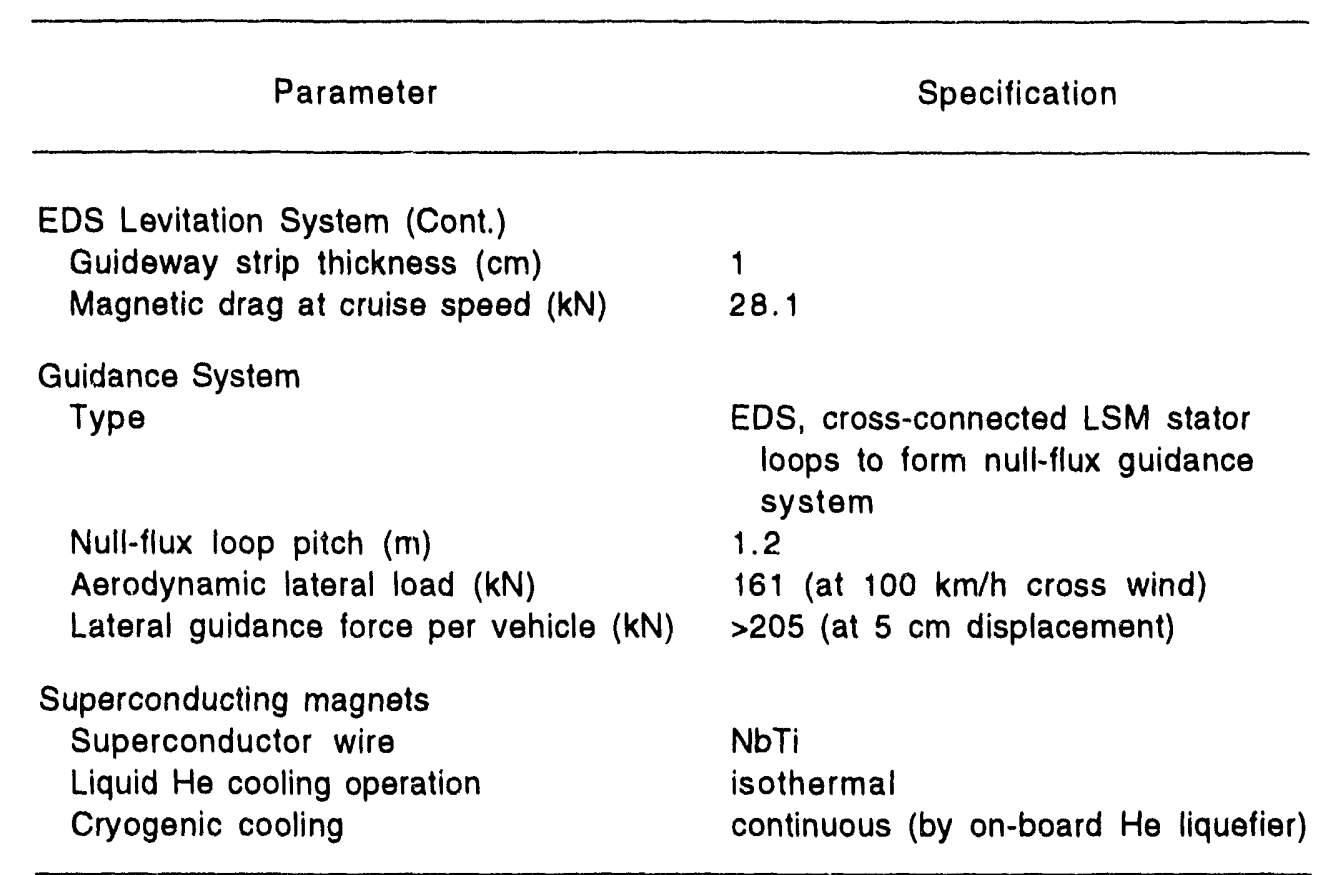

\subsection{References}

1. Rudback, N.E., and W.F. Hayes, et al., 1985, "An Overview of Canadian Maglev Research and Development," in Proceedings of the International Conference on Maglev Transport '85, published by the Institute of Electrical Engineers of Japan, Tokyo, Japan, pp. 13-20, held at Keidanren Kaikan, Tokyo, Japan, in Sept.

2. Hayes, W.F., and H.G. Tucker, 1984, "Design Concept and Comparative Performance of an Electrodynamic Maglev Transportation System for the Toronto-Montreal Corridor of Canada," in Proceedings of the International Conference on Maglev Transport, Now and for the Future, Institution of Mechanical Engineers Conference Publication 1984-12, published by Mechanical Engineers Publications, Ltd., London, England, pp. 137-146, held in Oct.

3. Audette, M., and A.R. Eastham, 1984, "Research, Assessment, and Prospects for Implementation of Maglev in Canada," in Proceedings of the International Conference on Maglev Transport, Now and for the Future, Institution of Mechanical Engineers Conference Publication 1984-12, published by Mechanical Engineers Publications, Ltd., London, England, pp. 37-46, held in Oct. 
4. Fife, A.A., H.J. Ensing, M. Tillotsnn, and W. Westera, 1986, "Development of Superconducting Magnets for the Canadian Electrodynamic Maglev Vehicle," in Proceedings of the International Conference on Maglev and Linear Drives, document 86CH2274-6, published by the Institute of Electrical and Electronics Engineers, New York, N.Y., pp. 211-217, held at Vancouver, British Columbia, Canada, in May.

5. Atherton, D.L., and A.R. Eastham, 1975, "Superconducting Maglev and LSM Development in Canada," IEEE Transactions on Magnetics MAG-11(2):627-632, March.

6. Atherton, D.L., and A.R. Eastham, 1974, "Guidance of a High Speed Vehicle with Electrodynamic Suspension," IEEE Transactions on Magnetics MAG-10(3):413-416, Sept.

7. Eastham, A.R. (editor), 1977, Electrodynamic Suspension and Linear Synchronous Motor Propulsion for High Speed Guided Ground Transportation, report 77-13, prepared by Canadian Institute of Guided Ground Transport, Queen's University, Kingston, Ontario, Canada, for Transport Canada Research and Development Center, Sept.

8. Eastham, A.R. (editor), 1975, Superconducting Magnetic Levitation and Linear Synchronous Motor Propulsion for High Speed Guided Ground Transportation, report 75-5, prepared by Canadian Institute of Guided Ground Transport, Queen's University, Kingston, Ontario, Canada, for Transportation Development Agency, March. 


\section{Maglev-System Research and Development in Other Countries}

\subsection{Research and Development Efforts}

In addition to Germany, Japan, the United Kingdom, and Canada, several other countries, including the former Soviet Union, Romania, China, and Korea, have also been involved in the worldwide maglev research and development competition. Among these countries, the Soviet Union may have been the most active. According to a report written in 1989 in New Technology Week, ${ }^{1}$ more than 40 organizations under 12 ministries and departments in the former USSR were involved in maglev research. The leading organization was the Moscow Gidrotruboproved research and development establishment, which built the first Soviet maglev vehicle in 1978 and was testing it on a 600-m-long test track. More than 100 researchers had received patent certificates for their maglev design innovations. In 1989, the maglev program entitled "HighSpeed Environmentally Safe Transport for City and Intercity Communication and Commuting" was included as one of the priority programs in 14 states for the period ending in 2005 . The investment in specific systems was expected to reach 100 million rubles. Feasibility studies of a maglev line between Moscow Center and Sheremetyevo Airport were in progress, with the involvement of West German specialists.

The development of maglev programs in other countries is not covered in this report because of limited information and resources.

\subsection{Reference}

1. New Technology Week, "Inside the USSR's Maglev Program," 1989, p. 5, Sept. 25. 


\section{Bibliography}

Johnson, L.R., et al., 1989, Maglev Vehicles and Superconductor Technology: Integration of High-Ground Transportation into the Air Travel System, report ANL/CNSV-67, Center for Transportation Research, Argonne National Laboratory, Argonne, Ill. (Available from NTIS).

U.S. Department of Transportation, Federal Railroad Administration, 1990, Assessment of the Potential for Magnetic Levitation Transportation Systems in the United States.

Proceedings of the International Seminar on the Superconductive Magnetic Levitated Train, 1978, held at Miyazaki, Japan, in Nov.

Proceedings of the 2nd International Seminar on the Superconductive Magnetic Levitated Train, 1982, held at Miyazaki, Japan, in Nov.

Proceedings of the International Conference on Maglev Transport '85, 1985, published by the Institute of Electrical Engineers of Japan, Tokyo, Japan, held at Keidanren Keikan, Tokyo, Japan, in Sept.

Proceedings of the International Conference on Maglev and Linear Drives, 1986, document 86CH2276-4, published by the Institute of Electrical and Electronics Engineers, New York, N.Y., held at Vancouver, British Columbia, Canada, in May.

Proceedings of the International Conference on Maglev and Linear Drives, 1987, document 87CH2443-0, published by the Institute of Electrical and Electronics Engineers, New York, N.Y., held at Las Vegas, Nev., in May.

Proceedings of the 11 th International Conference on Magnetically Levitated Systems and Drives, 1989, published by the Institute of Electrical Engineers of Japan, Tokyo, Japan, held at Yokohama, Japan, in July.

Proceedings of the 6th World Conference on Transportation Research, 1992, sponsored by Laboratoire d'Economie des Transports, Lyon, France, held at Lyon, France, in July (in press). 


\section{Distribution for ANL/ESD-17}

\section{Internal}

ANL Patent Department

K.S. Macal (7)

ANL Technical Publications Services

J.L. He (250)

\section{External}

U.S. Department of Energy Office of Scientific and Technical Information (12) Manager, U.S. Department of Energy Chicago Field Office

ANL-E Library

ANL-W Library 

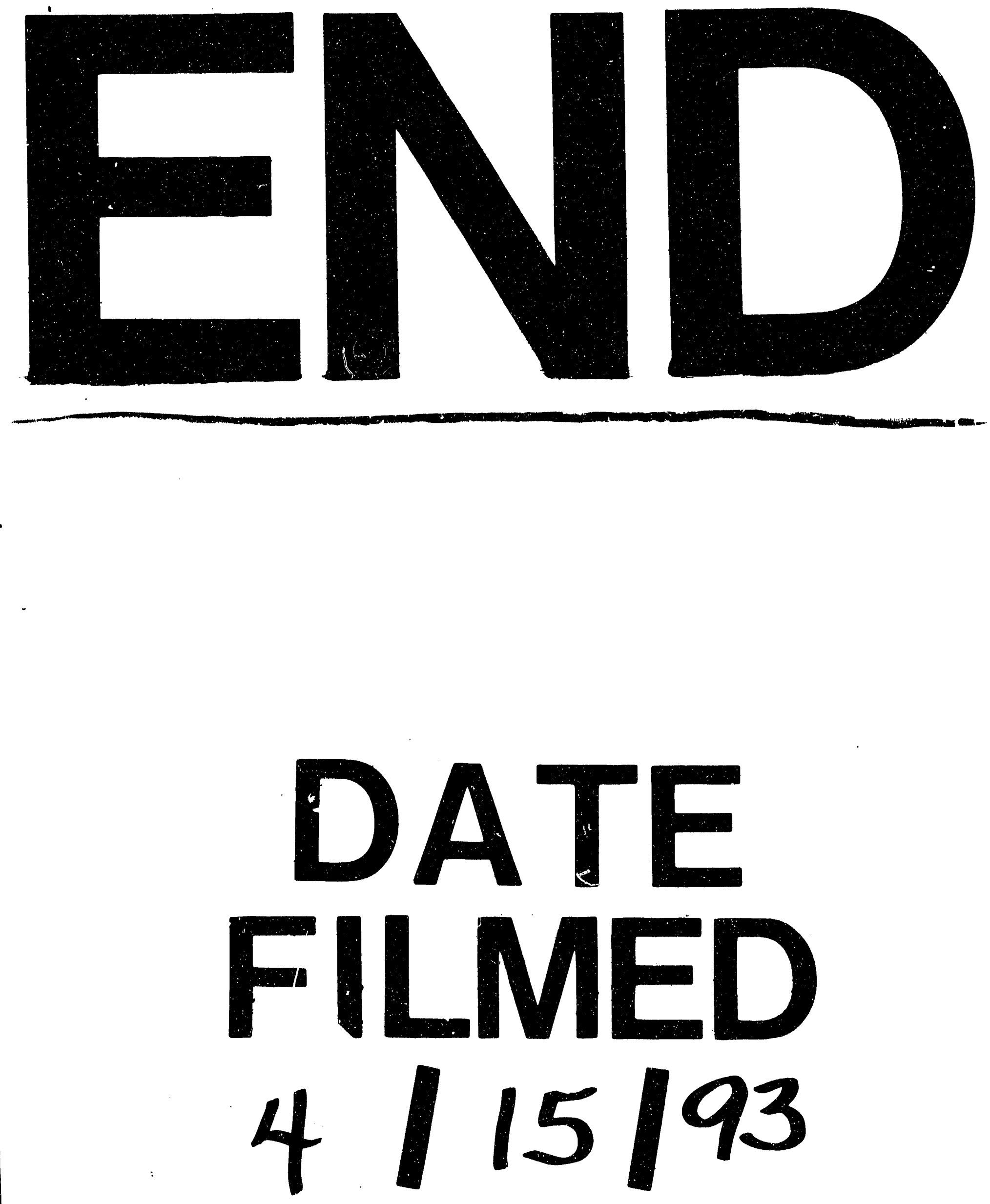
